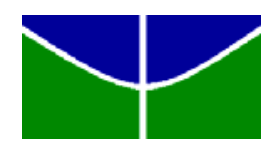

Universidade de Brasília

Faculdade de Economia, Administração, Contabilidade e Ciência da Informação e Documentação

Departamento de Ciência da Informação e Documentação

Graduação em Biblioteconomia

Angélica Gasparotto de Oliveira

\title{
MICROTESAURO EM CINEMA
}

Brasília

2008 


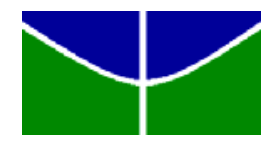

Universidade de Brasília

Faculdade de Economia, Administração, Contabilidade e Ciência da Informação e Documentação

Departamento de Ciência da Informação e Documentação

Graduação em Biblioteconomia

Angélica Gasparotto de Oliveira

\section{MICROTESAURO EM CINEMA}

Monografia apresentada como um dos requisitos para a obtenção do grau de bacharel em Biblioteconomia pelo Departamento de Ciência da Informação e Documentação, Universidade de Brasília.

Orientadora: Prof. ${ }^{a}$ Dra Marisa Bräsher

Brasília

2008 


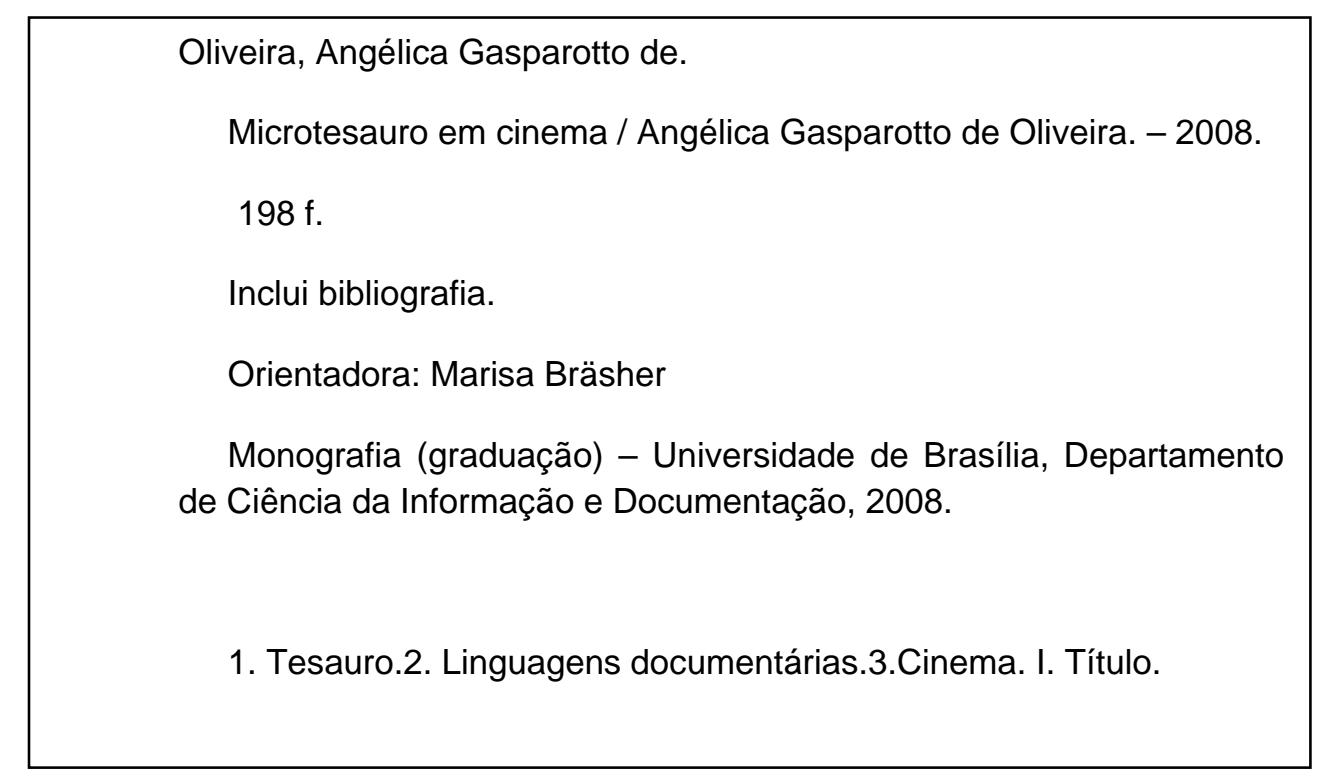




\section{Aluno: Angélica Gasparotto de Oliveira}

Monografia: Microtesauro em cinema. Apresentada ao Departamento de Ciência da Informação e Documentação da Universidade de Brasília, como parte dos requisitos para obtenção do grau de Bacharel em Biblioteconomia.

Brasília, 30 de junho de 2007.

Aprovada por:

\section{Marisa Bräsher - Orientadora}

Professora do Departamento de Ciência da Informação e Documentação (CID)

\section{Eliana Carlan - Membro}


À minha família pela ajuda, e pelo apoio na realização dos meus sonhos. E também à todos os amigos, que partilharam comigo nesses seis anos minha paixão por cinema, ajudando para que meu sonho se tornasse realidade.

Agradecimentos

Ao Sérgio Moriconi, pelos cursos do Espaço Cultural Renato Russo, sem eles esse trabalho não teria se realizado.

Ao Romélio e à Cris, que me ajudaram muitas vezes na troca de opiniões sobre o assunto.

À família pelo apoio dado nesses anos . 


\section{RESUMO}

O trabalho apresentado é a proposta de um microtesauro em cinema, com termos retirados de vários sites, artigos de periódicos, do Dicionário Teórico e Crítico de Cinema, que deu suporte a termos técnicos como nomes de equipamentos e de movimentos do cinema, e da coleção Cinema no Mundo, de onde foram retirados os nomes de filmes, principalmente africanos e asiáticos, mais difíceis de serem encontrados. Apresenta uma revisão da literatura sobre tesauro com aspectos como a Teoria do Conceito, As quatro vertentes de Ranganathan, o controle de vocabulário, expondo características da linguagem livre e controlada, e as relações num tesauro. A metodologia apresenta informações sobre as ferramentas utilizadas, forma de coleta de dados, e os critérios para relacionar os termos no tesauro.

Palavras-chave: tesauro; microtesauro em cinema; filmes excêntricos; Ranganathan; teoria do conceito; controle de vocabulário. 


\section{ABSTRACT}

The work presented is a proposal for a microthesaurus in cinema, with terms taken from various websites, journal articles, and from the Dicionário Teórico e Crítico de Cinema (Dictionnaire théorique et critique du cinéma), which has technical equipment names and movements of cinema, and the collection Cinema no Mundo, from where were taken the names of movies, mainly African and Asian, more difficult to find. It presents a review of the literature on thesaurus with aspects such as the Theory of Meaning, the four strands of Ranganathan, the control of vocabulary, exposing characteristics of natural language and controlled vocabulary, and the structure of thesauri. The methodology provides information on the tools used, method of data collection, and the criteria to relate the terms in the thesaurus.

Keywords: thesaurus; microthesaurus in cinema, eccentric cinema;

Ranganathan; theory of concept; vocabulary control. 


\section{SUMÁRIO}

1. Introdução

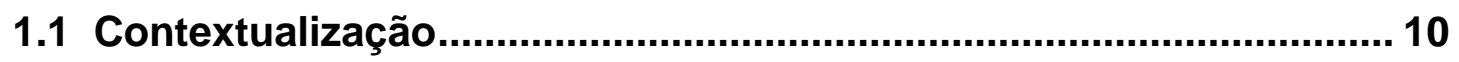

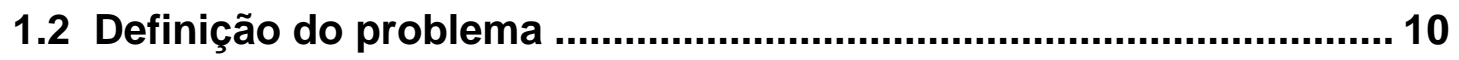

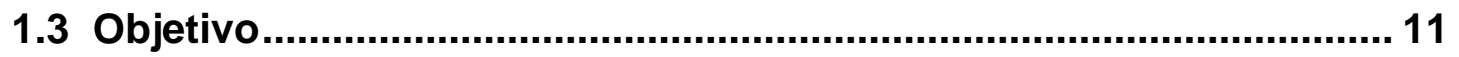

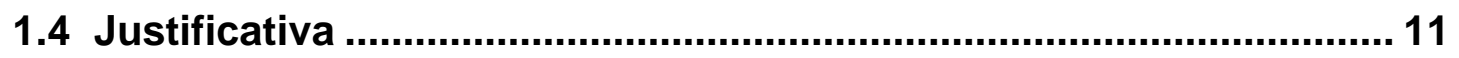

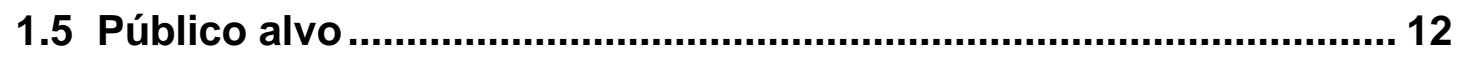

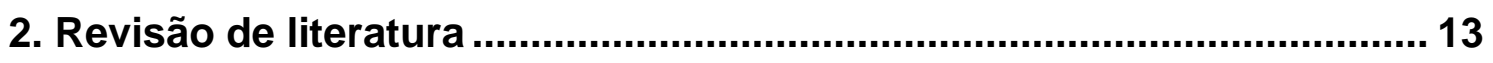

2.1 As quatro vertentes de Ranganathan ................................................. 13

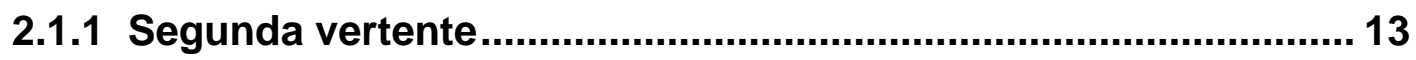

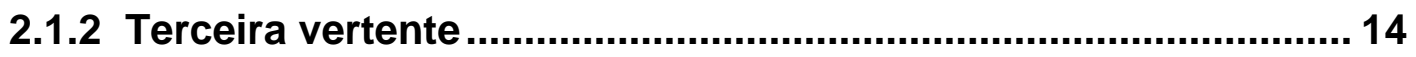

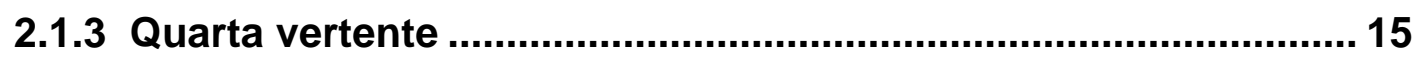

2.1.4 As quatro vertentes se complementam ...................................... 16

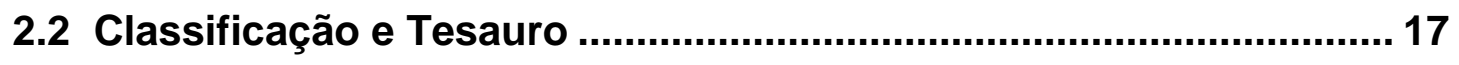

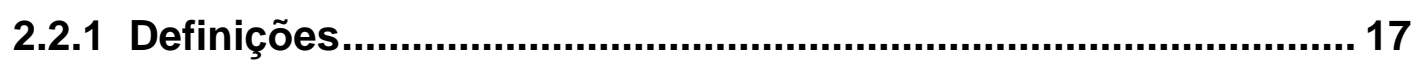

2.2.2 Conhecimento e Informação..................................................... 18

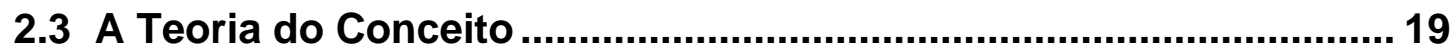

2.3.1 O termo

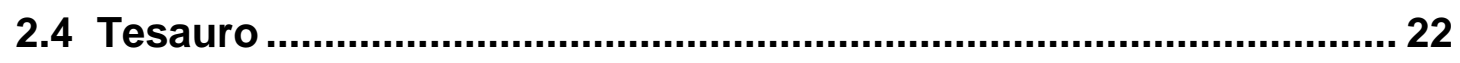

2.4.1 O controle de vocabulário........................................................ 23

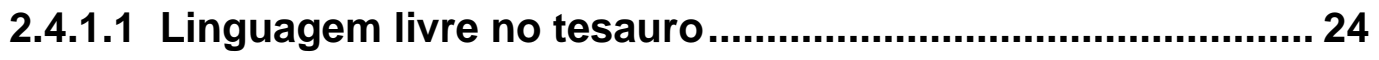

2.4.1.2 Linguagem controlada no tesauro......................................... 25

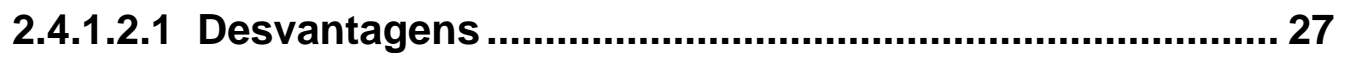

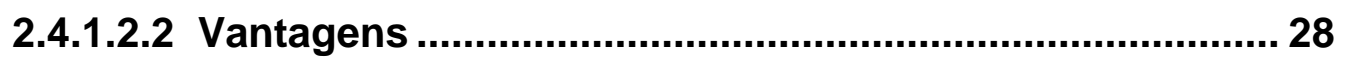

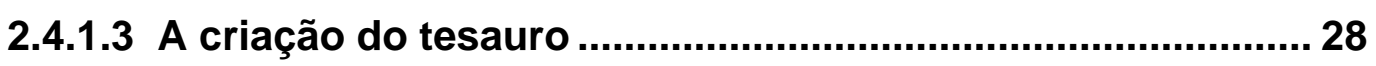

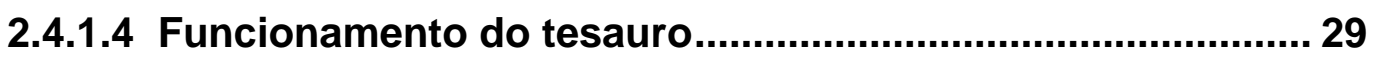

2.4.1.5 Dificuldades em relação ao tesauro........................................ 29

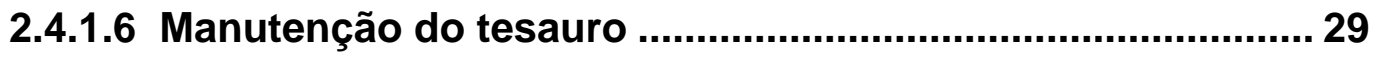

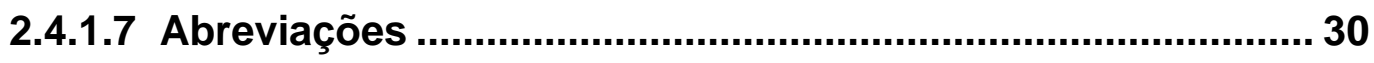


2.4.1.8 Seleção de termos para inclusão em vocabulários controlados

2.4.1.9 O impacto do vocabulário controlado na recuperação da informação ................................................................................. 31

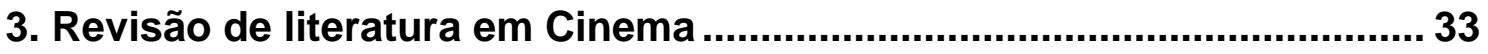

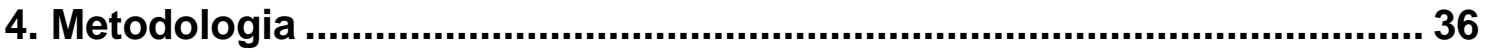

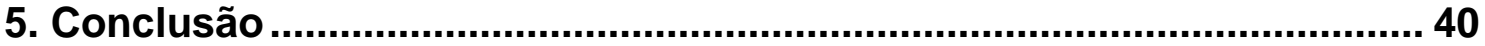

6. Referências bibliográficas...................................................................... 41

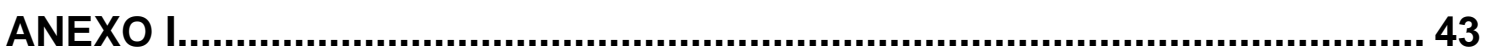

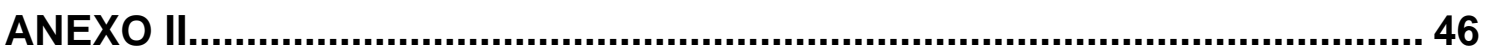

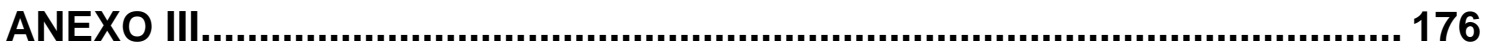




\section{Introdução}

\subsection{Contextualização}

Três das definições do dicionário Michaelis para a palavra excêntrico se encaixam exatamente na definição dos filmes apresentados neste microtesauro: esquisito, extravagante, original.

Esse trabalho monográfico com termos cinematográficos, não visa desmerecer o cinema comercial, ou excluí-lo de um trabalho que tem como objetivo a recuperação da informação cinematográfica, mas ressaltar informações que acabam ficando menos acessíveis porque os espectadores as desconhecem, já que os filmes aqui retratados não são os comerciais, os mais conhecidos e populares. Contudo, eles não deixam de ser importantes para o público, desde os estudantes de audiovisuais até os admiradores da Sétima Arte. Vale ressaltar também que o trabalho se trata de um microtesauro, e abrange desde as origens do tesauro, até as origens do cinema.

\subsection{Definição do problema}

Existem hoje pouquíssimos tesauros que falam sobre o assunto Cinema e pode-se encontrar um dos registros na Internet, o do estudante Fernando Mendonça, da UFPE. Ele começou seu tesauro na disciplina de Linguagens Documentárias o desenvolvendo até tornar-se seu tema de monografia. 


\subsection{Objetivo}

Assim como o tesauro de Fernando, o arquitetado aqui foi criado pela escassez de sistemas que organizassem e tratassem os termos desta área das Artes, com o diferencial de o objetivo do trabalho que apresento não ser englobar os termos da área de Cinema de um modo geral, e sim de modo mais específico, dando ênfase nas obras mais importantes para os estudantes de Cinema, as que não seguem padrões ou buscam apenas entretenimento do público nas grandes salas, e por isso mesmo se prestam a uma análise de conteúdo mais aprofundada. Além das citadas existem também aquelas de alta qualidade temática, mas de pouco valor comercial - segundo o julgamento do que seria valor comercial para os grandes industriais cinematográficos - ou que não possuíram verbas suficientes para ficar muito tempo em circuito, e acabaram esquecidas pelo grande público mesmo com seu grande valor.

\subsection{Justificativa}

O tesauro apresentado visa resgatar o nome de boa parte destas obras, não as deixando cair no esquecimento ou no anonimato pela dificuldade de recuperá-las em uma pesquisa.

O excêntrico a que me referi anteriormente, diz respeito a composições artísticas que não devem ser ignoradas, pelo seu valor cultural, instrucional, e por que não, de grande entretenimento. Todos devem ter direito a esta informação.

Dentro das categorias do tesauro, um estudante de cinema pode ter noção desde o tipo de equipamento usado numa filmagem até os termos-padrão da cinematografia, para construção de um roteiro ou explicação de uma técnica que se pretende usar. 


\subsection{Público alvo}

O público alvo do projeto de microtesauro são estudantes de audiovisuais, admiradores do Cinema e cinéfilos. Aumont e Marie (2003), determinam em seu dicionário de cinema o significado da palavra cinefilia, como sendo, etimologicamente, o amor pelo cinema, e esclarecem que o cinéfilo não é um amador, mas sim, alguém que se preocupa em compreender as obras, por meio de uma experiência estética. 


\section{Revisão de literatura}

\subsection{As quatro vertentes de Ranganathan}

A existência de quatro vertentes distintas originou o tesauro, mas vale ressaltar que, segundo Hagar Espanha Gomes (1996), as estruturas não são suficientes para elaborar um tesauro.

A primeira vertente de Ranganathan diz respeito ao método de faceta que teve como base o sistema da Colon Classification, onde livros seriam indexados e as idéias dos materiais bibliográficos seriam combinadas de diferentes maneiras de modo que se encontrasse qualquer assunto desejado.

Para indexar um assunto, Ranganathan criou o método das Facetas, definidas pelas 5 categorias: Personalidade, Matéria, Energia, Espaço e Tempo (GOMES,1996, p.3). Uma relação fundamental entre os termos era estabelecida por meio dessas facetas, assim como Cinema - década de 30, que é uma subdivisão de tempo importante para o pesquisador.

\subsubsection{Segunda vertente}

A segunda vertente diz respeito à organização alfabética dos descritores.

Os cabeçalhos de assunto não supriam toda a demanda por informações porque só davam acesso a um termo específico. Foi assim que surgiu o sistema Unitermo que culminou com o tesauro. O método é similar ao tesauro pois havia um único termo técnico daí o nome Unitermo - na ficha, que também tinha registros dos números de documentos ligados à idéia do termo. A combinação de termos nesse sistema possuía freqüentemente algumas incoerências. (GOMES, 1996, p.4) 


\subsubsection{Terceira vertente}

Com estudos para aprofundamento dos métodos de classificação de assuntos e o reconhecimento, até mesmo do próprio Ranganathan, de que as 5 categorias - personalidade, matéria, energia, espaço e tempo - não bastavam para a formação de um bom sistema de recuperação de informações, surge o Thesaurofacet. (Gomes,1996, p. 5)

Aitchison, que estudou a fundo a classificação com outros ingleses, como Douglas Foskett, usou o método de faceta, construindo assim uma tabela de classificação para energia elétrica. Para facilitar o próprio trabalho, percebeu que um tesauro alfabético utilizado como índice no processo de criação da tabela o ajudaria muito.

Nesse tesauro:

- Termos e relações repetiam as relações que estavam evidentes na tabela.

- Cada termo de entrada na ordem alfabética remetia ao código de classificação.

"[...]na organização de um Tesauro documentário, a classificação estava na base, embora desconstruída em favor da ordem alfabética". (Gomes, 1996, p.6) 


\subsubsection{Quarta vertente}

A quarta vertente, ou Teoria Geral da Terminologia (TGT) permite a comparação entre Tesauro e Terminologia, onde, de acordo com a análise de Gomes entende-se que:

- ambos são sistemas classificatórios;

- a Biblioteconomia não guarda relação com a Terminologia, mas ambas são de natureza sistemática, tendo fundamentos comuns a Classificação, o Tesauro e a Terminologia;

- a Terminologia oferece bases mais seguras para o estabelecimento das chamadas relações não-hierárquicas (associativas) nos Tesauros.

Observa-se também que na TGT os conceitos mantêm relação lógica e ontológica.

As relações lógicas se dão por abstração.

\section{Exemplo: Superordenação/subordinação}

\section{Genérico-específicas}

As relações ontológicas tratam da relação de um objeto com outros no tempo ou espaço, ou seja, tratam de sua realidade empírica. Essas relações possibilitaram o surgimento de ligações entre classes de diferentes naturezas ( não-hierárquicas).

\section{Exemplo: Relações partitivas}

\section{Relações seqüenciais - contigüidade no tempo} ou no espaço.

A Teoria Geral da Terminologia, desenvolvida pelo engenheiro austríaco Wüster,além de ter dado origem à Escola de Terminologia de Viena, determinou a definição dos 
conteúdos dos conceitos pelo que vem a ser chamado de descritor - aquele que descreve o conteúdo de uma unidade conceitual. O importante aí, não é o número de palavras que constituam um termo, mas sim a possibilidade de sua identificação. (GOMES,1996,p.6)

\subsubsection{As quatro vertentes se complementam}

A apresentação sistemática dos termos no glossário, no método de Faceta de Ranganthan fornece uma visão ampla da área de assunto e propicia a organização do Tesauro, pois as hierarquias(relações dentro de uma mesma faceta) são organizadas dedutivamente, marca registrada desse método. Já a Terminologia não permite uma visão tão ampla da área de assunto, pois não tem similaridades com o método de Faceta em tal aspecto, mas em contrapartida, a Teoria Geral da Terminologia é a grande responsável pela estruturação de relações lógicas/ hierárquicas. Na Teoria da Classificação, a unidade a ser manipulada é o conceito, que é uma unidade de conhecimento.(GOMES,1996, p.7) 


\subsection{Classificação e Tesauro}

\subsubsection{Definições}

As linguagens documentárias possuem a função de fazer a conexão entre a linguagem natural dos usuários e o Sistema de Informação, facilitando inclusive a comunicação indexador usuário, além de representarem o conteúdo do documento. Classificações e tesauros são tipos de linguagens documentárias, e são definidos da seguinte maneira:

Classificação: conjunto de conceitos organizados sistematicamente de acordo com os critérios ou características escolhidas (TRISTÃO, 2004 apud ISO TR 14177, 1994).

Tesauro: definido como um vocabulário de termos relacionados genérica e semanticamente sobre determinada área do conhecimento (TRISTÃO, 2004 apud Motta,1987).

A International Society for Knowledge Organization (ISKO), faz considerações sobre o uso das classificações e tesauros no contexto atual, pois os mesmos não se restringem mais apenas ao âmbito das Bibliotecas, mas a sistemas gerais e específicos de organização e representação do conhecimento, segundo Tristão (2004).

Gomes(1996), identifica que nesses sistemas e atividades, a unidade a ser manipulada será sempre o conceito, que é a unidade de conhecimento. 


\subsubsection{Conhecimento e Informação}

Straioto (2001) relata que a informação é o conhecimento registrado, pois esse pode juntar-se a outras informações formando um novo conhecimento que, divulgado, reinicia um novo ciclo.

Assim, é gerado o modelo sistêmico chamado "Ciclo da Informação", o qual tem como objetivo transferir e disseminar a informação, por isso também é conhecido como modelo de "Transferência da Informação". Esse modelo divide a representação do conhecimento em seis etapas: produção, registro, aquisição, organização, disseminação e assimilação.(DODEBEI, 2002, p.24-25)

O Ciclo da Informação é considerado por TRISTÃO (2004) o mais adequado para demonstrar o papel social de instituições e pessoas preocupadas com a transferência e preservação da informação. A importância da informação e do documento pode ser resumida na seguinte frase de Tristão( 2004, p.162): "Incorpora no modelo o conceito 'memória documentária', dividindo o universo do conhecimento em dois subconjuntos, informação e documento [...]". CICLO DA INFORMAÇÃO

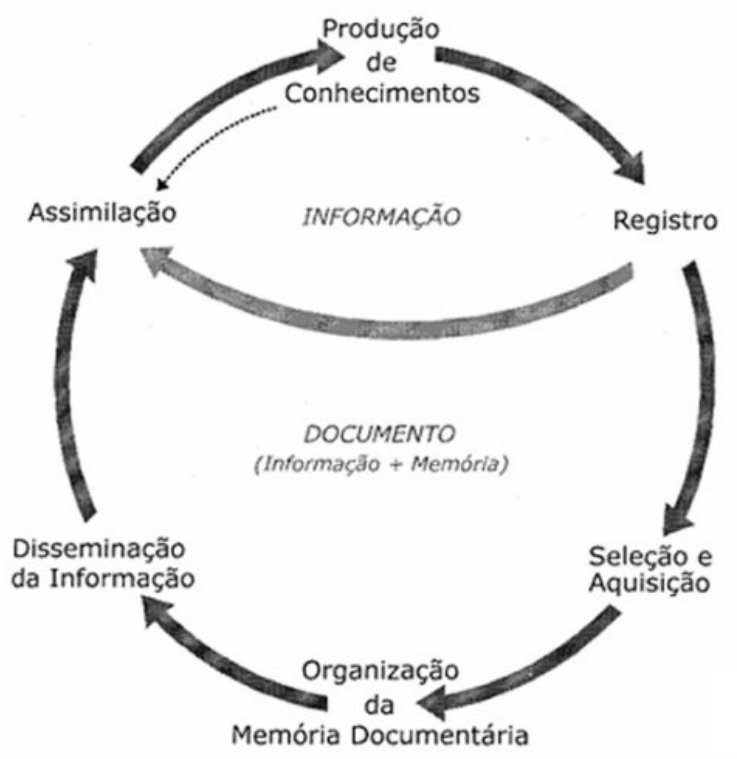

Fonte: Dodebei, 2002, p.25 
A Classificação representa a ordenação de objetos ou idéias em classes, por possuirem características comuns e ao mesmo tempo integrarem um elemento único.

[...] a classificação é um processo mental por meio do qual podemos distinguir coisas, seres ou pensamentos pelas suas semelhanças ou diferenças, estabelecer as suas relações e agrupá-las em classes de acordo com essas relações. A classificação torna-se, pois, a arte de colocar diversas coisas desordenadas em um todo ordenado (TRISTÃO apud Straioto,2001).

A classificação, segundo Lopes (2002) torna-se uma rede ou estrutura de relacionamentos que pode dar suporte a qualquer área do conhecimento. Ela organiza nomes de estrutura similar, possui uma notação para diminuir o número de itens no sistema, e um índice que facilita a pesquisa do usuário.

\subsection{A Teoria do Conceito}

De acordo com Tristão (2004), os vocabulários controlados ou tesauros, hoje, são considerados um caso especial de classificação facetada. Nesse contexto, existe a proposta de Dahlberg (1978), que distribui os tesauros como descrito abaixo:

- naqueles que dizem respeito a objetos como minerais, plantas, animais, etc., conhecidos como Taxonomias;

- em classificações mono ou pluridisciplinares, que dizem respeito a uma disciplina;

- naqueles que dizem respeito a todas as disciplinas ou assuntos, as chamadas classificações universais.

Aspectos comuns entre as classificações e os tesauros foram apontados por Campos (1994) em sua pesquisa sobre recuperação da informação. Esses aspectos dizem respeito à Teoria da 
Classificação Facetada, à Teoria do Conceito e à Teoria Geral da Terminologia que estão na base de formação dos tesauros, pois são a relação entre os conceitos e a apresentação desse sistema de relações.(TRISTÃO, 2004, p.167)

Surge, então, a percepção de que devem ser consideradas as ligações e combinações entre conceitos pela idéia que representam, e não as classes, com seu sistema de subdivisões de um todo. Os sistemas de classificação não deveriam apenas apresentar as classes sistematicamente, mas conceitos voltados para o objeto, o que é o primordial na teoria do conceito. (TRISTÃO apud Dahlberg, 2004, p.167)

\begin{abstract}
A Teoria do Conceito apresenta princípios que podem auxiliar na determinação do conceito e de suas relações, seja para elaborar tabelas de classificação, seja para elaborar tesauros.[...] O conceito não é apenas um elemento de significação do termo: o termo acaba sendo um elemento do próprio conceito - o terminum - que sintetiza o conceito como um todo e permite a comunicação, nesse caso, verbal. Não importa se o termo é formado por uma ou mais palavras, se é constituído por um substantivo mais um adjetivo etc. $O$ que importa é que ele denota um referente. Assim, tratar o termo como representante de um referente, com suas características, é dar a ele um tratamento terminológico (TRISTÃO apud DAHLBERG, 2004, p.168).
\end{abstract}

\title{
2.3.1 O termo
}

É muito importante a definição de um termo dentro do tesauro ou de qualquer outro mecanismo de pesquisa. As características do conceito é que vão determinar os agrupamentos de termos, as relações entre eles e a formação de categorias. Quando um termo tiver múltiplas definições, escolhe-se a mais útil (TRISTÃO, 2004, p.168).

A autora faz ainda considerações em seu texto sobre a função da caracterização de um objeto, pois isso define conceitos 
e incita a criação de novos termos. Características comuns reúnem os termos em classes comuns que, por sua vez, contêm subclasses, formando assim o tesauro direcionado a uma área específica do conhecimento.

Exemplo de termos com características comuns, pertencentes a uma classe:

ABSTRACTS: publicação periódica e resumo de artigos

REVISTA CIENTÍFICA: publicação periódica que contém comunicações científicas

CARACTERÍSTICAS COMUNS: publicação e periodicidade que os aproxima em um sistema de conceitos. A análise do conceito mostra que se trata de uma publicação que por sua vez é um documento, assim chega-se à classe geral: Documento Publicação - Publicação periódica - Periódico de resumos. (TRISTÃO, 2004, p.168)

Dahlberg (1978) enfatiza a importância da categoria na estruturação do sistema de conceitos e faz uma analogia dessa estrutura com a do corpo humano, dizendo que as categorias fornecem o esqueleto, os ossos e os tendões para compor todo o conhecimento. O corpo do conhecimento pode se estender se usado de forma consciente. É fundamental compreender que a seleção de características para definir um conceito deve acontecer de acordo com o tema do futuro sistema de conceitos e com as expectativas dos usuários.

Dois fatores que influenciam diretamente a elaboração da definição do conceito são a intensão e a extensão.

A intensão é o conjunto de características de um conceito, quanto mais características possuir um conceito, maior sua especificidade. Por exemplo: miocardite chagásica é mais específico do que doença de chagas, onde a hierarquia constitui: Doença - Doença parasitária - Doença de Chagas - Miocardite chagásica (TRISTÃO, 2004, p.169). 


\subsection{Tesauro}

É possível encontrar várias definições de diversos autores para o esquema de organização de conhecimento denominado Tesauro:

"Tesauro é um conjunto de termos semântica e genericamente relacionados, cobrindo uma área específica do conhecimento". (GOMES, 1996, p.1)

"Os tesauros são as classificações que não ousam dizer o próprio nome [...]" [CAMPOS apud GROLIER (1976)]

"[...] os tesauros são mecanismos que formam uma estrutura de conceitos, ou seja, criam uma lista de termos relacionados entre si, definindo os termos mais usados, quer de forma geral, quer de forma mais específica e suas co-relações". (TRISTÃO, 2004, p.170)

O tesauro é chamado de classificação de idéias por Roget, autor do dicionário analógico Thesaurus of English words and phrases, pois a relação que seus termos mantêm é hierárquica, mas também associativa.

Como observado por Gomes (1996), os especialistas precisavam de uma ferramenta que encontrasse um assunto por qualquer um dos aspectos que ele contivesse, e não apenas pelo seu nome.

A organização de assuntos de acordo como conteúdo dos termos é a ideal para a construção de um mecanismo que recupere informações da área cinematográfica, pois no caso é mais útil a associação de idéias, como a de um filme a um diretor, do que buscar termos que integram uma lista pronta, e que não necessariamente corresponderiam a um termo fluente na 
linguagem cinematográfica considerando que surgem termos mais modernos, e os antigos, em decorrência do fato, acabam sendo suprimidos da linguagem técnica e da popular.

Segundo o ANSI/NISO Z39.19-2005 (2005, p.20) o tesauro é um vocabulário controlado organizado numa ordem conhecida e estruturado de modo que as várias relações entre termos sejam exibidas claramente e identificadas por indicadores de relações normalizados. O exemplo abaixo ilustra essas relações (ANSI/NISO Z39.19-2005, 2005, p.18).

\author{
ABSORPTION \\ The retention and convertion into another \\ form of energy of rays, waves, or particles \\ by a substance. \\ UF ABSORPTIVE PROPERTIES \\ BT SORPTION \\ NT BIOLOGICAL ABSORPTION \\ RESONANCE ABSORPTION \\ TWO PHOTON ABSORPTION \\ X RAY ABSORPTION ANALYSIS
}

Fonte: DTIC Thesaurus

\title{
2.4.1 O controle de vocabulário
}

O controle de vocabulário é usado para facilitar a recuperação da informação, tanto em unidades de informação como nos sistemas da Web. A necessidade de um vocabulário controlado surge com base em dois problemas: 
- quando duas ou mais palavras são utilizadas para representar um único conceito. Exemplo: AIDS/Síndrome da Imunodeficiência Adquirida

- quando duas ou mais palavras têm a mesma grafia, mas representam diferentes conceitos, sendo homógrafas.

Exemplo: manga (de camisa) manga (fruta)

Por tudo o que foi apresentado, conclui-se que o trabalho de controle de vocabulário exige a definição do significado dos termos, as relações de equivalência entre sinônimos ou quasesinônimos e a distinção de homógrafos.(ANSI/NISO Z39.192005,2005, p.1)

\subsubsection{Linguagem livre no tesauro}

Autores como Aitchison e Gilchrist (1979) aconselham o uso da linguagem livre em sistemas computadorizados, pois percebese, nesse caso, maior custo benefício. Contudo, Lopes (2002, p.48), afirma que os custos de acesso tendem a aumentar com a entrada de termos de busca aleatórios.

O problema que o uso da linguagem livre traz é a dificuldade que o usuário encontra na hora da busca, pois ele mesmo, e não o indexador ou o sistema, vai ter que fazer distinção entre homógrafos e lembrar de sinônimos e homônimos, recuperando termos com relações falhas por causa da falta de padronização no processo. Isso tudo faz com que o usuário perca a confiança no sistema. (LOPES, 2002, p. 31)

A solução para facilitar a pesquisa é desenvolver listas de sinônimos, hierarquias e tesauros de busca. Quanto mais 
específico for o assunto, menos entraves existirão na hora da busca num sistema que utiliza vocabulário livre.

\footnotetext{
A escolha de um sistema em linguagem livre pode ser cogitada quando levadas em consideração a disponibilidade de computador, a especificidade do campo de assunto, a terminologia familiar aos operadores do sistema; ou, em grandes sistemas mecanizados, quando se dispõe de formato legível por máquina; ou quando o custo para uma atualização rápida de um tesauro com linguagem controlada, para uso de um grupo amplo e disperso de indexadores, for proibitivo.(AITCHISON, 1979, p.21)
}

As vantagens da liguagem livre, segundo IIza Lopes Leite, são:

- Permitir o registro dos dados na base sem a necessidade de consultar uma linguagem de controle.

- A busca é mais fácil pois não exige a necessidade de treinamentos inerentes à linguagem controlada.

- Os termos de entrada são exatamente os indexados do documento, constituindo a base de dados.

- Temas específicos citados no documento podem ser encontrados.

- Indexadores e usuários terão acesso aos mesmos termos, o que evita dificuldades de comunicação entre os dois.

\subsubsection{Linguagem controlada no tesauro}

O vocabulário controlado facilita a tradução de um termo, a uniformização de processos de indexação, indica relações semânticas entre os termos e faz com que as hierarquias sejam mais claras. Contudo, existem termos retirados da linguagem natural que entram no vocabulário controlado. 
De acordo com a norma ANSI/NISO Z39.19-2005, um termo é usado para representar tanto os termos preferidos quanto os de entrada, conhecidos como não-preferidos. (ANSI/NISO Z39.19-2005, 2005,p.11)

Os termos utilizados num tesauro podem ser retirados de livros, websites, artigos científicos, entre outros.

No caso do tesauro sobre cinema existem os filmes que são os objetos primários, e dados sobre filmes como nome do filme, diretor, som, etc., que são os objetos secundários.
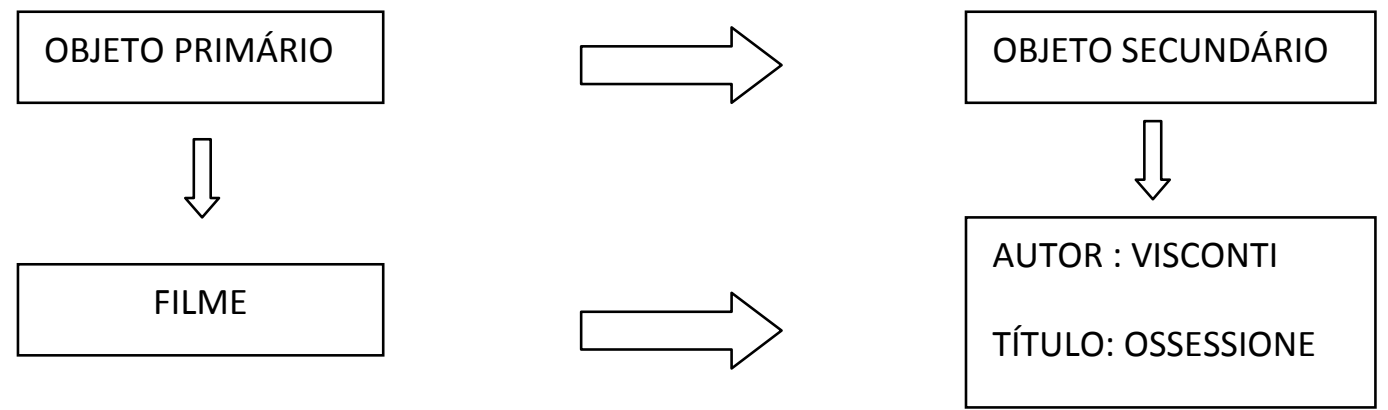

Independente de usar a linguagem controlada ou natural, o importante é descrever o objeto de forma que o usuário o encontre facilmente. Para isso, o processo de indexação descrito como um processo de escolha de termos ou cabeçalhos para descrever os conceitos e outros metadados associados ao conteúdo de um objeto (ANSI/NISO Z39.19-2005,2005,p.12), possui quatro importantes princípios:

- Eliminar ambigüidades

- Controlar sinônimos

- Estabelecer relações entre termos quando apropriado

- Teste e validação de termos

A ambigüidade, como já dito, ocorre na linguagem natural quando uma palavra ou frase tem mais de um significado, podendo ser homógrafa ou polissêmica. Diante de tal afirmação, o vocabulário controlado leva ao esclarecimento de que cada termo tem apenas um significado. 
A sinonínimia ocorre quando um conceito pode ser representado por vários termos de mesmo significado. $\mathrm{O}$ vocabulário controlado pode listar os sinônimos como termos não preferidos por meio do comando USE, remetendo ao termo preferido.

Vários tipos de relações semânticas entre termos devem ser identificadas num vocabulário controlado, assim como:

- relações de igualdade;

- relações hierárquicas e

- relações associativas.

Cada uma das relações deve ter um tratamento particular para que não haja recuperação de informação fora do contexto do que está sendo procurado. (ANSI/NISO Z39.19-2005, 2005,p.14)

Lopes (2002, p.47) aponta algumas vantagens e desvantagens da utilização do vocabulário controlado.

\subsection{Desvantagens}

Diferentemente dos baixos custos requeridos pela linguagem livre, a linguagem controlada exige despesas maiores devido à atualização da base de dados que deverá ocorrer periodicamente, e contratação de pessoal especializado para esta função, porque um tesauro desatualizado é um trabalho que acaba não atendendo os objetivos de seu criador e nem dos usuários da base de dados. Termos em desuso servem apenas para confundir o pesquisador em suas informações e levar a falsos resultados.

Um vocabulário de controle também tem a desvantagem de apresentar conceitos que não traduzem necessariamente o assunto de interesse solicitado pelo pesquisador naquele momento. Além 
disso, o usuário ainda deve ter treinamento prévio para recuperar corretamente o documento buscado.

\subsection{Vantagens}

Os problemas de comunicação entre usuário e indexador que ocorrem na linguagem natural pelo uso de termos diferentes não ocorrem no vocabulário controlado, pois já existe um termo de controle utilizado tanto por indexadores quanto por usuários, o que gera maior precisão na revocação de termos e firma uma relação de confiança com o usuário, que percebe a melhoria da qualidade do serviço de recuperação pelas respostas positivas que adquire.

O uso do tesauro dispende menos tempo pela forma como é elaborada a estratégia de busca: o tesauro possui notas de escopo que definem os conceitos dos documentos, hierarquias e remissivas, que determinam a relação dos termos no vocabulário controlado.

\subsubsection{A criação do tesauro}

O tesauro foi criado para uma melhor combinação de termos, o chamado controle de vocabulário. A importância de tal sistema se constitui na idéia de aproximação dos termos por meio de características lógicas ou semânticas comuns ou próximas, segundo Gomes (1996).

É possível recuperar um termo mais importante para a pesquisa feita, do que o que foi introduzido no sistema primeiramente, por meio da associação de idéias, que é característica do tesauro. 
Em sua Introdução Roget define seu dicionário como uma 'classificação de idéias' e explica que, diferentemente dos outros dicionários, o seu permite que se chegue a uma palavra mais adequada ou que melhor se ajuste à necessidades do escritor, sem que, de início, ele saiba qual ela é. (GOMES, 1996, p.4)

\subsubsection{Funcionamento do tesauro}

A conhecida remissiva "ver também" é comumente usada nos cabeçalhos de assunto para relacionar termos concretos, que apesar de manterem relação estreita de significado, apresentavam-se totalmente desligados uns dos outros. No tesauro, a remissiva é representada pelas relações genérico/específicas e as associativas. No dicionário de Roget, as categorias são ordenadas do mais abstrato para o mais concreto. (Gomes, 1996, p.4)

\subsubsection{Dificuldades em relação ao tesauro}

Desvantagens do tesauro apontadas por Gomes (1996) estão relacionadas à eliminação do significado do termo e a falta de clareza no estabelecimento das relações.

A eliminação do significado se daria, segundo Hagar, pela fatoração dos termos para encontrar termos relacionados, descaracterizando assim, o significado do termo original.

\subsubsection{Manutenção do tesauro}

O vocabulário controlado pode ser simples ou complexo, desde uma pequena lista de termos até um grande tesauro, contendo milhares de termos com várias relações complexas e 
hierárquicas entre si. A manutenção do tesauro deve ocorrer porque a linguagem muda, alguns termos caem em desuso e outros, que não eram tão usados, acabam emergindo. $O$ vocabulário controlado apresenta-se flexível a mudanças, não é um sistema que pára no tempo. Pelo que foi citado, é aconselhável uma constante revisão de termos para manutenção do tesauro. (ANSI/NISO Z39.19-2005, 2005, p.3)

\subsubsection{Abreviações}

As abreviações usadas no tesauro de cinema são baseadas naquelas definidas pelo Manual de Vocabulários Controlados Monolíngües.( ANSI/NISO Z39.19-2005, 2005,p.10) As principais relações e seus significados seguem abaixo:

$\begin{array}{ll}\text { Abreviação } & \text { Definicão } \\ \text { TG } & \text { Termo geral } \\ \text { TE } & \text { Termo específico } \\ \text { TR } & \text { Termo relacionado } \\ \text { NE } & \text { Nota explicativa } \\ \text { USE } & \text { USE } \\ \text { UP } & \text { USADO PARA }\end{array}$

Termo geral (TG): É o termo genérico, ao qual vários outros estão subordinados numa hierarquia.

Termo específico (TE): Um termo subordinado a outro ou a múltiplos termos numa hierarquia.

Termo relacionado (TR): Um termo que está ligado a outro por associação e não por hierarquia no vocabulário controlado. Nota explicativa (NE): É uma nota explicativa do termo que aponta seu significado, área de cobertura e regras para designa-lo. 
U (USE) e UP (USADO PARA): Justifica-se o uso dessas expressões, use e usado para, quando um termo da linguagem livre é freqüentemente requerido num sistema que utiliza vocabulário controlado. O uso dessas expressões remete ao termo do vocabulário controlado.

\subsubsection{Seleção de termos para inclusão em vocabulários controlados}

Os critérios para esta seleção são baseados:

- na linguagem natural que descreve o conteúdo de objetos,

- na linguagem de usuários, e

- nas necessidades e prioridades da organização.

Selecionar termos para a inclusão no vocabulário controlado é um importante processo, pois os usuários de um sistema de busca são diretamente afetados pelo modo como foi feita a seleção. Por isso, devem ser considerados fatores como o domínio da informação ao qual o vocabulário será aplicado, garantia literária dos termos, especificidade e relações com outros termos (ANSI/NISO Z39.19-2005,2005, p.20).

\subsubsection{O impacto do vocabulário controlado na recuperação da informação}

Os parâmetros que medem este impacto são precisão e revocação.

A revocação pode ser melhorada na utilização do vocabulário controlado quando existem: 
- termos preferidos e relações equivalentes para o controle de sinônimos,

- relações associativas (termo relacionado),

- relações classificativas e hierárquicas,

- pós-coordenação e

- correspondência entre conceitos/grupos.

A precisão pode ser melhorada com um vocabulário controlado quando há:

- relações hierárquicas com termos genéricos e específicos,

- termos compostos,

- pré-coordenação e

- uso de qualificadores entre parênteses para controlar a ambigüidade. 


\title{
3. Revisão de literatura em Cinema
}

\author{
Por muito que se discuta as origens do cinema, é difícil \\ definir uma data para a origem dessa arte. Os estudiosos da \\ cultura magdalenense descobriram que na pré-história, ia-se às \\ cavernas para assistir a uma sessão de cinema. Algumas figuras \\ desenhadas nas paredes das cavernas estavam em relevo e com \\ detalhes dos sulcos pintados de diferentes cores.
}

\begin{abstract}
À medida que o observador se locomove nas trevas da caverna, a luz de sua tênue lanterna ilumina e obscurece parte dos desenhos: algumas linhas se sobressaem, suas cores são realçadas pela luz, ao passo que outras desaparecem nas sombras. (MACHADO, 1997, p.13 e 14)
\end{abstract}

Devido a essa mudança de iluminação, a mesma figura é desenhada várias vezes, mas apenas pintada de maneira diferente. Dessa forma, observa-se a movimentação de um animal, por exemplo. Hora você percebe sua cabeça dirigida para frente, hora dirigida para trás, dependendo de onde encontra-se a tinta.

Contudo, a data oficial do nascimento do cinematógrafo é 28 de dezembro de 1895 no subsolo do Grand Café, em Paris. O "moedor de imagens", como disse uma espectadora, foi apresentado ao público pela primeira vez numa sessão paga nesse dia, por causa de um industrial liônes, Antoine Lumière, que havia construído o aparelho que registrava imagens e seus movimentos.

Os cinéfilos de todo o mundo assimilaram o idioma francês porque foram os irmãos Lumière os inventores do cinematógrafo, o primeiro aparelho de projeção de imagens para uma platéia, substituindo os aparelhos de projeção individual - invento devidamente patenteado em 1895; e também porque foram franceses os primeiros teóricos a sistematizar o vocabulário da nova arte. (MOURA, 2005, p.5) 
No início, a cinematografia foi muito utilizada por cientistas, estudiosos do movimento e das articulações do corpo humano.

\begin{abstract}
Foi o caso do americano Muybridge, que, em conseqüência de uma aposta, conseguiu decompor o galope do cavalo (questionando, com isso, toda uma tradição da arte animalista); e, sobretudo, do fisiologista francês Étienne-Jules Marey (1830-1904), inventor da cronofotografia, que é a própria base do cinema. (A ARTE MUDA, p.63)
\end{abstract}

Vários filmes assim, sem encenação nem argumento, foram rodados ao ar livre. Eram documentários sobre trabalhadores saindo de uma fábrica, um bebê acordando ou uma casa pegando fogo.

Os irmãos Lumiére, num tempo onde na Alemanha, Inglaterra, França e Estados Unidos o cinema começava a se tornar a grande atração das feiras, o consideravam apenas uma descoberta tecnológica sem futuro comercial. Nesse contexto, Georges Méliès, previu o futuro promissor do cinema e fez o primeiro filme considerado de valor comercial Viagem à Lua, em 1902. (BETTON, 1986, p.10)

Outro nome importante dessa época é Charles Pathé, que marcou o fim da era artesanal do cinema, criando em 1900, em Vincennes, uma produtora de filmes.

\footnotetext{
Esta firma depressa se alarga, e em breve Charles Pathé monopoliza todo o cinema, fabricando não só o material para filmagem e a projecção [sic], mas também a película virgem, construindo laboratórios para o tratamento dos filmes, instalando estúdios um pouco por toda parte, assegurando a distribuição dos seus filmes, possuindo numerosas salas de projecção[sic]. (BETTON, 1986, p.11)
}

A partir dessa data surgiram estúdios na Inglaterra e Estados Unidos, onde predominava o teatro filmado, para chamar a atenção da aristocracia para o cinema.

Durante a Primeira Guerra Mundial, o cinema francês começa a declinar, dando lugar ao americano, que de 1914 em diante, torna-se uma febre mundial. Foi assim que se estabeleceram firmas a vinte quilômetros de Los Angeles, numa pequena povoação índia de duzentos habitantes, chamada Hollywood. 
Os cinéfilos assimilaram igualmente o idioma inglês porque, a partir da Primeira Guerra Mundial (1914-1918), que arrasou a Europa, os USA tomaram a dianteira na produção cinematográfica, importando talentos, desenvolvendo tecnologias, fazendo do cinema uma grande indústria que não cessará de renovar a linguagem da câmara acrescentando-Ihe, a cada ano, novos termos técnicos especializados. (MOURA, 2005, p.5)

O vocabulário cinematográfico se construiu a partir de estrangeirismos, palavras formadas principalmente pelos radicais latinos originários da língua francesa e dos saxões vindos da língua inglesa. Neologismos são observados com freqüência, em adaptações de palavras estrangeiras para o português como o verbo renderizar que vem da palavra inglesa render.

Os instrumentos de produção do cinema se renovam muito rapidamente, principalmente com as tecnologias que tem grande aplicação nessa área.Novos equipamentos precisam de novas nomenclaturas, e sendo assim, a atualização dos termos é constante e necessária. Moura (2005) enfatiza : "Às vezes, o objeto cinematográfico ganha diferentes termos conforme a época: a obra é chamada de fita, película e filme segundo as gerações". 


\section{Metodologia}

O processo metodológico aqui adotado seguiu os princípios abordados por Gomes (1996), Aitichison e Gilchrist (1979), Dodebei (2002) e Dahlberg (1978), a autora da Teoria do Conceito. Cito também Tristão (2004), que em muito contribuiu para essa Teoria.

As quatro vertentes e a Teoria das Facetas de Ranganathan são igualmente mencionadas nesse trabalho monográfico.

Primeiramente foi escolhido o tema do trabalho, 'Cinema'. Partindo dessa área temática, foi feito um organograma que delineou a atividade de categorização, facilitando a visualização das relações entre termos, o que permitiu a definição dos potenciais usuários do tesauro elaborado.

As fontes de informação especializadas utilizadas para pesquisa incluem livros, artigos de periódicos, sites da internet e conversas com cineastas. Os termos foram recolhidos dessas fontes, que indicaram também a terminologia preferida a ser usada num tesauro em língua portuguesa. O livro de destaque para a formulação da parte técnica do tesauro, incluindo equipamentos, nome de diretores, principais períodos do Cinema, gênero de filmes, e terminologias relacionadas à técnica, à montagem e ao som na área é o "Dicionário Teórico e Crítico de Cinema" de Aumont e Marie(2007). A obra que mais contribuiu para a coleta dos nomes de filmes foi a coleção "Cinema no Mundo: indústria, política e mercado", dividida em cinco volumes.

Esses documentos são considerados de grande credibilidade, pois Aumont e Marie são renomados professores de cinema na Universidade de Paris, capazes de criar uma literatura cinematográfica a partir de vários anos de experiência no assunto. A coleção Cinema no Mundo é patrocinada pela Sony Brasil empresa que financia vários projetos relacionados à Cinema e visa o crescimento da indústria cinematográfica no Brasil. 
A categoria "filme" é dividida por continentes em África, Ásia, Américas do Norte e do Sul e Europa. São também termos gerais dessa categoria atores e diretores, sendo que os termos específicos são os nomes de diretores dos filmes e esses são termos relacionados. É possível saber o nome do diretor do filme, e em alguns casos o assunto, ou alguma curiosidade sobre o filme quando for extremamente antigo ou desconhecido, como filmes africanos, muito pouco acessíveis para nós. Os marcos da história do cinema também possuem uma nota explicativa.

As outras categorias são equipamento, Escola, estética, gênero e técnica.

Como a literatura existente sobre tesauro já estava um pouco ultrapassada, o trabalho foi organizado com base na norma ANSI/NISO Z39.19-2005, de título "Guidelines for the construction, format and management of monolingual controlled vocabularies" publicado pela Niso - National Information Standards Organization - dos Estados Unidos. Apesar de o manual ser ainda editado unicamente em inglês, é de fácil compreensão, e deu uma boa orientação na estruturação do trabalho.

Quanto à pesquisa em relação à existência prévia de um tesauro sobre cinema, foi possível detectar o de Fernando Mendonça, da Universidade Federal de Pernambuco. O acesso ao tesauro de Fernando me foi disponibilizado via e-mail há pouco tempo, mas incompatibilidades entre programas não me permitiram abrir o trabalho. Contudo, sabe-se que o tesauro de Fernando contém 216 termos, sendo 202 descritores e 14 não-descritores.

Assim, a decisão de fazer um tesauro em cinema foi tomada tanto por causa da afinidade que possuo com o assunto quanto pela carência de uma lista de termos sobre esse tema, principalmente quando se trata de filmes mais desconhecidos, como é o caso do tesauro proposto aqui.

Para Roget, não seria uma lista alfabética a forma mais eficiente para recuperar idéias, e mesmo palavras. É onde a 
Linguagem Documentária traz à tona uma estrutura concreta, com relações entre idéias, no processo de ordenação do conhecimento.

Algumas teorias ligadas ao conceito têm importância na base de formação dos tesauros. A Teoria do Conceito de Dahlberg, A Teoria da Terminologia de Wüester, a Teoria da Classificação Facetada de Ranganathan, assim como vários ramos da lingüística. Por meio dessas teorias, chega-se à conclusão de que o conceito poderá se tornar um termo, pois é exatamente isso que o trabalho terminológico faz, transforma o conteúdo de um conceito em termo.

O controle de linguagem também é abordado no texto, pois, como apresentado pela própria Dodebei (2002, p.33), o método do tesauro decodifica a linguagem em unidades mínimas de representação.

Para a apresentação do tesauro apresentado nesta monografia, foi utilizado o software "MultiTes Pro". Esse software permite a construção de bases terminológicas em várias línguas, inclusive português. Os formatos de saída podem ser em TXT, HTML, XML, entre outros, sendo que a saída em HTML possibilita a formação de uma página da Web. Além disso, ele é disponibilizado gratuitamente pela internet por um período de três meses, que é o período de teste do produto. Esse tesauro é de fácil utilização, contudo, não permite a inserção de figuras, que são significativas numa base que contém nomes de filmes e diretores, que demandam o aspecto visual.

A princípio, uma dificuldade que surgiu em relação à categoria "Filme" foi a divisão dos filmes por países, pois isso faria com que existisse uma gama de termos gerais. Numa tentativa de solucionar o problema, e seguindo a organização do material bibliográfico que possuía para a coleta de termos, optei por fazer as divisões por continente. Assim, o tesauro possui categorias como gênero, som, técnica, estética e filme com 
divisões que geram termos gerais, específicos e relacionados de forma mais equilibrada.

A construção do tesauro seguiu os seguintes passos:

- Identificação e seleção de termos;

- Escolha das categorias;

- Escolha dos termos gerais, subordinados às categorias;

- Escolha dos termos específicos, subordinados aos termos gerais.

E na metodologia, foram usadas as seguintes orientações para a apresentação dos descritores:

- Análise de conceitos;

- Padronização formal dos descritores fundamentada na NISO, que tem como base de referência a ISO 5127:

o Uso no singular;

- Uso no plural apenas quando o singular não exprimir o significado;

- Uso da língua original quando não houver tradução;

- Utilização das referências USE ou Usado Para quando o termo é familiar em duas línguas como faroeste e western, sendo o termo preferido sempre aquele em português.

As relações hierárquicas foram assinaladas pelos códigos TG (Termo Geral) e TE (Termo Específico); as relações associativas pelo código TR (Termo Relacionado) e as nãohierárquicas pelos códigos UP (Usado Para) antecedendo o nãodescritor e USE antecedendo o descritor preferido. As notas de escopo, que dão uma noção sobre o termo e ajudam na atualização do tesauro, são sinalizadas pela sigla NE. A abreviação CAT diz respeito às categorias. 


\section{Conclusão}

Foi constatado no momento do levantamento de dados para recolher termos sobre cinema, que vários sites, como o IMDb (Internet Movie Database) ou o adorocinema.com , possuem já em sua base filmes antigos, ou mais recentes e deconhecidos. Nem por isso, a proposta inicial de fazer um tesauro que contenha apenas filmes mais raros de se encontrar foi abandonada, visto que um site pode recuperar tanto estes filmes quanto outros mais comerciais, sem fazer distinção, e o tesauro proposto lista apenas os filmes mais raros. Ou seja, para acessar um filme raro num site é necessário que se saiba previamente deste detalhe, e o acesso aos filmes do tesauro necessariamente leva o usuário a filmes excêntricos.

Além de citar filmes, o tesauro foi montado de forma que estudantes de Cinema, ou mesmo interessados pela parte técnica desta área de assunto possam recuperar nomes de equipamentos, escolas, gêneros e saber as relações entre termos de Cinema, quais são os principais nomes, a que período artístico estes grandes nomes são relacionados, e ainda, uma pequena explicação sobre alguns termos por meio das notas de escopo.

O microtesauro aqui apresentado também deseja auxiliar projetos futuros que se baseiem numa expansão desse trabalho para formar um tesauro por meio da ampliação do número de categorias e termos. O projeto elaborado e apresentado nesse trabalho possui 1109 termos, sendo 1079 preferidos e 30 nãopreferidos. Possui ainda 6 categorias, 977 relações hierárquicas, 30 relações de equivalência e 1286 relações associativas. 


\section{Referências bibliográficas}

AITCHISON, Jean; GILCHRIST, Alan. Manual para construção de tesauros. Rio de Janeiro: BNG/Brasilart, 1979. 142 p.

ANSI/NISO Z39.19-2005. Guidelines for the Construction, Format, and Management of Monolingual Controlled Vocabularies, ANSI/NISO. 2005, 184 p. ISBN 1880124653.

Arte muda. A pré-história do cinema. Texto fornecido sem nome de autor ou data de publicação no Espaço Cultural Renato Russo de Brasília pelo cineasta Sérgio Moriconi em junho de 2005.

BETTON, Gerard. História do cinema: das origens até 1986. Mem Martins: Euro-America. 129p.

DODEBEI, Vera Lucia Doyle Louzada de Mattos. Tesauro: linguagem de representação da memória documentária. Niterói: Intertexto, 2002. 119 p. ISBN 8587258303.

GOMES,Hagar Espanha. Classificação, tesauro e terminologia: fundamentos comuns. Rio de Janeiro: UNIRIO,1996. Disponível em : $<$ www.conexaorio.com/biti>. Acesso em: maio de 2007. Palestra preparada para as Tertúlias do Departamento de Biblioteconomia da UNIRIO, apresentada em julho de 1996.

LOPES, Ilza Leite.Uso das linguagens controlada e natural em bases de dados: revisão da literatura. Ciência da Informação, Brasília, v.31, n.1,p. 4152, jan./abr.2002. Disponível em:

<http://www.scielo.br/pdf/ci/v31n1/a05v31n1.pdf> . Acesso em: mar.2006.

MACHADO, Arlindo. Pré-cinemas \& pós-cinemas. Campinas: Papirus, 1997. 303 p. 
MENDONÇA, Fernando de; CARVALHO, Maria Auxiliadora de . A informação cinematográfica e seus instrumentos de recuperação: a elaboração de um tesauro em Cinema. Biblionline, João Pessoa, v.3, n.1, 2007. Disponível em: $<$ http://www.okara.ufpb.br>. Acesso em: dez. 2007.

MICHAELIS, H. Michaelis: Moderno dicionario da lingua portuguesa. Sao paulo: Melhoramentos, 1998. $2267 \mathrm{p}$

MOURA, Maria Aparecida; NAZÁRIO, Luiz. Linguagens de indexação em contextos cinematográficos: a experiência de elaboração do tesauro eletrônico do cinema brasileiro. Perspectivas em ciência da informação, Belo Horizonte, v.10, n.1, p. 54-69, jan./jun. 2005. Disponível em: <http:// www.eci.ufmg.br/pcionline/index.php/pci/article/view/302/105 >. Acesso em: jun. 2008.

STRAIOTO, Ana Claudia. A análise em facetas como dimensão teórica e prática na organização do conhecimento. 2001. 163 f. Dissertação (Mestrado) - Faculdade de Filosofia e Ciências, Universidade Estadual Paulista, Marília, 2001.

TRISTÃO, Ana Maria Delazari; FACHIN, Gleisy Regina Bóries; ALARCON, Orestes Estevam. Sistema de classificação facetada e tesauros: instrumentos para a organização do conhecimento. Ciência da Informação, Brasília, v.33,n.2, p.161-171, maio/ago.2004. Disponível em: <http://www.scielo.br/pdf/ci/v33n2/a17v33n2.pdf>. Acesso em: mar. 2007. 


\section{ANEXO I}

\section{Referências utilizadas na pesquisa sobre o tema e recolhimento de termos para o tesauro}

Os 100 mais sexy. SET: cinema e vídeo. São Paulo: Editora Azul, ano 9, n.100,out.1995.

1000 que fizeram 100 anos de cinema. São Paulo: Três.260p.

Arte muda. Nascimento da indústria cinematográfica. Texto fornecido sem nome de autor ou data de publicação no Espaço Cultural Renato Russo de Brasília pelo cineasta Sérgio Moriconi em junho de 2005.

AUMONT, Jacques; MARIE, Michel. Dicionário teórico e crítico de cinema. 3.ed. Campinas: Papirus, 2007. 335 p. ISBN 8530807030.

BERNARDET, Jean Claude. O que é cinema. São Paulo: Nova Cultural. 117p.

Cinema no mundo: indústria, política e mercado: África. São Paulo: Escrituras Editora, v.1, 2007. 213 p. ISBN 857531257X.

Cinema no mundo: indústria, política e mercado: América Latina. São Paulo: Escrituras Editora, v.2, 2007. 213 p. ISBN 857531260X.

Cinema no mundo: indústria, política e mercado: Ásia. São Paulo: Escrituras Editora, v.3, 2007. 213 p. ISBN 8575312588.

Cinema no mundo: indústria, política e mercado: Estados Unidos. São Paulo: Escrituras Editora, v.4, 2007. 213 p. ISBN 978-85-7531-259-9.

Cinema no mundo: indústria, política e mercado: Europa. São Paulo: Escrituras Editora, v.5, 2007. 213 p. ISBN 8575312618.

Cinemas novos. A nouvelle vague. Texto fornecido sem nome de autor ou data de publicação no Espaço Cultural Renato Russo de Brasília pelo cineasta Sérgio Moriconi em junho de 2005. 
CONY, Carlos Heitor. Chaplin: ensaio-antologia. Rio de Janeiro: Civilização Brasileira, 1967. 401p.

DA-RIM, Sílvio. Espelho partido: tradição e transformação do documentário. Rio de Janeiro: Azougue,2004.248 p.

FRIEDRICH,Otto,1929. Cidade das redes: Hollywood nos anos 40. São Paulo: Cia Das Letras, 1988. 477 p.

GRANJA, Vasco. Dziga Vertov. Lisboa: Livros Horizonte.95 p.

La guerra del trust y La fundación de Hollywood. Texto fornecido sem nome de autor ou data de publicação no Espaço Cultural Renato Russo de Brasília pelo cineasta Sérgio Moriconi em junho de 2005.

GUINCHAT, C., MENOU, M. As linguagens documentais. In:_. Introdução geral às ciências e técnicas da informação e documentação. Brasília, IBICT,1994.p.133-69.(leitura 1). Disponível em: <>. Acesso em: mar. 2007.

A idade de ouro. O expressionismo alemão. Disponível em: <www.tcu.gov.br>. Acesso em: jun.2006.

LANCASTER, F. Wilfrid. Construção e uso de tesauros: Curso condensado. Brasília: Instituto Brasileiro de Informação em Ciência e Tecnologia, 1987. 114 p.

MARINHO, Marcilio Teixeira; GOMES, Hagar Espanha.Introdução ao Estudo do Cabeçalho de Assunto. 1984. Disponível em:

$<$ http://www.conexaorio.com/biti/cabecalho/cab_ass.htm>. Acesso em: 03/05/2007.

MARRONI, Gilza Núria Brandão. Identificação e delimitação de relações associativas em tesauros: um estudo de caso na área do direito do trabalho . Brasília, 2006. Dissertação (mestrado) - Universidade de Brasília.

MORICONI, Sérgio. Curso oferecido pelo Espaço Cultural Renato Russo em outubro de 2005 sobre A História do Cinema Mundial. Informação verbal.

Newnes. Film Technique,1929.

SALOMON, Délcio Vieira. Como fazer uma monografia. 11. ed. São Paulo: Martins Fontes, 2001. 412 p. ISBN 85-336-1436-5.

SANTOS, Joao Almeida; PARRA FILHO, Domingos. Metodologia cientifica. São Paulo: Futura, 1998. 277 p. ISBN 85-86082-81-3. 
SEVERINO, Antônio Joaquim. Metodologia do trabalho cientifico. 13. ed. São Paulo: Cortez, 1986. 237 p.

Unesco. Normas para elaboração de thesaurus. Brasilia 1975. 33 p .

VIET, Jean. Thesaurus internacional do desenvolvimento cultural. Rio de janeiro: Fundação Casa de Rui Barbosa, 1983. 504 p.

\section{Sites}

$<h t t p: / / w w w . a d o r o c i n e m a . c o m . b r>$

$<$ http://www.cineplayers.com>

$<$ http://epipoca.uol.com.br>

$<$ http://www.imdb.com>

$<$ http://www.mnemocine.com.br>

$<$ http://www.webcine.com.br> 
ANEXO II

RELAÇÃO DE TERMOS EM ORDEM ALFABÉTICA 
CAT: equipamento

TG: bitola

A bela da tarde

CAT: filme

1942: a conquista do paraíso

TG: filme europeu

CAT: filme

TR: drama

TG: filme norte-americano

Luis Buñuel

TR: Ridley Scott

sociedade burguesa

2001: Odisseia no Espaço

A câmera de madeira

CAT: filme

CAT: filme

TG: filme norte-americano

TG: filme africano

TR: Stanley Kubrick

TR: apartheid

Ntshaveni Wa Luruli

2046 - Os Segredos do Amor

CAT: filme

A concepção

TG: filme asiático

CAT: filme

TR: Wong Kar-wai

TG: filme sul-americano

TR: José Eduardo Belmonte

21 gramas

CAT: filme

A doce vida

TG: filme norte-americano

CAT: filme

TR: Alejandro González

TG: filme europeu

Iñárritu

TR: Federico Fellini

$35 \mathrm{~mm}$

CAT: equipamento 
A flor do meu segredo

CAT: filme

TG: filme europeu

TR: Pedro Almodóvar

A força do amor

CAT: filme

NE: Baseado no roteiro

original de Jean-Luc Godard e na história de François Truffaut.

TG: filme norte-americano

TR: Jim McBride

A fraternidade é vermelha

CAT: filme

TG: filme europeu

TR: Krzysztof Kieslowski

A gardênia azul

CAT: filme

TG: filme europeu

TR: Fritz Lang

A grande ilusão

CAT: filme

TG: filme europeu

TR: Jean Renoir
A guerra dos Roses

CAT: filme

TG: filme norte-americano

TR: Danny De Vito

A história real

CAT: filme

TG: filme norte-americano

TR: David Lynch

A igualdade é branca

CAT: filme

TG: filme europeu

TR: Krzysztof Kieslowski

A insustentável leveza do ser

CAT: filme

TG: filme norte-americano

TR: Philip Kaufman

A irmandade da guerra

CAT: filme

TG: filme asiático

TR: ação

Kang Je Gyu

melodrama 
A liberdade é azul

CAT: filme

TG: filme europeu

TR: Krzysztof Kieslowski

A má educação

CAT: filme

TG: filme europeu

TR: Pedro Almodóvar

A marca da maldade

CAT: filme

TG: filme norte-americano

TR: filme noir

Orson Welles

A menina santa

CAT: filme

TG: filme sul-americano

TR: Lucrecia Martel

A morte passou por perto

CAT: filme

TG: filme norte-americano

TR: filme noir

Stanley Kubrick
A noite americana

CAT: filme

TG: filme europeu

TR: François Truffaut

A pequena loja da rua principal

CAT: filme

TG: filme europeu

TR: Ján Kadár

A perversa

CAT: filme

TG: filme europeu

TR: Leslie Arliss

A rainha

CAT: filme

TG: filme europeu

TR: Stephen Frears

A regra do jogo

CAT: filme

TG: filme europeu

TR: Jean Renoir 
A rosa púrpura do Cairo

CAT: filme

TG: filme norte-americano

TR: Woody Allen

A última sessão de cinema

CAT: filme

TG: filme norte-americano

TR: Peter Bogdanovich

A última tentação de Cristo

CAT: filme

TG: filme norte-americano

TR: Martin Scorcese
A vida secreta das

palavras

CAT: filme

TG: filme europeu

TR: Isabel Coixet

Abdelatif Bem Ammar

CAT: filme

TG: diretor

TR: Sejnane

Une si simple histoire

aberto

CAT: equipamento

TG: Acessório de iluminação

A viagem de Chihiro

CAT: filme

TG: filme asiático

TR: animação

Hayao Miyazaki

A vida de Oharu

CAT: filme

TG: filme asiático

TR: Kenji Mizoguchi abertura

CAT: equipamento

UP: aperture

TR: câmera

Abra os olhos

CAT: filme

TG: filme europeu

TR: Alejandro Amenábar 
Abril despedaçado

CAT: filme

TG: filme sul-americano

TR: Walter Salles

abstrato

CAT: gênero

TR: cinema de poesia

ação

CAT: gênero

TE: épico

TG: ficção

TR: A irmandade da guerra

ator

Bayside Shakedown

Sholay

Accident

CAT: filme

TG: filme africano

TR: Benoît Ramampy

crítica

independência africana
TE: aberto

bandô

brut

cabo

caixa distribuidora

caixa intermediária

calha-brut

dedolight

difusor de metal

fresnéis

garra jacaré

$\mathrm{HMI}$

kino-floo

photo-flood

prolonga

quadro de luz

rebatedor

soft

spot

sun gun

tripé de luz

tripé grande de luz

acessório de estúdio

CAT: equipamento

Acessório de iluminação

CAT: equipamento 
TE: banqueta

praticável

tabela

acessórios

CAT: equipamento

TE: bateria

cabeça de tripé

cabeça do tripé

cabo

carregador de bateria

cartão cinza

filtro

fotômetro incidente

kelvinômetro

lente

pára-sol

pilhas

spot meter

suporte para ombro

tabela de cores

tripé

video-assist

visor de contraste

TR: câmera acompanhamento ao

vivo

CAT: técnica

TR: música

Aconteceu naquela noite

CAT: filme

TG: filme norte-americano

TR: Gus Van Sant

adaptação

CAT: gênero

TG: ficção

Adrián Caetano

CAT: filme

TG: diretor

TR: Memórias de quem fica

Adrián Suar

CAT: filme

TG: diretor

TR: Memórias de quem fica

afílmico

CAT: gênero

TR: documentário 
Akira Kurosawa

CAT: filme

TG: diretor

TG: diretor

TR: Memórias de quem fica

TR: Rashomon

Alec Baldwin

Al Pacino

CAT: filme

CAT: filme

TG: ator

TG: ator

Alejandro Amenábar

Alain Delon

CAT: filme

CAT: filme

TE: diretor

TG: ator

TR: Abra os olhos

Mar adentro

Alain Fresnot

CAT: filme

Alejandro Doria

TG: diretor

CAT: filme

TR: Desmundo

TG: diretor

Ed Mort

TR: Memórias de quem fica

Alan J. Pakula

Alejandro González Iñárritu

CAT: filme

CAT: filme

TG: diretor

TG: diretor

TR: Klute, o passado

condena

TR: 21 gramas

Amores brutos

Babel

Alberto Lecchi

CAT: filme 
Alemanha

CAT: Escola

TR: expressionista

Alexander Payne

CAT: filme

TG: diretor

TR: Ruth em questão

Alexandre Nevski

CAT: técnica

TR: montagem vertical

Alexandre Stockler

CAT: filme

TG: diretor

TR: Cama de gato

Alfonso Arau

CAT: filme

TG: diretor

TR: Como água para

chocolate

Alfred Hitchcock

CAT: filme

TG: diretor
TR: Correspondente

estrangeiro

Disque M para matar

Interlúdio

Janela indiscreta

Ladrão de casaca

Marnie - confissões de

uma ladra

Os pássaros

Psicose

Um corpo que cai

alicate

CAT: equipamento

TG: kit ferrramentas

Allah Tantou

CAT: filme

TG: filme africano

TR: crítica

David Achkar

independência africana

Aluízio Abranches

CAT: filme

TG: diretor

TR: Um copo de cólera 
Amor à flor da pele

CAT: filme

TG: filme asiático

TR: Wong Kar-wai

Amores brutos

CAT: filme

TG: filme norte-americano

TR: Alejandro González

Iñárritu

Amores expressos

CAT: filme

TG: filme asiático

TR: Wong Kar-wai

Anant Balani

CAT: filme

TG: diretor

TR: Joggers park

Andie McDowell

CAT: filme

TG: ator

Andrés Cotler

CAT: filme
TG: diretor

TR: Pasajeros

Andrew Adamson

CAT: filme

TG: diretor

TR: Crônicas de Nárnia

Andrucha Waddington

CAT: filme

TG: diretor

TR: Casa de areia

Andy Garcia

CAT: filme

TG: ator

diretor

TR: Cidade perdida

Ang Lee

CAT: filme

TG: diretor

TR: O tigre e o dragão

ângulo da câmera

CAT: técnica

TG: parâmetro 
animação

CAT: gênero

TG: ficção

TR: A viagem de Chihiro

Princess Mononoke

Anjos caídos

CAT: filme

TG: filme asiático

TR: Wong Kar-wai

TG: diretor

TR: Durval Discos

Ann-Margret

CAT: filme

TG: ator

Ânsia de amar

CAT: filme

TG: filme norte-americano

TR: Mike Nichols
TG: ator

António Hernández

CAT: filme

TG: diretor

TR: Los Borgia

Anurag Basu

CAT: filme

TG: diretor

TR: Life in a metro

apartheid

CAT: filme

TE: tema

TR: A câmera de madeira

aperture

CAT: equipamento

USE: abertura

Après lui

CAT: filme

TG: filme europeu

TR: Gaël Morel

Antonio Banderas

CAT: filme 
CAT: filme

TG: diretor

TR: Caçada humana

As pontes de Madison

CAT: filme

TG: filme norte-americano

TR: Clint Eastwood

CAT: filme

TG: filme asiático

TR: Wong Kar-wai

Ashwini Chaudhary

CAT: filme

TG: diretor

TR: Good boy, bad boy

Assassinato em Gosford Park

CAT: filme

TG: filme europeu

TR: Robert Altman

assistente

CAT: equipamento assistente de câmera

CAT: equipamento

TR: kit ferrramentas

Ata-me!

CAT: filme

TG: filme europeu

TR: Pedro Almodóvar

ator

CAT: filme

TE: Al Pacino

Alain Delon

Alec Baldwin

Andie McDowell

Andy Garcia

Ann-Margret

Antonio Banderas

Audrey Hepburn

Ava Gardner

Barbara Hershey

Brad Pitt

Bridget Fonda

Brigitte Bardot

Cameron Diaz 
Cary Grant

Catherine Deneuve

Christian Slater

Clark Gable

Claudia Cardinale

Clint Eastwood

Daniel Day-Lewis

Demi Moore

Dennis Quaid

Denzel Washington

Drew Barrymore

Elvis Presley

Emmanuelle Seigner

Gary Oldman

Grace Kelly

Gregory Peck

Greta Garbo

Harrison Ford

Hugh Grant

Humphrey Bogart

Ingrid Bergman

Isabella Rossellini

Isabelle Adjani

Jack Nicholson

Jacqueline Bisset

James Dean

Jane Fonda
Jeremy Irons

Jessica Lange

John Malkovich

Johnny Depp

Julia Roberts

Julie Delpy

Juliette Binoche

Kathleen Turner

Keanu Reeves

Kelly Lynch

Kevin Costner

Kim Basinger

Kim Novak

Lana Turner

Lauren Bacall

Leila Diniz

Lena Olin

Liz Taylor

Madeleine Stowe

Mae West

Marcello Mastroianni

Marilyn Monroe

Marlene Dietrich

Marlon Brando

Matt Dillon

Meg Ryan

Mel Gibson 
Michelle Pfeiffer

Montgomery Clift

Nastassja Kinski

Ornella Muti

Paul Newman

Ralph Fiennes

Raquel Welch

Richard Gere

Rita Hayworth

River Phoenix

Robert Redford

Romy Schneider

Sandra Bullock

Sean Connery

Sharon Stone

Sophia Loren

Steve McQueen

Susan Sarandon

Terence Stamp

Tim Robbins

Tom Cruise

Uma Thurman

Val Kilmer

Victoria Abril

William Holden

Winona Ryder

TR: ação
Atração mortal

CAT: filme

TG: filme norte-americano

TR: Michael Lehman

Através de um espelho

CAT: filme

TG: filme europeu

TR: Ingmar Bergman

Audrey Hepburn

CAT: filme

TG: ator

Ava Gardner

CAT: filme

TG: ator

aventura

CAT: gênero

TG: ficção

Awara

CAT: filme

TG: filme asiático

TR: Raj Kapoor 
CAT: filme

TG: filme africano

TR: crítica

independência africana

Souleymane Cissé

Babaçu

CAT: filme

TG: filme sul-americano

TR: Lyonel Lucini

Babel

CAT: filme

TG: filme norte-americano

TR: Alejandro González

Iñárritu

Baile perfumado

CAT: filme

TG: filme sul-americano

TR: Paulo Caldas

Barbara Hershey

CAT: filme

TG: ator

bandeira

bandô

banqueta

iluminação

CAT: técnica

Baixo gávea

CAT: filme

TG: filme sul-americano

TR: Haroldo Marinho

Barbosa

CAT: equipamento

TG: maquinaria

CAT: equipamento

TG: acessório de estúdio

TG: Acessório de

UP: sound track

R: cinema sonoro

composição

contraponto orquestral

CAT: equipamento 
Barbet Schroeder

CAT: filme

TG: diretor

TR: O reverso da fortuna

barn-door

CAT: equipamento

TR: refletor

Barra 68

CAT: filme

TG: filme sul-americano

TR: Vladimir Carvalho

barracuda

CAT: equipamento

TG: maquinaria

Barry Lyndon

CAT: filme

TG: filme norte-americano

TR: Stanley Kubrick

bateria

CAT: equipamento

TG: acessórios
Batismo de sangue

CAT: filme

TG: filme sul-americano

TR: Helvécio Ratton

batoque

CAT: equipamento

TG: maquinaria

Bayside Shakedown

CAT: filme

UP: Odoru Daisosasen

TG: filme asiático

TR: ação

Katsuyuki Motohiro

Bazin

CAT: filme

TE: diretor

TR: plano-sequência

Beijo da morte

CAT: filme

TG: filme norte-americano

TR: filme noir

Henry Hathaway 
Benoît Ramampy

CAT: filme

TG: diretor

TR: Accident

Bernardo Bertolucci

CAT: filme

TG: diretor

TR: Os sonhadores

Bicho de sete cabeças

CAT: filme

TG: filme sul-americano

TR: Laís Bodanzky

Bicots-nègres, vos voisins

CAT: filme

TG: filme africano

TR: emigração

Med Hondo

Billy Wilder

CAT: filme

TG: diretor

TR: Crepúsculo dos deuses

O pecado mora ao lado
Quanto mais quente

melhor

Bin-jip

CAT: filme

USE: Casa vazia

bitola

CAT: equipamento

TE: $16 \mathrm{~mm}$

$35 \mathrm{~mm}$

super-8

TR: câmera

Black girl

CAT: filme

TG: filme africano

TR: Ousmane Sembène

Blake Edwards

CAT: filme

TG: diretor

TR: Bonequinha de luxo 
Blasetti

CAT: filme

TE: diretor

TR: neorealista

Boa noite e boa sorte

CAT: filme

TG: filme norte-americano

TR: George Clooney

Bob Rafelson

CAT: filme

TG: diretor

TR: $\mathrm{O}$ destino bate à sua

porta

Bobby

CAT: filme

TG: filme asiático

TR: drama

Raj Kapoor

boletim de câmera

CAT: equipamento

TG: maquinaria
Bolshe Vita

CAT: filme

TG: filme europeu

TR: Ibolya Fekete

Bonequinha de luxo

CAT: filme

TG: filme norte-americano

TR: Blake Edwards

Brad Pitt

CAT: filme

TG: ator

Bráulio Mantovani

CAT: filme

TG: diretor

TR: Cidade de Deus

Bridget Fonda

CAT: filme

TG: ator

Brigitte Bardot

CAT: filme

TG: ator 
Brilho eterno de uma mente sem lembranças

CAT: filme

TG: filme norte-americano

TR: Charlie Kaufman

brut

CAT: equipamento

TG: Acessório de

iluminação

Bubble

CAT: filme

TG: filme norte-americano

TR: Steven Soderbergh

Building n.7

CAT: filme

TG: filme norte-americano

TR: Steven Soderbergh

Burial of a potato

CAT: filme

TG: filme europeu

TR: Jan Jakub Kolski

burlesco

CAT: gênero
TE: o gordo e o magro

TG: ficção

TR: comédia

\section{Buttoners}

CAT: filme

TG: filme europeu

TR: Petr Zelenka

Bye, bye Africa

CAT: filme

TG: filme africano

TR: Mahamat-Saleh Haroun

cabeça de efeito

CAT: equipamento

TG: maquinaria

cabeça de tripé

CAT: equipamento

TG: acessórios

maquinaria

cabeça do tripé

CAT: equipamento

TG: acessórios 
cabo

CAT: equipamento

TG: Acessório de

iluminação

acessórios

maquinaria

cabo de segurança

CAT: equipamento

TG: maquinaria

Cabra cega

CAT: filme

TG: filme sul-americano

TR: Di Moretti

Toni Venturi

Cabra marcado para morrer

CAT: filme

TG: filme sul-americano

TR: Eduardo Coutinho

Caçada humana

CAT: filme

TG: filme norte-americano

TR: Arthur Penn
Cães de aluguel

CAT: filme

TG: filme norte-americano

TR: Quentin Tarantino

caixa distribuidora

CAT: equipamento

TG: Acessório de

iluminação

caixa intermediária

CAT: equipamento

TG: Acessório de

iluminação

calha-brut

CAT: equipamento

TG: Acessório de

iluminação

Caligarismo

CAT: Escola

TR: expressionista

Cama adentro

CAT: filme

TG: filme sul-americano

TR: Jorge Gaggaro 
Cameron Diaz

Cama de gato

CAT: filme

TG: filme sul-americano

TR: Alexandre Stockler

câmera

CAT: equipamento

TR: abertura

acessórios

bitola

chassis

cinematógrafo

corpo

foco

kinetógrafo

laçada

mecanismo de tração

obturador

perspectiva

tacômetro

Cameron Crowne

CAT: filme

TG: diretor

TR: Vida de solteiro
CAT: filme

TG: ator

Camp Thiaroye

CAT: filme

TG: filme africano

TR: colonialismo

movimentos de libertação

Ousmane Sembène

Campanella

CAT: filme

TG: diretor

TR: O filho da noiva

campo

CAT: estética

TE: contracampo

TR: espaço

quadro

Canção da estrada

CAT: filme

TG: filme asiático

TR: Satyajit Ray 
caneta hidrocor

CAT: equipamento

TG: kit ferrramentas

canivete

CAT: equipamento

TG: kit ferrramentas

Cantando na chuva

CAT: filme

NE: Com a trama passada em 1927 - ano do lançamento de "O Cantor de Jazz", o primeiro filme falado da história - "Cantando na Chuva" faz sátira com a própria Hollywood e é considerado um dos maiores musicais já realizados.

TG: filme norte-americano

TR: Gene Kelly

Canudos

CAT: filme

TG: filme sul-americano

TR: Ipojuca Pontes

Carandiru

CAT: filme

TG: filme sul-americano

TR: Hector Babenco
Carl Dreyer

CAT: técnica

NE: Produziu filmes introspectivos filosóficos, quase um estudo sobre a alma humana. É possível encontrar em suas obras o modo paramétrico de narração.

TG: diretor

TR: parâmetro

Carlos Reichenbach

CAT: filme

TG: diretor

TR: Falsa loura

Garotas do ABC

Carlos Sorin

CAT: filme

TG: diretor

TR: Memórias de quem fica

Carne trêmula

CAT: filme

TG: filme europeu

TR: Pedro Almodóvar 
TR: Michael Curtiz

carregador de bateria

CAT: equipamento

TG: acessórios

cartão cinza

CAT: equipamento

TG: acessórios

Cary Grant

CAT: filme

TG: ator

Casa de areia

CAT: filme

TG: filme sul-americano

TR: Andrucha Waddington

Casa vazia

CAT: filme

UP: Bin-jip

TG: filme asiático

TR: Kim Ki Duk
Catherine Deneuve

CAT: filme

TG: ator

\section{Ceddo}

CAT: filme

TG: filme africano

TR: Ousmane Sembène

Celebridades

CAT: filme

TG: filme norte-americano

TR: Woody Allen

cena

CAT: estética

TR: clássico

espaço

plano de exposição

sequência

Cenas de um casamento

Casablanca

CAT: filme

TG: filme norte-americano
CAT: filme

TG: filme europeu

TR: Ingmar Bergman 
CAT: filme

Central do Brasil

CAT: filme

TG: filme sul-americano

TR: Walter Salles

Cesar e Rosalie

CAT: filme

TG: filme europeu

TR: Claude Sautet

Chaga de fogo

CAT: filme

TG: filme norte-americano

TR: filme noir

William Wyler

Chandni bar

CAT: filme

TG: filme asiático

TR: Madhur Bhandarkar

changing bag

CAT: equipamento

TG: maquinaria
NE: Chaplin é comparado a Shakespeare, que também mostra simplicidade e complexidade ao mesmo tempo em suas obras, que se tornaram, por essa razão, extremamente populares. O vagabundo é o personagem principal de todos os filmes de Chaplin.

TG: diretor

TR: cinema mudo

Luzes da cidade

O grande ditador

Tempos modernos

Vida de cão

Charles Vidor

CAT: filme

TG: diretor

TR: Gilda

Charlie Kaufman

CAT: filme

TG: diretor

TR: Brilho eterno de uma mente sem lembranças

Quero ser John Malkovich

Charles Chaplin

Charlotte Gray 
CAT: filme

TG: filme europeu

TR: Gillian Armstrong

Chega de saudade

CAT: filme

chassis

TG: filme sul-americano

CAT: equipamento

TR: Laís Bodanzky

TE: coaxial

plano

Cheikh Oumar Sissoko

plano de dois eixos

CAT: filme

TG: maquinaria

TG: diretor

TR: câmera

TR: Finzan

Guimba: un tyran, une

Chat Gim époque

CAT: filme

USE: Seven swords

chave de fenda

CAT: equipamento

CAT: filme

TG: filme europeu

TR: Ibolya Fekete

TG: kit ferrramentas

Chingoo

chave halen

CAT: equipamento

CAT: filme

USE: Friend

TG: kit ferrramentas

Christian Slater

chave Philips

CAT: filme

CAT: equipamento

TG: ator

TG: kit ferrramentas 
CAT: filme

TG: filme norte-americano

Chronique des années de braise

TR: Andy Garcia

CAT: filme

TG: filme africano

cinema de poesia

TR: colonialismo

CAT: gênero

Mohamed Lakhdar-

TG: ficção

Hamina

TR: abstrato

movimentos de libertação

Cidadão Kane

CAT: filme

TG: filme norte-americano

TR: Orson Welles

indireto livre

plano subjetivo

cinema estrutural

CAT: Escola

TR: montagem métrica

Cidade de Deus

CAT: filme

TG: filme sul-americano

TR: Bráulio Mantovani

Fernando Meirelles

cinema moderno

CAT: Escola

TE: cinema pós-moderno

Roberto Rossellini

cinema mudo

Cidade dos sonhos

CAT: filme

TG: filme norte-americano

TR: David Lynch

Cidade perdida

CAT: Escola técnica

TG: som

TR: Charles Chaplin

divismo

impressionista 
música

pantomima

CAT: Escola

TG: cinema novo

cinema não-encenado

CAT: Escola

TR: vanguardista

cinema novo

CAT: Escola

TE: cinema nacional

Cinema Paradiso

CAT: filme

TG: filme europeu

TR: Giuseppe Tornatore

cinema pós-moderno

CAT: Escola

TG: cinema moderno cinema nacional

cinematurgia

fala

música gravada em

película

teatro filmado

cinematógrafo

CAT: equipamento

TR: câmera

cinematurgia

CAT: técnica

TR: cinema sonoro

Cinzas do passado

CAT: filme

TG: filme asiático

TR: Wong Kar-wai

Clair

CAT: filme

TE: diretor

TR: realista

cinema sonoro

CAT: técnica

TG: som
TG: maquinaria

claquete

\section{CAT: equipamento}

TR: banda som 
Clark Gable

CAT: filme

TG: ator

clássico

CAT: gênero

TG: ficção

TR: cena

raccord

Claude Sautet

CAT: filme

TG: diretor

TR: Cesar e Rosalie

Claudia Cardinale

CAT: filme

TG: ator

\section{Clint Eastwood}

CAT: filme

TG: ator

TR: As pontes de Madison

Meia-noite no jardim do

bem e do mal coaxial

CAT: equipamento

TG: chassis

colonialismo

CAT: filme

TE: tema

TR: Camp Thiaroye

Chronique des années de braise

Emitai

Mortu Nega

Samory

Sarraounia

colorido

CAT: estética

TG: cor

comédia

CAT: gênero

TG: ficção

TR: burlesco

Notre fille 
Pousse- pousse

contracampo

Como água para chocolate

CAT: estética

CAT: filme

TG: campo

TG: filme norte-americano

TR: regra dos $180^{\circ}$

TR: Alfonso Arau

contraponto orquestral

composição

CAT: técnica

CAT: técnica

TR: banda som

TR: banda som

música gravada em

película

CAT: estética

TE: colorido

Conspiração Tequila

CAT: filme

preto-e-branco

TG: filme norte-americano

TR: Robert Towne

CAT: equipamento

TR: câmera

Contos da lua vaga

CAT: filme

TG: filme asiático

Correspondente estrangeiro

CAT: filme

TR: Kenji Mizoguchi

TG: filme norte-americano

TR: Alfred Hitchcock

Contra todos

CAT: filme

TG: filme sul-americano

TR: Roberto Moreira

corte seco

CAT: técnica

TR: montagem 
TG: filme norte-americano

TR: Marco Ferreri

Crepúsculo dos deuses

CAT: filme

NE: É uma crítica a Hollywood e sua adoração da juventude e do

próprio passado.

TG: filme norte-americano

TR: Billy Wilder

criminal

CAT: gênero

TE: filme noir

TG: ficção

CAT: filme

TE: tema

TR: Accident

Allah Tantou

Baara

Den muso

Finyé

Xala

Crônica de um amor louco

CAT: filme
Crônicas de Nárnia

CAT: filme

TG: filme europeu

TR: Andrew Adamson

Cuba baila

CAT: filme

TG: filme sul-americano

TR: Julio García Espinosa

cunha

CAT: equipamento

TG: maquinaria

Dançando no escuro

CAT: filme

TG: filme europeu

TR: Lars Von Trier

Daniel Burman

CAT: filme

TG: diretor

TR: Memórias de quem fica

O abraço partido 
Darren Aronofsky

CAT: filme

Daniel Day-Lewis

TE: diretor

CAT: filme

TR: Réquiem para um sonho

TG: ator

data

Daniel Kamwa

CAT: equipamento

CAT: filme

TR: etiqueta

TG: diretor

TR: Notre fille

David Achkar

Pousse- pousse

CAT: filme

TG: diretor

Danny Boyle

TR: Allah Tantou

CAT: filme

TG: diretor

TR: Trainspotting

David Cronenberg

CAT: filme

TG: diretor

Danny Cannon

TR: O almoço nu

CAT: filme

TG: diretor

David Lean

TR: Juiz

CAT: filme

TG: diretor

Danny De Vito

TR: Grandes esperanças

CAT: filme

TG: diretor

David Lynch

TR: A guerra dos Roses

CAT: filme

TG: diretor 
TR: A história real

Cidade dos sonhos

O homem elefante

Twin Peaks: Os últimos

dias de Laura Palmer

Veludo azul

De olhos bem fechados

CAT: filme

TG: filme norte-americano

TR: Stanley Kubrick

decupagem

CAT: técnica

TR: falso-raccord

montagem

raccord

regra dos $180^{\circ}$

dedolight

CAT: equipamento

TG: Acessório de

iluminação

Demi Moore

CAT: filme

TG: ator
Den muso

CAT: filme

TG: filme africano

TR: crítica

independência africana

Souleymane Cissé

Dennis Quaid

CAT: filme

TG: ator

Denzel Washington

CAT: filme

TG: ator

Der Kaiser Von Kalifornien

CAT: filme

TG: filme europeu

TR: Luis Trenker

Desconstruindo Harry

CAT: filme

TG: filme norte-americano

TR: Woody Allen

Desejo humano

CAT: filme 
TG: filme norte-americano

TR: filme noir

Fritz Lang

Desmundo

CAT: filme

TG: filme sul-americano

TR: Alain Fresnot

Deus e o diabo na terra do sol

CAT: filme

TG: filme sul-americano

TR: Glauber Rocha

Devdas

CAT: filme

TG: filme asiático

TR: Sanjay Leela Bhansali

Di Moretti

CAT: filme

TG: diretor

TR: Cabra cega

difusor de metal

CAT: equipamento
TG: Acessório de

iluminação

difusor tecron

CAT: equipamento

TG: maquinaria

Dikongue-Pipa

CAT: filme

TG: diretor

TR: Le prix de la liberté

Muna Moto

dimensão dos planos

CAT: técnica

TG: parâmetro

direção dos movimentos

CAT: técnica

TG: parâmetro

direto

CAT: técnica

TR: documentário

montagem

diretor 
CAT: filme

TE: Abdelatif Bem Ammar

Adrián Caetano

Adrián Suar

Akira Kurosawa

Alain Fresnot

Alan J. Pakula

Alberto Lecchi

Alejandro Amenábar

Alejandro Doria

Alejandro González

Iñárritu

Alexander Payne

Alexandre Stockler

Alfonso Arau

Alfred Hitchcock

Aluízio Abranches

Anant Balani

Andrés Cotler

Andrew Adamson

Andrucha Waddington

Andy Garcia

Ang Lee

Anna Muylaer

António Hernández

Anurag Basu

Arthur Penn
Ashwini Chaudhary

Barbet Schroeder

Bazin

Benoît Ramampy

Bernardo Bertolucci

Billy Wilder

Blake Edwards

Blasetti

Bob Rafelson

Bráulio Mantovani

Cameron Crowne

Campanella

Carl Dreyer

Carlos Reichenbach

Carlos Sorin

Charles Chaplin

Charles Vidor

Charlie Kaufman

Cheikh Oumar Sissoko

Clair

Claude Sautet

Daniel Burman

Daniel Kamwa

Danny Boyle

Danny Cannon

Danny De Vito

Darren Aronofsky 
David Achkar

David Cronenberg

David Lean

David Lynch

Di Moretti

Dikongue-Pipa

Don Siegel

Dziga Vertov

Eduardo Coutinho

Eduardo Mendonza

Eduardo Schuldt

Edwin S. Porter

Eisenstein

Eklavya

Elia Kazan

Elia Schneider

Eliseo Subiella

Erika Bauer

Ernst Lubitsch

Fabián Bielinsky

Federico Fellini

Feng Xiaogang

Fernando Meirelles

Flora Gómez

Francis Ford Coppola

François Truffaut

Fritz Lang
Fruit Chan

Gaël Morel

Gene Kelly

George Clooney

George Stevens

Gillian Armstrong

Giuseppe Tornatore

Glauber Rocha

Grémillon

Gus Van Sant

Guy Ritchie

Hanns Schwarz

Hans Deppe

Hans Weingartner

Hark Tsui

Harold Becker

Haroldo Marinho Barbosa

Hayao Miyazaki

Hector Babenco

Helmut Weiss

Helvécio Ratton

Henry Hathaway

Hideo Nakata

Howard Hawks

Humberto Solás

Hung-I Yao

Ibolya Fekete 


\begin{tabular}{|c|c|}
\hline Iciar Bollain & Jorge Gaggaro \\
\hline Im Kwon Taek & José Eduardo Belmonte \\
\hline Ingmar Bergman & José Joffily \\
\hline Inoussa Ousseini & José Padilha \\
\hline Ipojuca Pontes & Josef von Sternberg \\
\hline Isabel Coixet & Joshua Logan \\
\hline Jacques Tourneur & Juan Bautista Stagnaro \\
\hline Jae-young Kwak & Juan Pablo Rebella \\
\hline James Ivory & Juan Padrón \\
\hline Jamie Uys & Juan Taratuto \\
\hline Jan Hrebejk & Juan Villegas \\
\hline Jan Jakub Kolski & Jules Dassin \\
\hline Ján Kadár & Julia Solomonoff \\
\hline Jean Renoir & Júlio Bressane \\
\hline Jean-Luc Godard & Julio García Espinosa \\
\hline Jim Jarmusch & Jural Jabukisko \\
\hline Jim McBride & Kabir Khan \\
\hline João Batista & Kang Je Gyu \\
\hline João Jardim & Karan Johar \\
\hline Joe Wright & Karel Reisz \\
\hline John Ford & Karim Aïnouz \\
\hline John Huston & Katsuyuki Motohiro \\
\hline John Sturges & Kevin McDonald \\
\hline Jonas Mekas & Kim Ki Duk \\
\hline Joshua Logan & Kim Sang Jin \\
\hline Jonathan Dayton & Krzsztof Zanussi \\
\hline Jonathan Jakobowicz & Krzysztof Kieslowski \\
\hline
\end{tabular}


Kwah Ansah

Kyung-Taek Kwal

Laís Bodanzky

Lars Von Trier

Leon Hirszman

Leslie Arliss

Li Zhi-Chiang

Louis Malle

Luc Besson

Luchino Visconti

Lucía Cedrón

Luciano Ligabue

Lucrecia Martel

Luis Buñuel

Luis Mandoki

Luis Trenker

Luiz Fernando Carvalho

Lyonel Lucini

M. Night Shyamalan

Madhur Bhandarkar

Mahamat-Saleh Haroun

Man Ray

Manfredo Caldas

Manthia Diawara

Manuel Pérez

Marcelo Schapces

Marco Ferreri
María Victoria Menis

Martín de Salvo

Martin Ritt

Martin Scorcese

Mauricio Wainrot

Mauro Lima

Méd Hond

Med Hondo

Mehboob Khan

Michael Curtiz

Michael Lehman

Mike Figgis

Mike Leigh

Mike Nichols

Mira Nair

Mohamed Lakhdar-

Hamina

Momar Thian

Murnau

Naomi Kawase

Neil Jordan

Nelson Pereira dos Santos

Nicholas Ray

Ntshaveni Wa Luruli

Octavio Cortázar

Oldrich Lipsky

Orson Welles 
Otto Preminger

Ousmane Sembène

Pablo Stoll

Pablo Trapero

Paolo Agazzi

Park Chan Wook

Pasolini

Pastor Veja

Paulo Caldas

Pedro Almodóvar

Pen-ek Ratanaruang

Peter Bogdanovich

Peter Sollet

Petr Zelenka

Philip Kaufman

Pierre-Marie Dong

Quentin Tarantino

Raj Kapoor

Ramesh Sippy

René Clément

Richard Thorpe

Ridley Scott

Rob Reiner

Robert Siodmak

Robert Altman

Robert Redford

Robert Towne
Robert Wiene

Robert Wise

Roberto Farias

Roberto Gervitz

Roberto Moreira

Roberto Rossellini

Rodrigo Triana

Roger Vadim

Román Chalbaud

Roman Polanski

Sanjay Leela Bhansali

Sanou Kollo

Satyajit Ray

Sebastian Kamba

Sega Coulibaly

Sérgio Bianchi

Sérgio Moriconi

Shinji Aoyama

Sidney Sokhona

Sílvio Tendler

Song Hae Sun

Sönke Wortmann

Souleymane Cissé

Stan VanderBeek

Stanley Kubrick

Stephen Frears

Steve Kloves 
Steven Soderbergh

Sujoy Ghosh

Takeshi Miike

Tidiane Aw

Tod Browning

Tomás Gutiérrez Alea

Toni Venturi

Tsui Hark

Valerie Faris

Vera Fogwill

Vittorio De Sica

Vladimir Carvalho

Volker Schloendorff

Walter Ruttmann

Walter Salles

Wesley Ruggles

William Wyler

Willian Keighley

Wolfgang Staudte

Wong Kar-wai

Woody Allen

Woo-Suk Kang

Yojiro Takita

Zero Chou

Zhang Yimou
CAT: filme

TG: filme norte-americano

TR: Alfred Hitchcock

divismo

CAT: técnica

TR: cinema mudo

melodrama

Do outro lado da lei

CAT: filme

TG: filme sul-americano

TR: Pablo Trapero

documentário

CAT: gênero

NE: É uma montagem

cinematográfica de imagens visuais e sonoras dadas como reais e nãofictícias. Mostra as coisas e o mundo tais como eles são, tendo quase sempre um caráter didático ou informativo.

UP: não-ficção

TR: afílmico

direto

Dogville

Disque M para matar 
TG: filme europeu

TR: Lars Von Trier

dolly

CAT: equipamento

TG: maquinaria

TR: movimento de câmera

CAT: filme

TG: filme sul-americano

TR: Erika Bauer

Domésticas

CAT: filme

TG: filme sul-americano

TR: Fernando Meirelles

Don Siegel

CAT: filme

TG: diretor

TR: Perseguidor implacável

drama

CAT: gênero
TE: épico

TG: ficção

TR: A bela da tarde

Bobby

personagem

Drew Barrymore

CAT: filme

TG: ator

Drugstore cowboy

CAT: filme

TG: filme norte-americano

TR: Gus Van Sant

duração

CAT: técnica

TR: tempo

duração dos planos

CAT: técnica

TG: parâmetro

Durval Discos

CAT: filme

TG: filme sul-americano

TR: Anna Muylaer 
Dziga Vertov

CAT: filme

NE: É um cineasta russo, nascido em 1896 com o nome de Denis Arkadievtich Kaufman, depois adotando o nome Dziga Vertov, que significa movimento perpétuo ou roda que gira sem parar. Não fazia filmes encenados e filmava os participantes de seus filmes espontaneamente.

TE: diretor

TG: futurista

TR: intervalo

E Deus criou a mulher

CAT: filme

NE: O filme fala sobre uma órfã marginalizada pela sociedade por ter um comportamento liberal. Foi condenado pela Legião da Decência, organização ligada à Igreja Católica Apostólica Romana nos Estados Unidos, devido ao seu conteúdo sexual.

TG: filme norte-americano

TR: Roger Vadim

Ed Mort

CAT: filme

TG: filme sul-americano

TR: Alain Fresnot
Eduardo Coutinho

CAT: filme

TG: diretor

TR: Cabra marcado para

morrer

Eduardo Mendonza

CAT: filme

TG: diretor

TR: Mañana te cuento

Eduardo Schuldt

CAT: filme

TG: diretor

TR: Piratas en el Callao

Edukators

CAT: filme

TG: filme europeu

TR: Hans Weingartner

Edwin S. Porter

CAT: filme

NE: É o antigo operador de câmera de Thomas Edison, e realizador do primeiro faroeste da história do cinema. 
TR: O grande roubo do trem

efeito Kulechov

CAT: técnica

NE: Lev Kulechov foi um cineasta que fez uma experiência em 1919, a qual mostra o poder da montagem, pois o modo como ela é feita influencia na idéia que se tem de um filme.

TR: montagem

efeito Schufftan

CAT: técnica

TG: trucagem

efeitos especiais

CAT: técnica

TG: trucagem

Eisenstein

CAT: filme

$$
\text { técnica }
$$

TG: diretor

TR: montagem harmônica montagem vertical música

\section{Eklavya}

CAT: filme

TG: diretor

TR: Vidhu Vinod Chopra

El atraco

CAT: filme

TG: filme sul-americano

TR: Paolo Agazzi

El brigadista

CAT: filme

TG: filme sul-americano

TR: Octavio Cortázar

El caracazo

CAT: filme

TG: filme sul-americano

TR: Román Chalbaud

El cielito

CAT: filme

TG: filme sul-americano

TR: María Victoria Menis 
El hombre de Maisinicu

CAT: filme

TG: filme sul-americano

TR: Manuel Pérez

elástico

CAT: equipamento

TG: kit ferrramentas

Elephant

CAT: filme

TG: filme norte-americano

TR: Gus Van Sant

Eles não usam black-tie

CAT: filme

TG: filme sul-americano

TR: Leon Hirszman

Elia Kazan

CAT: filme

TG: diretor

TR: Sindicato de Ladrões

Uma rua chamada pecado

Elia Schneider

CAT: filme

TG: diretor
TR: Punto y raya

\author{
Eliseo Subiella \\ CAT: filme \\ TG: diretor \\ TR: O lado escuro do \\ coração
}

Elpidio Valdés

CAT: filme

TG: filme sul-americano

TR: Juan Padrón

\section{Elvis Presley}

CAT: filme

TG: ator

emigração

CAT: filme

TE: tema

TR: Bicots-nègres, vos voisins

Nationalité immigré

Paris, c'est joli

Safrana

Soleil 
CAT: filme

TG: filme africano

TR: colonialismo

movimentos de libertação

Ousmane Sembène

Emmanuelle Seigner

CAT: filme

TG: ator

emulsão

CAT: equipamento

TR: etiqueta

Encontro com Milton Santos ou o mundo global visto do lado de cá

CAT: filme

TG: filme sul-americano

TR: Sílvio Tendler

enquadramento

CAT: estética

TR: plano subjetivo

quadro

CAT: filme

Envolto nas sombras
TG: filme norte-americano

TR: filme noir

Henry Hathaway

épico

CAT: gênero

TG: ação

drama

\section{Erika Bauer}

CAT: filme

TG: diretor

TR: Dom Hélder Câmara: o santo rebelde

Ernst Lubitsch

CAT: filme

TG: diretor

TR: Madame Bovary

espaço

CAT: estética

TR: campo

cena

perspectiva

Essa pequena é uma parada 
CAT: filme

TG: filme norte-americano

TR: Peter Bogdanovich

Esse obscuro objeto do desejo

CAT: filme

TG: filme europeu

TR: Luis Buñuel

establishing shot

CAT: técnica

USE: plano de exposição

estrela

CAT: equipamento

TG: maquinaria

estrutural

CAT: gênero

USE: experimental

etiqueta

CAT: equipamento

TG: maquinaria

TR: assistente

data

emulsão instruções para laboratório

metragem

nome da produtora

título

Eureka

CAT: filme

TG: filme asiático

TR: Shinji Aoyama

êxodo rural

CAT: filme

TE: tema

TR: Le bracelet de bronze

Paweogo

experimental

CAT: gênero

UP: estrutural

TG: ficção

TR: vanguardista

expressionista

CAT: Escola

NE: O expressionismo teve destaque na Alemanha nos anos que antecederam a Segunda Guerra Mundial, sendo que alguns autores, como Siegfried Kracauer que escreveu De Caligari a Hitler, 
chegaram a dizer que os cineastas

prenunciavam outra terrível guerra,

e por isso fizeram filmes tão

perturbadores.

TR: Alemanha

Caligarismo

Nosferatu

O gabinete do Doutor

Caligari

Fabián Bielinsky

CAT: filme

TG: diretor

TR: Nove rainhas

Failan

CAT: filme

TG: filme asiático

TR: gângster

melodrama

Song Hae Sun

fala

CAT: técnica

TR: cinema sonoro
TG: filme europeu

TR: Pedro Almodóvar

Falsa loura

CAT: filme

TG: filme sul-americano

TR: Carlos Reichenbach

falso-raccord

CAT: técnica

TR: decupagem

Roberto Rossellini

Viagem à Itália

Week-end

Família rodante

CAT: filme

TG: filme sul-americano

TR: Pablo Trapero

Fanny e Alexander

CAT: filme

TG: filme europeu

TR: Ingmar Bergman

Fale com ela

CAT: filme faroeste

CAT: gênero 
UP: western

TG: ficção

TR: No tempo das

diligências

O grande roubo do trem

Federico Fellini

CAT: filme

TE: diretor

TR: A doce vida

Feliz ano velho

CAT: filme

TG: filme sul-americano

TR: Roberto Gervitz

Felizes juntos

CAT: filme

TG: filme asiático

TR: Wong Kar-wai

Feng Xiaogang

CAT: filme

TG: diretor

TR: O funeral do chefão

Férias de amor

CAT: filme
TG: filme norte-americano

TR: Joshua Logan

Fernando Meirelles

CAT: filme

TG: diretor

TR: Cidade de Deus

Domésticas

ficção

CAT: gênero

NE: Do latim, fingo que

originou a palavra figura . É uma forma de discurso que faz referência a personagens ou a ações que só existem na imaginação de seu autor e, em seguida, na do leitor/espectador. Tudo o que é inventado como simulacro.

TE: ação

adaptação

animação

aventura

burlesco

cinema de poesia

clássico

comédia

criminal

drama

experimental 
faroeste

melodrama

paródia

remake

suspense

terror

TG: gângster

filme africano

CAT: filme

TE: A câmera de madeira

Accident

Allah Tantou

Baara

Bicots-nègres, vos voisins

Black girl

Bye, bye Africa

Camp Thiaroye

Ceddo

Chronique des années de

braise

Den muso

Emitai

Finyé

Finzan

Guelwaar

Guimba: un tyran, une
Heritage Africa

Identité

Le bracelet de bronze

Le destin

Le prix de la liberté

Mortu Nega

Muna Moto

Nationalité immigré

Notre fille

Paris, c'est joli

Paweogo

Pousse- pousse

Rançon d'une alliance

Rouch in reverse

Safrana

Samory

Sarraounia

Sarzan

Sejnane

Soleil

The gods must be crazy

The money order

Une si simple histoire

Xala

\section{filme asiático}

CAT: filme 
TE: 2046 - Os Segredos do Amor

A irmandade da guerra

A viagem de Chihiro

A vida de Oharu

Amor à flor da pele

Amores expressos

Anjos caídos

As time goes by

Awara

Bayside Shakedown

Bobby

Canção da estrada

Casa vazia

Chandni bar

Cinzas do passado

Contos da lua vaga

Devdas

Eureka

Failan

Felizes juntos

Friend

Good boy, bad boy

Herói

Hotaru

Jhankaar beats

Joggers park
Joint security área

Kabhi Alvidaa Na Kehna

Kabul Express

Kick the moon

Life in a metro

Mandala

Mother India

My Sassy girl

Nome de família

Nossos anos selvagens

O clã das adagas

voadoras

O funeral do chefão

O tempo não espera

O tigre e o dragão

Old boy

Princess Mononoke

Rashomon

Reflections

Ringu

Samaritan girl

Seven swords

Shiri

Sholay

Silmido

Sopyonje

Spyder and Lilies 
Tempos felizes

The bow

The happening

The Road on the air

Three extremes

Ultima vida no Universo

Um beijo roubado

Vidhu Vinod Chopra

When the last sword is

drawn

Windstruck

filme europeu

CAT: filme

TE: A bela da tarde

A doce vida

A flor do meu segredo

A fraternidade é vermelha

A gardênia azul

A grande ilusão

A igualdade é branca

A liberdade é azul

A má educação

A noite americana

A pequena loja da rua

principal

A perversa

A rainha
A regra do jogo

A vida secreta das

palavras

Abra os olhos

Après lui

Assassinato em Gosford

Park

Ata-me!

Através de um espelho

Bolshe Vita

Burial of a potato

Buttoners

Carne trêmula

Cenas de um casamento

Cesar e Rosalie

Charlotte Gray

Chico

Cinema Paradiso

Crônicas de Nárnia

Dançando no escuro

Der Kaiser Von Kalifornien

Dogville

Edukators

Esse obscuro objeto do

desejo

Fale com ela

Fanny e Alexander

Grandes esperanças 
Gritos e sussurros

Herói acidental

Joana D'arc

Jogos, trapaças e dois canos fumegantes

Johnie Waterman

Juiz

Ladrões de bicicleta

Lemonade Joe radio international

L'etoile de mer

Leve meus olhos

Life as fatal sexually transmitted disease

Los Borgia

Dusseldorf

M - O vampiro de

Madame Bovary

Malena

Mar adentro

Melody of the heart

Melody of the world

Metropolis

Minha adorável lavanderia

Minha vida sem mim

Morangos silvestres

Mulheres à beira de um

ataque de nervos

Murderers among us
Nosferatu

O anjo azul

O charme discreto da

burguesia

O encouraçado Potemkin

O fantasma da liberdade

O gabinete do Doutor

Caligari

O homem mais desejado do mundo

O homem que quis matar Hitler

O leopardo

O silêncio

O sol por testemunha

O testamento do Dr.

Mabuse

O último rei da Escócia

Obsessão

Ontem, hoje e amanhã

Orgulho e preconceito

Os Incompreendidos

Os sonhadores

Perdas e danos

Radiofreccia

Repulsa ao sexo

Retorno a Howards End

Roma, cidade aberta

Segredos e mentiras 
Tell the truth

Teorema

The Black Forest girl

Traídos pelo desejo

Trainspotting

Tudo começou no sábado

Tudo sobre minha mãe

Um relatório ambíguo

sobre o fim do mundo

Um retrato de mulher

Uma janela para o amor

Uma Simples Formalidade

Volver

TG: Quatro passi tra le nuvole

filme noir

CAT: gênero

TG: criminal

TR: A marca da maldade

A morte passou por perto

Beijo da morte

Chaga de fogo

Desejo humano

Envolto nas sombras

Fuga do passado

Horas de desespero

Laura
Mercado de ladrões

O grande golpe

O segredo de Berlim

Punhos de campeão

Relíquia macabra

Rua sem nome

Uma vida marcada

filme norte-americano

CAT: filme

TE: 1942: a conquista do paraíso

2001: Odisseia no Espaço

21 gramas

A força do amor

A guerra dos Roses

A história real

A insustentável leveza do

ser

A marca da maldade

A morte passou por perto

A rosa púrpura do Cairo

A última sessão de

cinema

A última tentação de

Cristo

Aconteceu naquela noite

Amores brutos 
Ânsia de amar

As pontes de Madison

Atração mortal

Babel

Barry Lyndon

Beijo da morte

Boa noite e boa sorte

Bonequinha de luxo

Brilho eterno de uma

mente sem lembranças

Bubble

Building n.7

Caçada humana

Cães de aluguel

Cantando na chuva

Casablanca

Celebridades

Chaga de fogo

Cidadão Kane

Cidade dos sonhos

Cidade perdida

Como água para

chocolate

Conspiração Tequila

Correspondente

estrangeiro

Crepúsculo dos deuses

Crônica de um amor louco
De olhos bem fechados

Desconstruindo Harry

Desejo humano

Disque M para matar

Drugstore cowboy

E Deus criou a mulher

Elephant

Envolto nas sombras

Essa pequena é uma

parada

Férias de amor

Fuga do passado

Fugindo do inferno

Ghost dog

Gilda

Glória feita de sangue

Harry e Sally

Horas de desespero

Interlúdio

Irresistível paixão

Janela indiscreta

Justiça cega

Juventude transviada

Kafka

Kill Bill

Klute, o passado condena

Ladrão de casaca 
Laranja mecânica

Laura

Ligações perigosas

Lolita

Loucos de paixão

Luzes da cidade

Marnie - confissões de

uma ladra

Mash

Meia-noite no jardim do

bem e do mal

Menina de ouro

Mercado de ladrões

Monstros

Nascido para matar

No tempo das diligências

Noivo neurótico, noiva nervosa

O almoço nu

O destino bate à sua porta

O grande ditador

O grande golpe

O grande roubo do trem

O homem elefante

O iluminado

O jogador

O mercador de almas

O pecado mora ao lado
O prisioneiro do rock

O reverso da fortuna

O segredo de Berlim

O selvagem da

motocicleta

O sonho de Cassandra

O verão de Victor Vargas

O viajante

Os assassinos

Os pássaros

Paranoid Park

Pequena Miss Sunshine

Perseguidor implacável

Psicose

Pulp fiction

Punhos de campeão

Quanto mais quente

melhor

Quero ser John Malkovich

Quiz Show - a verdade dos bastidores

Relíquia macabra

Réquiem para um sonho

Rua sem nome

Ruth em questão

Santa não sou

Sexo, mentiras e

videotape 
Sin City - a cidade do

pecado

Sindicato de Ladrões

Sobre meninos e lobos

Susie e os Baker Boys

Tempos modernos

Thelma e Louise

Twin Peaks: Os últimos

dias de Laura Palmer

Um corpo que cai

Um lugar ao sol

Um misterioso

assassinato em Manhattan

Uma aventura na

Martinica

Uma rua chamada pecado

Uma vida marcada

Veludo azul

Vida de cão

Vida de solteiro

Vítimas de uma paixão

\section{filme sul-americano}

CAT: filme

TE: A concepção

A menina santa

Abril despedaçado

Babaçu
Baile perfumado

Baixo gávea

Barra 68

Batismo de sangue

Bicho de sete cabeças

Cabra cega

Cabra marcado para

morrer

Cama adentro

Cama de gato

Canudos

Carandiru

Casa de areia

Central do Brasil

Chega de saudade

Cidade de Deus

Contra todos

Cuba baila

Desmundo

Deus e o diabo na terra do sol

Do outro lado da lei

Dom Hélder Câmara: 0 santo rebelde

Domésticas

Durval Discos

Ed Mort

El atraco 


\begin{tabular}{|c|c|c|}
\hline & El brigadista & Meu nome não é Johnny \\
\hline & El caracazo & Não é você, sou eu \\
\hline & El cielito & Nove rainhas \\
\hline & El hombre de Maisinicu & O abraço partido \\
\hline & Eles não usam black-tie & O assalto ao trem pagador \\
\hline & Elpidio Valdés & O engenho de Zé Lins \\
\hline & Encontro com Milton & O filho da noiva \\
\hline $\begin{array}{l}\text { Santos ol } \\
\text { lado }\end{array}$ & o mundo global visto do & O lado escuro do coração \\
\hline & de cá & O pântano \\
\hline & Falsa loura & O vaqueiro voador \\
\hline & Família rodante & Ônibus 174 \\
\hline & Feliz ano velho & Pasajeros \\
\hline & Garotas do ABC & Piratas en el Callao \\
\hline & Guardafronteras & Punto y raya \\
\hline & quilo? & Quanto vale ou é por \\
\hline & Janela da alma & Quem matou Pixote? \\
\hline Quinquín & Las aventuras de Juan & Retrato de Teresa \\
\hline & Las doce sillas & Rua Seis, Sem Número \\
\hline & Las mantenidas sin & Sábado \\
\hline sueños & & Secuestro express \\
\hline & Lavoura arcaica & Soñar no cuesta nada \\
\hline & Lucía & Terra em transe \\
\hline & Madame satã & Tropa de elite \\
\hline & Mañana te cuento & Um copo de cólera \\
\hline & Matou a família e foi ao & Vidas secas \\
\hline & Memórias de quem fica & \\
\hline
\end{tabular}


montagem cubista

filtro

CAT: equipamento

TG: acessórios

Finyé

CAT: filme

TG: filme africano

TR: crítica

independência africana

Souleymane Cissé

Finzan

CAT: filme

TG: filme africano

TR: Cheikh Oumar Sissoko

liberdade

mulher africana

fita adesiva

CAT: equipamento

TG: maquinaria

flashback

CAT: Escola

técnica

TR: impressionista
Flora Gómez

CAT: filme

TG: diretor

TR: Mortu Nega

foco

CAT: equipamento

UP: focus

TR: câmera

focus

CAT: equipamento

USE: foco

fora-de-campo

CAT: estética

USE: off

fora-de-quadro

CAT: estética

TR: quadro

fotômetro incidente

CAT: equipamento

TG: acessórios 
Friend

fragmento

CAT: técnica

TR: montagem

CAT: Escola

TR: impressionista

nouvelle vague

realista

Francis Ford Coppola

CAT: filme

TG: diretor

TR: O selvagem da

motocicleta

François Truffaut

CAT: filme

TG: diretor

TR: A noite americana

Os Incompreendidos

CAT: equipamento

TG: Acessório de

iluminação
CAT: filme

UP: Chingoo

TG: filme asiático

TR: Kyung-Taek Kwal

Fritz Lang

CAT: filme

TG: diretor

TR: A gardênia azul

Desejo humano

M - O vampiro de

Dusseldorf

Metropolis

O homem que quis matar

Hitler

O testamento do Dr.

Mabuse

Um retrato de mulher

Fruit Chan

CAT: filme

TG: diretor

TR: Three extremes

Fuga do passado

CAT: filme

TG: filme norte-americano 
TR: filme noir

Jacques Tourneur

Fugindo do inferno

CAT: filme

TG: filme norte-americano

TR: John Sturges

futurista

CAT: Escola

TE: Dziga Vertov

O homem com a câmera

de filmar

vanguardista

gângster

CAT: gênero

TE: ficção

TR: Failan

Garotas do ABC

CAT: filme
TG: filme sul-americano

TR: Carlos Reichenbach

garra

CAT: equipamento

TG: maquinaria

garra jacaré

CAT: equipamento

TG: Acessório de

iluminação

Gary Oldman

CAT: filme

TG: ator

gelatina

CAT: equipamento

TG: maquinaria

Gene Kelly

CAT: filme

TG: diretor

TR: Cantando na chuva

George Clooney

CAT: filme 
TG: diretor

TR: Boa noite e boa sorte

George Stevens

CAT: filme

TG: diretor

TR: Um lugar ao sol

Ghost dog

CAT: filme

TG: filme norte-americano

TR: Jim Jarmusch

Gilda

CAT: filme

TG: filme norte-americano

TR: Charles Vidor

Gillian Armstrong

CAT: filme

TG: diretor

TR: Charlotte Gray

Giuseppe Tornatore

CAT: filme

TG: diretor

TR: Cinema Paradiso
Malena

Uma Simples Formalidade

Glauber Rocha

CAT: filme

TG: diretor

TR: Deus e o diabo na terra do sol

Terra em transe

Glória feita de sangue

CAT: filme

TG: filme norte-americano

TR: Stanley Kubrick

gobo

CAT: equipamento

TG: maquinaria

Gongdong gyeongbi guyeok JSA

CAT: filme

USE: Joint security área

Good boy, bad boy

CAT: filme

TG: filme asiático

TR: Ashwini Chaudhary 
grifa

Grace Kelly

CAT: filme

TG: ator

grande angular

CAT: equipamento

TG: objetiva

Grandes esperanças

CAT: filme

TG: filme europeu

TR: David Lean

Gregory Peck

CAT: filme

TG: ator

CAT: filme

TE: diretor

TR: realista

Greta Garbo

CAT: filme

TG: ator
CAT: equipamento

USE: mecanismo de tração

Gritos e sussurros

CAT: filme

TG: filme europeu

TR: Ingmar Bergman

grua

CAT: equipamento

TG: maquinaria

TR: movimento de câmera

Guardafronteras

CAT: filme

TG: filme sul-americano

TR: Octavio Cortázar

Guelwaar

CAT: filme

TG: filme africano

TR: Ousmane Sembène

guerra coreana

CAT: filme

TE: tema 
TR: Joint security área

Shiri

Guimba: un tyran, une époque

CAT: filme

TG: filme africano

TR: Cheikh Oumar Sissoko

Gus Van Sant

CAT: filme

TG: diretor

TR: Aconteceu naquela noite

Drugstore cowboy

Elephant

Paranoid Park

Guy Ritchie

CAT: filme

TG: diretor

TR: Jogos, trapaças e dois

canos fumegantes

Hanns Schwarz

CAT: filme

TG: diretor

TR: Melody of the heart
Hans Deppe

CAT: filme

TG: diretor

TR: The Black Forest girl

Hans Weingartner

CAT: filme

TG: diretor

TR: Edukators

Hark Tsui

CAT: filme

TG: diretor

TR: Seven swords

Harold Becker

CAT: filme

TG: diretor

TR: Vítimas de uma paixão

Haroldo Marinho Barbosa

CAT: filme

TG: diretor

TR: Baixo gávea

Harrison Ford

CAT: filme 
TG: ator

Harry e Sally

CAT: filme

TG: filme norte-americano

TR: Rob Reiner

Hayao Miyazaki

CAT: filme

TG: diretor

TR: A viagem de Chihiro

Princess Mononoke

Hector Babenco

CAT: filme

TG: diretor

TR: Carandiru

Helmut Weiss

CAT: filme

TG: diretor

TR: Tell the truth

Helvécio Ratton

CAT: filme

TG: diretor
TR: Batismo de sangue

Henry Hathaway

CAT: filme

TG: diretor

TR: Beijo da morte

Envolto nas sombras

Heritage Africa

CAT: filme

TG: filme africano

TR: independência africana

Kwah Ansah

Herói

CAT: filme

TG: filme asiático

TR: Zhang Yimou

Herói acidental

CAT: filme

TG: filme europeu

TR: Jan Hrebejk

Hideo Nakata

CAT: filme

TG: diretor 
TR: Ringu

hi-hat

CAT: equipamento

TG: maquinaria

$\mathrm{HMI}$

CAT: equipamento

TG: Acessório de

iluminação

Horas de desespero

CAT: filme

TG: filme norte-americano

TR: filme noir

William Wyler

Hotaru

CAT: filme

TG: filme asiático

TR: Naomi Kawase

Howard Hawks

CAT: filme

TG: diretor
TR: Uma aventura na

Martinica

Hugh Grant

CAT: filme

TG: ator

Humberto Solás

CAT: filme

TG: diretor

TR: Lucía

Humphrey Bogart

CAT: filme

TG: ator

Hung-I Yao

CAT: filme

TG: diretor

TR: Reflections

Hwal

CAT: filme

USE: The bow

Ibolya Fekete

CAT: filme 
TG: diretor

TR: montagem

TR: Bolshe Vita

Chico

impressionista

CAT: Escola

Iciar Bollain

TR: cinema mudo

CAT: filme

flashback

TG: diretor

França

TR: Leve meus olhos

primeiro plano

Identité

independência africana

CAT: filme

CAT: filme

TG: filme africano

TE: tema

TR: independência africana

Pierre-Marie Dong

TR: Accident

Allah Tantou

Baara

Im Kwon Taek

Den muso

CAT: filme

Finyé

TG: diretor

Heritage Africa

TR: Mandala

Identité

Sopyonje

Sarzan

Une si simple histoire

imagem

Xala

CAT: estética

TR: superposição

indireto livre

CAT: gênero

implant TR: cinema de poesia

CAT: técnica 
Ingmar Bergman

CAT: filme

TG: diretor

TR: Através de um espelho

Cenas de um casamento

Fanny e Alexander

Gritos e sussurros

Morangos silvestres

O silêncio

Ingrid Bergman

CAT: filme

TG: ator

Inoussa Ousseini

CAT: filme

TG: diretor

TR: Paris, c'est joli

instruções para laboratório

CAT: equipamento

TR: etiqueta

Interlúdio

CAT: filme

TG: filme norte-americano

TR: Alfred Hitchcock intervalo

CAT: técnica

TR: Dziga Vertov

montagem

O homem com a câmera

de filmar

Ipojuca Pontes

CAT: filme

TG: diretor

TR: Canudos

Irmãs

CAT: filme

TG: filme sul-americano

TR: Julia Solomonoff

Irresistível paixão

CAT: filme

TG: filme norte-americano

TR: Steven Soderbergh

Isabel Coixet

CAT: filme

TG: diretor

TR: A vida secreta das

palavras

Minha vida sem mim 
TG: diretor

Isabella Rossellini

TR: Fuga do passado

CAT: filme

TG: ator

Jae-young Kwak

CAT: filme

Isabelle Adjani

CAT: filme

TG: diretor

TR: My Sassy girl

TG: ator

Windstruck

Itália

James Dean

CAT: Escola

CAT: filme

TR: neorealista

TG: ator

Jack Nicholson

CAT: filme

CAT: filme

TG: ator

TG: diretor

TR: Retorno a Howards End

Jacqueline Bisset Uma janela para o amor

CAT: filme

TG: ator

Jamie Uys

CAT: filme

Jacques Tati

TG: diretor

CAT: técnica

TR: The gods must be crazy

TR: parâmetro

Jan Hrebejk

Jacques Tourneur

CAT: filme

CAT: filme

TG: diretor 
TR: Herói acidental

Jan Jakub Kolski

CAT: filme

TG: diretor

TR: Burial of a potato

Johnie Waterman

Ján Kadár

CAT: filme

TG: diretor

TR: A pequena loja da rua principal

Jane Fonda

CAT: filme

TG: ator

Janela da alma

CAT: filme

TG: filme sul-americano

TR: João Jardim

Janela indiscreta

CAT: filme

TG: filme norte-americano

TR: Alfred Hitchcock
Jean Renoir

CAT: filme

TG: diretor

TR: A grande ilusão

A regra do jogo

realista

Jean-Luc Godard

CAT: filme

TG: diretor

TR: nouvelle vague

Jeremy Irons

CAT: filme

TG: ator

Jessica Lange

CAT: filme

TG: ator

Jhankaar beats

CAT: filme

TG: filme asiático

TR: Sujoy Ghosh

Jim Jarmusch 
CAT: filme

TR: Orgulho e preconceito

TG: diretor

TR: Ghost dog

Joggers park

CAT: filme

Jim McBride

TG: filme asiático

CAT: filme

TR: Anant Balani

TG: diretor

TR: A força do amor

Jogos, trapaças e dois canos fumegantes

CAT: filme

Joana D'arc

CAT: filme

TG: filme europeu

TG: filme europeu

TR: Guy Ritchie

TR: Luc Besson

John Ford

João Batista

CAT: filme

CAT: filme

TG: diretor

TR: Rua Seis, Sem Número

TG: diretor

TR: No tempo das

diligências

John Huston

João Jardim

CAT: filme

CAT: filme

TG: diretor

TG: diretor

TR: Relíquia macabra

TR: Janela da alma

John Malkovich

Joe Wright

CAT: filme

CAT: filme

TG: ator

TG: diretor 
John Sturges

CAT: filme

TG: diretor

TR: Fugindo do inferno

Johnie Waterman

CAT: filme

TG: filme europeu

TR: Jan Jakub Kolski

Johnny Depp

CAT: filme

TG: ator

guyeok JSA

TG: filme asiático

TR: guerra coreana

Park Chan Wook

Jonas Mekas

CAT: filme

TE: diretor
TR: underground

Jonathan Dayton

CAT: filme

TG: diretor

TR: Pequena Miss Sunshine

Jonathan Jakobowicz

CAT: filme

TG: diretor

TR: Secuestro express

Jorge Gaggaro

CAT: filme

TG: diretor

TR: Cama adentro

José Eduardo Belmonte

CAT: filme

TG: diretor

TR: A concepção

José Joffily

CAT: filme

TG: diretor

TR: Quem matou Pixote? 
José Padilha

CAT: filme

TG: diretor

TR: Ônibus 174

Tropa de elite

Josef von Sternberg

CAT: filme

TG: diretor

TR: O anjo azul

Joshua Logan

CAT: filme

TE: diretor

TR: Férias de amor

Juan Bautista Stagnaro

CAT: filme

TG: diretor

TR: Memórias de quem fica

Juan Pablo Rebella

CAT: filme

TG: diretor

TR: Whisky
Juan Taratuto

CAT: filme

Juan Padrón

CAT: filme

TG: diretor

TR: Elpidio Valdés

TG: diretor

TR: Não é você, sou eu

Juan Villegas

CAT: filme

TG: diretor

TR: Sábado

Juiz

CAT: filme

TG: filme europeu

TR: Danny Cannon

Jules Dassin

CAT: filme

TG: diretor

TR: Mercado de ladrões

Julia Roberts

CAT: filme 
TG: ator

Julia Solomonoff

CAT: filme

TG: diretor

TR: Irmãs

Julie Delpy

CAT: filme

TG: ator

Juliette Binoche

CAT: filme

TG: ator

Júlio Bressane

CAT: filme

TG: diretor

TR: Matou a família e foi ao cinema

Julio García Espinosa

CAT: filme

TG: diretor

TR: Cuba baila

Las aventuras de Juan

Quinquín jump cut

CAT: técnica

USE: salto

junção

CAT: estética

técnica

TR: plano

raccord

Jural Jabukisko

CAT: filme

TG: diretor

TR: Um relatório ambíguo

sobre o fim do mundo

Justiça cega

CAT: filme

TG: filme norte-americano

TR: Mike Figgis

Juventude transviada

CAT: filme

TG: filme norte-americano

TR: Nicholas Ray

Kabhi Alvidaa Na Kehna 
CAT: filme

TG: filme asiático

TR: Karan Johar

Kabir Khan

CAT: filme

TG: diretor

TR: Kabul Express

Kabul Express

CAT: filme

TG: filme asiático

TR: Kabir Khan

Kafka

CAT: filme

TG: filme norte-americano

TR: Steven Soderbergh

Kang Je Gyu

CAT: filme

TG: diretor

TR: A irmandade da guerra

Shiri

Karan Johar

CAT: filme
TG: diretor

TR: Kabhi Alvidaa Na Kehna

Karel Reisz

CAT: filme

TG: diretor

TR: Tudo começou no

sábado

Karim Aïnouz

CAT: filme

TG: diretor

TR: Madame satã

Kathleen Turner

CAT: filme

TG: ator

Katsuyuki Motohiro

CAT: filme

TG: diretor

TR: Bayside Shakedown

Keanu Reeves

CAT: filme

TG: ator 
Kelly Lynch

CAT: filme

TG: ator

kelvinômetro

CAT: equipamento

TG: acessórios

Kenji Mizoguchi

CAT: técnica

NE: Seus filmes contém

exemplos de enquadramentos

esmerados e ricamente detalhados

e seu interesse pela psicologia das

mulheres japonesas. Tornou-se

diretor em 1922 e seu trabalho tem

sido elogiado como estando entre os mais poéticos e expressivos da história do cinema.

TR: A vida de Oharu

Contos da lua vaga

parâmetro
TG: diretor

TR: O último rei da Escócia

Kick the moon

CAT: filme

UP: Shinlaui dalbam

TG: filme asiático

TR: Kim Sang Jin

Kill Bill

CAT: filme

TG: filme norte-americano

TR: Quentin Tarantino

Kim Basinger

CAT: filme

TG: ator

Kim Ki Duk

CAT: filme

TG: diretor

TR: Casa vazia

Samaritan girl

TG: ator

The bow

Kim Novak

CAT: filme

CAT: filme 
TG: ator

Kim Sang Jin

CAT: filme

TG: diretor

TR: Kick the moon

kinetógrafo

CAT: equipamento

TR: câmera

voz

kino-floo

CAT: equipamento

TG: Acessório de iluminação

kit ferrramentas

CAT: equipamento

TE: alicate

caneta hidrocor

canivete

chave de fenda

chave halen

chave Philips

elástico

kit lens cleaner

lanterna lápis

lupa

multímero

palitos de madeira

pano anti-estático

pano de câmera

pinça

pincel médio

seringa de ar

tesoura

trena

TG: maquinaria

TR: assistente de câmera

kit lens cleaner

CAT: equipamento

TG: kit ferrramentas

Klute, o passado condena

CAT: filme

TG: filme norte-americano

TR: Alan J. Pakula

Krzsztof Zanussi

CAT: filme

TG: diretor 
TR: Life as fatal sexually transmitted disease

Krzysztof Kieslowski

CAT: filme

TG: diretor

TR: A fraternidade é

vermelha

A igualdade é branca

A liberdade é azul

Kwah Ansah

CAT: filme

TG: diretor

TR: Heritage Africa

Kyung-Taek Kwal

CAT: filme

TG: diretor

TR: Friend

laçada

CAT: equipamento

TR: câmera

Ladrão de casaca

CAT: filme

TG: filme norte-americano
TR: Alfred Hitchcock

Ladrões de bicicleta

CAT: filme

TG: filme europeu

TR: neorealista

Vittorio De Sica

Laís Bodanzky

CAT: filme

TG: diretor

TR: Bicho de sete cabeças

Chega de saudade

Lana Turner

CAT: filme

TG: ator

lanterna

CAT: equipamento

TG: kit ferrramentas

lápis

CAT: equipamento

TG: kit ferrramentas

Laranja mecânica 
CAT: filme

TG: filme norte-americano

TR: Stanley Kubrick

Lars Von Trier

CAT: filme

TG: diretor

TR: Dançando no escuro

Dogville

Las aventuras de Juan Quinquín

CAT: filme

TG: filme sul-americano

TR: Julio García Espinosa

Las doce sillas

CAT: filme

TG: filme sul-americano

TR: Tomás Gutiérrez Alea

Las mantenidas sin sueños

CAT: filme

TG: filme sul-americano

TR: Martín de Salvo

Vera Fogwill

lata vazia de negativo
CAT: equipamento

TG: maquinaria

Laura

CAT: filme

TG: filme norte-americano

TR: filme noir

Otto Preminger

Lauren Bacall

CAT: filme

TG: ator

Lavoura arcaica

CAT: filme

TG: filme sul-americano

TR: Luiz Fernando Carvalho

Le bracelet de bronze

CAT: filme

TG: filme africano

TR: êxodo rural

Tidiane Aw

Le destin

CAT: filme

TG: filme africano 
TR: liberdade

mulher africana

Sega Coulibaly

Le prix de la liberté

CAT: filme

TG: filme africano

TR: Dikongue-Pipa

liberdade

mulher africana

CAT: filme

TG: ator

Lemonade Joe radio international

CAT: filme

TG: filme europeu

TR: Oldrich Lipsky

Lena Olin

CAT: filme

TG: ator

CAT: equipamento

TG: acessórios
TR: objetiva

Leon Hirszman

CAT: filme

TG: diretor

TR: Eles não usam black-tie

Leslie Arliss

CAT: filme

TG: diretor

TR: A perversa

L'etoile de mer

CAT: filme

NE: Filme do movimento

surrealista da década de 20 .

TG: filme europeu

TR: Man Ray

surrealismo

Leve meus olhos

CAT: filme

TG: filme europeu

TR: Iciar Bollain

Li Zhi-Chiang

CAT: filme 
TG: diretor

TR: The Road on the air

Liz Taylor

CAT: filme

TG: ator

liberdade

CAT: filme

TE: tema

TR: Finzan

Le destin

Le prix de la liberté

Muna Moto

Life as fatal sexually transmitted disease

CAT: filme

TG: filme europeu

TR: Krzsztof Zanussi

Life in a metro

CAT: filme

TG: filme asiático

TR: Anurag Basu

Ligações perigosas

CAT: filme

TG: filme norte-americano

TR: Stephen Frears
Lolita

CAT: filme

TG: filme norte-americano

TR: Stanley Kubrick

looping

CAT: equipamento

TG: maquinaria

Los Borgia

CAT: filme

TG: filme europeu

TR: António Hernández

Loucos de paixão

CAT: filme

TG: filme norte-americano

TR: Luis Mandoki

Louis Malle

CAT: filme

TG: diretor

TR: Perdas e danos 
TR: Memórias de quem fica

louma

CAT: equipamento

TG: maquinaria

TR: movimento de câmera

Luc Besson

CAT: filme

TG: diretor

TR: Joana D'arc

Luchino Visconti

CAT: filme

TG: diretor

TR: neorealista

O leopardo

Obsessão

Lucía

CAT: filme

TG: filme sul-americano

TR: Humberto Solás
Luciano Ligabue

CAT: filme

TG: diretor

TR: Radiofreccia

Lucrecia Martel

CAT: filme

TG: diretor

TR: A menina santa

O pântano
Luis Buñuel

CAT: filme

TG: diretor

TR: A bela da tarde

Esse obscuro objeto do

desejo

O charme discreto da

burguesia

O fantasma da liberdade

Luis Mandoki

CAT: filme

Lucía Cedrón

TG: diretor

CAT: filme

TR: Loucos de paixão

TG: diretor 
Luis Trenker

CAT: filme

TG: diretor

TR: Der Kaiser Von

Kalifornien

Luiz Fernando Carvalho

CAT: filme

TG: diretor

TR: Lavoura arcaica

lupa

CAT: equipamento

TG: kit ferrramentas

Luzes da cidade

CAT: filme

TG: filme norte-americano

TR: Charles Chaplin

Lyonel Lucini

CAT: filme

TG: diretor

TR: Babaçu

M - O vampiro de Dusseldorf
CAT: filme

TG: filme europeu

TR: Fritz Lang

M. Night Shyamalan

CAT: filme

TG: diretor

TR: The happening

Madame Bovary

CAT: filme

TG: filme europeu

TR: Ernst Lubitsch

Madame satã

CAT: filme

TG: filme sul-americano

TR: Karim Aïnouz

Madeleine Stowe

CAT: filme

TG: ator

Madhur Bhandarkar

CAT: filme

TG: diretor

TR: Chandni bar 
Mandala

Mae West

CAT: filme

TG: ator

Mahamat-Saleh Haroun

CAT: filme

TG: diretor

TR: Bye, bye Africa

Malena

CAT: filme

TG: filme europeu

TR: Giuseppe Tornatore

Man Ray

CAT: filme

TG: diretor

TR: L'etoile de mer

Mañana te cuento

CAT: filme

TG: filme sul-americano

TR: Eduardo Mendonza
CAT: filme

TG: filme asiático

TR: Im Kwon Taek

mandrake

CAT: equipamento

TG: maquinaria

Manfredo Caldas

CAT: filme

TG: diretor

TR: O vaqueiro voador

Manthia Diawara

CAT: filme

NE: Nativo de Mali, o professor Diawara foi educado na França e depois cursou a universidade nos Estados Unidos. Fez mestrado na Universidade da Indiana, e sua tese, sobre política e estética no cinema africano, formou a base deste cinema. Essa tese foi publicada em 1985 pela editora da Universidade.

TG: diretor

TR: Rouch in reverse

Manuel Pérez 
CAT: filme

TG: diretor

TR: El hombre de Maisinicu

maquinaria

CAT: equipamento

TE: bandeira

barracuda

batoque

boletim de câmera

cabeça de efeito

cabeça de tripé

cabo

cabo de segurança

changing bag

chassis

claquete

cunha

difusor tecron

dolly

estrela

etiqueta

fita adesiva garra

gelatina

gobo

grua

hi-hat

kit ferrramentas

lata vazia de negativo

looping

louma

mandrake

motor

negativo virgem

refletor

saco de areia

saco preto

sargento

steadycam

travelling

trilho de travelling

tripé grande

tripé pequeno

vareta

Mar adentro

CAT: filme

TG: filme europeu

TR: Alejandro Amenábar 
TG: ator

Marcello Mastroianni

CAT: filme

TG: ator

Marcelo Schapces

CAT: filme

TG: diretor

TR: Memórias de quem fica

Marco Ferreri

CAT: filme

TR: Crônica de um amor

louco

CAT: filme

TG: diretor

TR: El cielito

María Victoria Menis

TG: ator

Marlene Dietrich

CAT: filme

Marilyn Monroe
TG: diretor

Marlon Brando

CAT: filme

TG: ator

Marnie - confissões de uma ladra

CAT: filme

TG: filme norte-americano

TR: Alfred Hitchcock

Martín de Salvo

CAT: filme

TG: diretor

TR: Las mantenidas sin

sueños

Martin Ritt

CAT: filme

TG: diretor

TR: O mercador de almas

Martin Scorcese

CAT: filme

TG: diretor

TR: A última tentação de

Cristo 
máscara

CAT: técnica

TG: trucagem

Mash

CAT: filme

TG: filme norte-americano

TR: Robert Altman

Matou a família e foi ao cinema

CAT: filme

TG: filme sul-americano

TR: Júlio Bressane

Matt Dillon

CAT: filme

TG: ator

matte

CAT: técnica

TG: trucagem

Mauricio Wainrot

CAT: filme

TG: diretor

TR: Memórias de quem fica

Mauro Lima
CAT: filme

TG: diretor

TR: Meu nome não é Johnny

mecanismo de tração

CAT: equipamento

UP: grifa

TR: câmera

Méd Hond

CAT: filme

TG: diretor

TR: Sarraounia

Med Hondo

CAT: filme

TG: diretor

TR: Bicots-nègres, vos

voisins

Soleil

Meg Ryan

CAT: filme

TG: ator

Mehboob Khan

CAT: filme

TG: diretor 
TR: Mother India

mal

CAT: filme

TG: filme norte-americano

TR: Clint Eastwood

Mel Gibson

CAT: filme

TG: ator

melodrama

CAT: gênero

TG: ficção

TR: A irmandade da guerra divismo

Failan

Melody of the heart

CAT: filme

TG: filme europeu

TR: Hanns Schwarz

Melody of the world

CAT: filme
TG: filme europeu

TR: Walter Ruttmann

Memórias de quem fica

CAT: filme

TG: filme sul-americano

TR: Adrián Caetano

Adrián Suar

Alberto Lecchi

Alejandro Doria

Carlos Sorin

Daniel Burman

Juan Bautista Stagnaro

Lucía Cedrón

Marcelo Schapces

Mauricio Wainrot

Menina de ouro

CAT: filme

TG: filme norte-americano

TR: Clint Eastwood

Mercado de ladrões

CAT: filme

TG: filme norte-americano

TR: filme noir

Jules Dassin 
TR: Atração mortal

metragem

CAT: equipamento

TR: etiqueta

CAT: filme

TG: filme europeu

TR: Fritz Lang

Meu nome não é Johnny

CAT: filme

TG: filme sul-americano

TR: Mauro Lima

Mibu gishi den

CAT: filme

USE: When the last sword is drawn

Michael Curtiz

CAT: filme

TG: diretor

TR: Casablanca

Michael Lehman

CAT: filme

TG: diretor
Michelle Pfeiffer

CAT: filme

TG: ator

Mike Figgis

CAT: filme

TG: diretor

TR: Justiça cega

Mike Leigh

CAT: filme

TG: diretor

TR: Segredos e mentiras

Mike Nichols

CAT: filme

TG: diretor

TR: Ânsia de amar

Minha adorável lavanderia

CAT: filme

TG: filme europeu

TR: Stephen Frears

Minha vida sem mim 
CAT: filme

TR: Tod Browning

TG: filme europeu

TR: Isabel Coixet

montagem

CAT: técnica

Mira Nair

NE: Trata-se de colar uns

CAT: filme

TG: diretor

TR: Nome de família

Mohamed Lakhdar-Hamina

CAT: filme

TG: diretor

montagem vertical

TR: Chronique des années

de braise

trucagem

TR: corte seco

decupagem

Momar Thian

CAT: filme

TG: diretor

TR: Sarzan

Mononokehime

CAT: filme

USE: Princess Mononoke

direto

efeito Kulechov

fragmento

implant

intervalo

regra dos $180^{\circ}$

segmentação

tempo

Monstros

CAT: filme

TG: filme norte-americano

montagem cubista

CAT: técnica

TG: montagem 
TR: flashback

montagem harmônica

CAT: técnica

TG: montagem

TR: Eisenstein

montagem vertical

montagem métrica

CAT: técnica

TG: montagem

TR: cinema estrutural

montagem vertical

CAT: técnica

NE: Prática da montagem na qual não basta juntar ponta à ponta fragmentos de filmes, entrando em relação segundo uma única dimensão, a de sua duração. A montagem vertical faz intervir, na determinação dos planos, parâmetros mais ou menos numerosos, ligados ao conteúdo dos planos e à sua formatação própria.

TG: montagem

TR: Alexandre Nevski

Eisenstein

montagem harmônica
O encouraçado Potemkin

Montgomery Clift

CAT: filme

TG: ator

Morangos silvestres

CAT: filme

TG: filme europeu

TR: Ingmar Bergman

Mortu Nega

CAT: filme

TG: filme africano

TR: colonialismo

Flora Gómez

movimentos de libertação

Mother India

CAT: filme

TG: filme asiático

TR: Mehboob Khan

motor

CAT: equipamento

TG: maquinaria 
movimento de câmera

CAT: equipamento

TR: dolly

grua

louma

plano-sequência

steadycam

travelling

movimentos de libertação

CAT: filme

TE: tema

TR: Camp Thiaroye

Chronique des années de

braise

Emitai

Mortu Nega

Samory

Sarraounia

mulher africana

CAT: filme

TE: tema

TR: Finzan

Le destin

Le prix de la liberté

Muna Moto
Mulheres à beira de um ataque de nervos

CAT: filme

TG: filme europeu

TR: Pedro Almodóvar

multímero

CAT: equipamento

TG: kit ferrramentas

Muna Moto

CAT: filme

TG: filme africano

TR: Dikongue-Pipa

liberdade

mulher africana

Murderers among us

CAT: filme

TG: filme europeu

TR: Wolfgang Staudte

Murnau

CAT: filme

TG: diretor

TR: Nosferatu 
música

CAT: técnica

TR: acompanhamento ao

vivo

cinema mudo

Eisenstein

O homem com a câmera

de filmar

música gravada em película

CAT: técnica

TR: cinema sonoro

composição

My Sassy girl

CAT: filme

UP: Yeopgijeogin

TG: filme asiático

TR: Jae-young Kwak

Nae yeojachingureul sogae habnida

CAT: filme

USE: Windstruck

Não é você, sou eu

CAT: filme
TG: filme sul-americano

TR: Juan Taratuto

não-ficção

CAT: gênero

USE: documentário

Naomi Kawase

CAT: filme

TG: diretor

TR: Hotaru

Nascido para matar

CAT: filme

TG: filme norte-americano

TR: Stanley Kubrick

Nastassja Kinski

CAT: filme

TG: ator

Nationalité immigré

CAT: filme

TG: filme africano

TR: emigração

Sidney Sokhona 
negativo virgem

CAT: equipamento

TG: maquinaria

Neil Jordan

CAT: filme

TG: diretor

TR: Traídos pelo desejo

Nelson Pereira dos Santos

CAT: filme

TG: diretor

TR: Vidas secas

neorealista

CAT: Escola

TG: realista

TR: Blasetti

Itália

Ladrões de bicicleta

Luchino Visconti

Obsessão

Quatro passi tra le nuvole

Roberto Rossellini
CAT: filme

TG: diretor

TR: Juventude transviada

No tempo das diligências

CAT: filme

TG: filme norte-americano

TR: faroeste

John Ford

Noivo neurótico, noiva nervosa

CAT: filme

TG: filme norte-americano

TR: Woody Allen

nome da produtora

CAT: equipamento

TR: etiqueta

Nome de família

CAT: filme

TG: filme asiático

TR: Mira Nair

Nosferatu

CAT: filme

Nicholas Ray 
NE: É um clássico do expressionismo alemão, baseado em Drácula de Bram Stoker.

TG: filme europeu

TR: expressionista

Murnau

Nossos anos selvagens

CAT: filme

TG: filme asiático

TR: Wong Kar-wai

Notre fille

CAT: filme

TG: filme africano

TR: comédia

Daniel Kamwa

nouvelle vague

\section{CAT: Escola}

NE: É um termo francês que significa nova onda. Esse

movimento começou com um grupo de jovens franceses, ávido em criar filmes livremente, sem depender de grandes acordos com grandes estúdios, sem fazer contratos que inibiam sua desenvoltura criativa.

TR: França

Jean-Luc Godard
Nove rainhas

CAT: filme

TG: filme sul-americano

TR: Fabián Bielinsky

Ntshaveni Wa Luruli

CAT: filme

TG: diretor

TR: A câmera de madeira

números-T

CAT: equipamento

TR: objetiva

O abraço partido

CAT: filme

TG: filme sul-americano

TR: Daniel Burman

O almoço nu

CAT: filme

TG: filme norte-americano

TR: David Cronenberg

O anjo azul

CAT: filme 
TG: filme europeu

TR: Josef von Sternberg

O assalto ao trem pagador

CAT: filme

TG: filme sul-americano

TR: Roberto Farias

O charme discreto da burguesia

CAT: filme

TG: filme europeu

TR: Luis Buñuel

O clã das adagas voadoras

CAT: filme

TG: filme asiático

TR: Zhang Yimou

O destino bate à sua porta

CAT: filme

TG: filme norte-americano

TR: Bob Rafelson

O encouraçado Potemkin

CAT: filme

TG: filme europeu

TR: Eisenstein montagem vertical
O engenho de Zé Lins

CAT: filme

TG: filme sul-americano

TR: Vladimir Carvalho

O fantasma da liberdade

CAT: filme

TG: filme europeu

TR: Luis Buñuel

O filho da noiva

CAT: filme

TG: filme sul-americano

TR: Campanella

O funeral do chefão

CAT: filme

TG: filme asiático

TR: Feng Xiaogang

O gabinete do Doutor Caligari

CAT: filme

NE: É a produção marcante do expressionismo alemão, que lembra um pesadelo. A realidade desse filme em nada se parece com a realidade exterior, mas em muito lembra o que se passa na mente de 
um ser humano em estado de pânico, de incerteza e de suspense, mostrando que não existe outra realidade senão aquela que vivemos subjetivamente.

TG: filme europeu

TR: expressionista

\section{Robert Wiene}

O gordo e o magro

CAT: filme

TG: burlesco

O grande ditador

CAT: filme

TG: filme norte-americano

TR: Charles Chaplin

grande golpe

CAT: filme

TG: filme norte-americano

TR: filme noir

Stanley Kubrick

O grande roubo do trem

Orande roubo do trem tem apenas doze minutos de duração, mas é um dos grandes marcos da história do cinema.

TG: filme norte-americano

TR: Edwin S. Porter faroeste

O homem com a câmera de filmar

\section{CAT: filme}

NE: É um filme sem suporte literário nenhum. O único ator desse filme é o irmão de Dziga Vertov, Mikhail Kaufman, o homem com a câmera de filmar. Vertov considerava nosso olho imperfeito e que só o olho da câmera é perfeito para observar o real. Máquinas e instrumentos, como barulhos cotidianos compõem a trilha sonora do filme.

TG: futurista

TR: intervalo música

O homem elefante

CAT: filme

TG: filme norte-americano

TR: David Lynch
CAT: filme
NE: É considerado o
primeiro Western, de 1903. O filme
O homem mais desejado do mundo
CAT: filme 
TG: filme europeu

TR: Sönke Wortmann

O mercador de almas

CAT: filme

O homem que quis matar Hitler

TG: filme norte-americano

CAT: filme

TR: Martin Ritt

TG: filme europeu

TR: Fritz Lang

O pântano

CAT: filme

O iluminado

TG: filme sul-americano

CAT: filme

TR: Lucrecia Martel

TG: filme norte-americano

TR: Stanley Kubrick

O pecado mora ao lado

CAT: filme

O jogador

TG: filme norte-americano

CAT: filme

TR: Billy Wilder

TG: filme norte-americano

TR: Robert Altman

O prisioneiro do rock

CAT: filme

O lado escuro do coração

TG: filme norte-americano

CAT: filme

TR: Richard Thorpe

TG: filme sul-americano

TR: Eliseo Subiella

O reverso da fortuna

CAT: filme

O leopardo

TG: filme norte-americano

CAT: filme

TR: Barbet Schroeder

TG: filme europeu

TR: Luchino Visconti

O segredo de Berlim 
CAT: filme

TG: filme norte-americano

TR: filme noir

Steven Soderbergh

O selvagem da motocicleta

CAT: filme

TG: filme norte-americano

TR: Francis Ford Coppola

O silêncio

CAT: filme

TG: filme europeu

TR: Ingmar Bergman

O sol por testemunha

CAT: filme

TG: filme europeu

TR: René Clément

O sonho de Cassandra

CAT: filme

TG: filme norte-americano

TR: Woody Allen
TG: filme asiático

TR: Tsui Hark

O testamento do Dr. Mabuse

CAT: filme

TG: filme europeu

TR: Fritz Lang

O tigre e o dragão

CAT: filme

TG: filme asiático

TR: Ang Lee

O último rei da Escócia

CAT: filme

TG: filme europeu

TR: Kevin McDonald

$\mathrm{O}$ vaqueiro voador

CAT: filme

TG: filme sul-americano

TR: Manfredo Caldas

Sérgio Moriconi

O verão de Victor Vargas

O tempo não espera

CAT: filme
CAT: filme

TG: filme norte-americano 
TR: Peter Sollet

O viajante

CAT: filme

TG: filme norte-americano

TR: Volker Schloendorff

objetiva

CAT: equipamento

TE: grande angular

TR: lente

números-T

pára-sol

zoom

Obsessão

CAT: filme

TG: filme europeu

TR: Luchino Visconti

neorealista

obturador

CAT: equipamento

UP: shutter

TR: câmera
CAT: filme

TG: diretor

TR: El brigadista

Guardafronteras

Odoru Daisosasen

CAT: filme

USE: Bayside Shakedown

off

CAT: estética

UP: fora-de-campo

TR: perspectiva

Old boy

CAT: filme

TG: filme asiático

TR: Park Chan Wook

Oldrich Lipsky

CAT: filme

TG: diretor

TR: Lemonade Joe radio international

Ônibus 174

CAT: filme

TG: filme sul-americano

Octavio Cortázar 
TR: José Padilha

Ontem, hoje e amanhã

CAT: filme

TG: filme europeu

TR: Vittorio De Sica

Orgulho e preconceito

CAT: filme

TG: filme europeu

TR: Joe Wright

Ornella Muti

CAT: filme

TG: ator

Orson Welles

CAT: filme

TG: diretor

TR: A marca da maldade

Cidadão Kane

plano-sequência

Os assassinos

CAT: filme

TG: filme norte-americano
TR: Robert Siodmak

Os Incompreendidos

CAT: filme

TG: filme europeu

TR: François Truffaut

Os pássaros

CAT: filme

TG: filme norte-americano

TR: Alfred Hitchcock

Os sonhadores

CAT: filme

TG: filme europeu

TR: Bernardo Bertolucci

Otto Preminger

CAT: filme

TG: diretor

TR: Laura

Ousmane Sembène

CAT: filme

TG: diretor

TR: Black girl

Camp Thiaroye 
Ceddo

Emitai

Guelwaar

Samory

The money order

Xala

CAT: filme

TG: diretor

TR: Whisky

Pablo Trapero

CAT: filme

TG: diretor

TR: Do outro lado da lei

Família rodante

palitos de madeira

CAT: equipamento

TG: kit ferrramentas

pano anti-estático

CAT: equipamento

TG: kit ferrramentas parâmetro

pano de câmera

CAT: equipamento

TG: kit ferrramentas

pantomima

CAT: técnica

TR: cinema mudo

Paolo Agazzi

CAT: filme

TG: diretor

TR: El atraco

papel

CAT: gênero

UP: rôle

TR: personagem

paramétrico

CAT: técnica

USE: parâmetro

CAT: técnica

UP: paramétrico

TE: ângulo da câmera

dimensão dos planos 
direção dos movimentos

duração dos planos

raccord espaço-temporal

relação campo /contra-

campo

velocidade dos

movimentos

TR: Carl Dreyer

Jacques Tati

Kenji Mizoguchi

segmentação

Yasujiro Ozu

Paranoid Park

CAT: filme

TG: filme norte-americano

TR: Gus Van Sant

pára-sol

CAT: equipamento

TG: acessórios

TR: objetiva

Paris, c'est joli

CAT: filme

TG: filme africano

TR: emigração
Inoussa Ousseini

Park Chan Wook

CAT: filme

TG: diretor

TR: Joint security área

Old boy

Three extremes

paródia

CAT: gênero

TG: ficção

Pasajeros

CAT: filme

TG: filme sul-americano

TR: Andrés Cotler

\section{Pasolini}

CAT: filme

TG: diretor

TR: plano-sequência

Teorema

Pastor Veja

CAT: filme

TG: diretor

TR: Retrato de Teresa 
Volver

Paul Newman

CAT: filme

TG: ator

Paulo Caldas

CAT: filme

TG: diretor

TR: Baile perfumado

Paweogo

CAT: filme

TG: filme africano

TR: êxodo rural

Sanou Kollo

Pedro Almodóvar

CAT: filme

TG: diretor

TR: A flor do meu segredo

A má educação

Ata-me!

Carne trêmula

Fale com ela

Mulheres à beira de um

ataque de nervos

Tudo sobre minha mãe
Pen-ek Ratanaruang

CAT: filme

TG: diretor

TR: Ultima vida no Universo

Pequena Miss Sunshine

CAT: filme

TG: filme norte-americano

TR: Jonathan Dayton

Valerie Faris

Perdas e danos

CAT: filme

TG: filme europeu

TR: Louis Malle

Perseguidor implacável

CAT: filme

TG: filme norte-americano

TR: Don Siegel

personagem

CAT: gênero

TR: drama

papel 
CAT: filme

perspectiva

TG: diretor

CAT: equipamento

TR: Buttoners

estética

TE: perspectiva temporal

Philip Kaufman

TR: câmera

CAT: filme

espaço

TG: diretor

off

TR: A insustentável leveza

projeção

do ser

perspectiva temporal

CAT: estética

TG: perspectiva

Peter Bogdanovich

CAT: filme

photo-flood

CAT: equipamento

TG: Acessório de

iluminação

Pierre-Marie Dong

CAT: filme

TG: diretor

TG: diretor

TR: A última sessão de

cinema

Essa pequena é uma

parada

pilhas

CAT: equipamento

Peter Sollet

TG: acessórios

CAT: filme

TG: diretor

pinça

TR: O verão de Victor

Vargas

CAT: equipamento

TG: kit ferrramentas

Petr Zelenka

pincel médio 
TG: kit ferrramentas

plano americano

Piratas en el Callao

CAT: filme

TG: filme sul-americano

TR: Eduardo Schuldt

plano

CAT: equipamento

estética

técnica

NE: O plano é, no filme

terminado, o que resta de uma tomada efetuada no momento da filmagem. É qualquer segmento de filme compreendido entre duas mudanças de plano.

TE: plano americano plano aproximado plano de conjunto plano de exposição plano geral plano médio plano-sequência primeiríssimo plano primeiro plano

TG: chassis

TR: junção
CAT: técnica

TG: plano

plano aproximado

CAT: técnica

TG: plano

plano de conjunto

CAT: técnica

TG: plano

plano de dois eixos

CAT: equipamento

TG: chassis

plano de exposição

CAT: estética

UP: establishing shot

TG: plano

TR: cena

plano geral

CAT: técnica

TG: plano 
praticável

plano médio

CAT: técnica

TG: plano

plano subjetivo

CAT: estética

TR: cinema de poesia

enquadramento

plano-sequência

CAT: estética

técnica

TG: plano

TR: Bazin

movimento de câmera

Orson Welles

Pasolini

The magnificent

Ambersons

Pousse- pousse

CAT: filme

TG: filme africano

TR: comédia

Daniel Kamwa
CAT: equipamento

TG: acessório de estúdio

preto-e-branco

CAT: estética

TG: cor

primeiríssimo plano

CAT: técnica

TG: plano

primeiro plano

CAT: técnica

TG: plano

TR: impressionista

Princess Mononoke

CAT: filme

UP: Mononokehime

TG: filme asiático

TR: animação

Hayao Miyazaki

projeção

CAT: estética

TR: perspectiva 
prolonga

CAT: equipamento

TG: Acessório de

iluminação

Psicose

CAT: filme

TG: filme norte-americano

TR: Alfred Hitchcock

Pulp fiction

CAT: filme

TG: filme norte-americano

TR: Quentin Tarantino

Punhos de campeão

CAT: filme

TG: filme norte-americano

TR: filme noir

Robert Wise quadro

CAT: estética

TR: campo

enquadramento

fora-de-quadro

plano

sobreenquadramento

quadro de luz

CAT: equipamento

TG: Acessório de

iluminação

Quanto mais quente melhor

CAT: filme

TG: filme norte-americano

TR: Billy Wilder

Quanto vale ou é por quilo?

CAT: filme

TG: filme sul-americano

TR: Sérgio Bianchi

Punto y raya

CAT: filme

TG: filme sul-americano

TR: Elia Schneider
Quatro passi tra le nuvole

CAT: filme

TE: filme europeu 
TR: neorealista

Quem matou Pixote?

CAT: filme

TG: filme sul-americano

TR: José Joffily

Quentin Tarantino

CAT: filme

TG: diretor

TR: Cães de aluguel

Kill Bill

Pulp fiction

Sin City - a cidade do

pecado

Quero ser John Malkovich

CAT: filme

TG: filme norte-americano

TR: Charlie Kaufman

Quiz Show - a verdade dos bastidores

CAT: filme

TG: filme norte-americano

TR: Robert Redford
CAT: técnica

TE: salto

TR: clássico

decupagem

junção

raccord espaço-temporal

CAT: técnica

TG: parâmetro

Radiofreccia

CAT: filme

TG: filme europeu

TR: Luciano Ligabue

Raj Kapoor

CAT: filme

TG: diretor

TR: Awara

Bobby

Ralph Fiennes

CAT: filme

TG: ator

Ramesh Sippy

CAT: filme 
TG: diretor

TR: Sholay

Rançon d'une alliance

CAT: filme

TG: filme africano

TR: Sebastian Kamba

Raquel Welch

CAT: filme

TG: ator

Rashomon

CAT: filme

TG: filme asiático

TR: Akira Kurosawa

realista

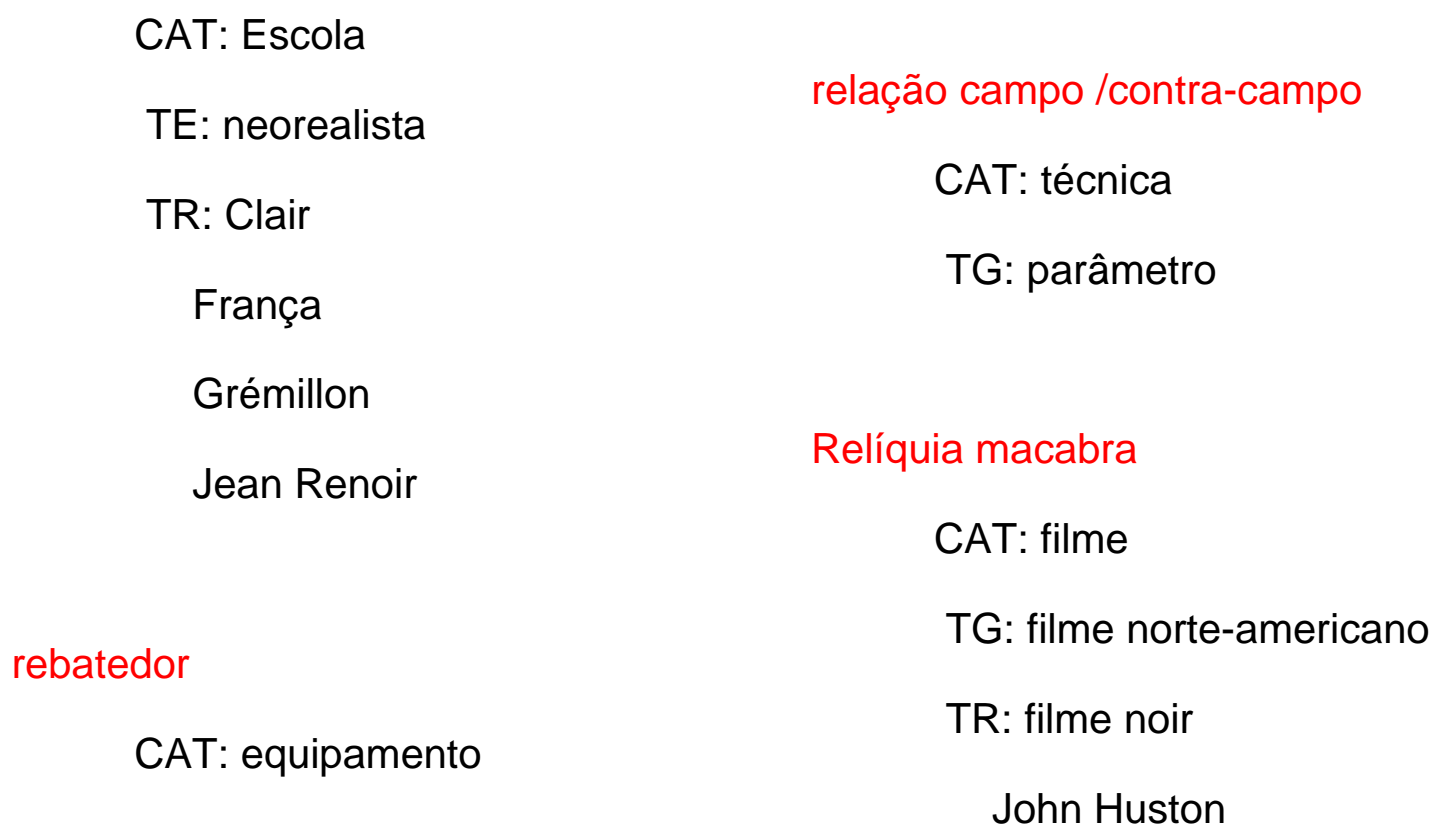

CAT: Escola

TE: neorealista

TR: Clair

França

Grémillon

Jean Renoir

rebatedor

CAT: equipamento

relação campo /contra-campo

CAT: técnica

TG: parâmetro

Relíquia macabra

CAT: filme

TG: filme norte-americano

TR: filme noir

John Huston

TG: Acessório de

iluminação

Reflections

CAT: filme

TG: filme asiático

refletor

CAT: equipamento

TG: maquinaria

TR: barn-door

regra dos $180^{\circ}$

CAT: estética

TR: contracampo

decupagem

montagem
TR: Hung-I Yao 
Retrato de Teresa

remake

CAT: gênero

TG: ficção

René Clément

CAT: filme

TG: diretor

TR: O sol por testemunha

Repulsa ao sexo

CAT: filme

TG: filme europeu

TR: Roman Polanski

Réquiem para um sonho

CAT: filme

TG: filme norte-americano

TR: Darren Aronofsky

Retorno a Howards End

CAT: filme

TG: filme europeu

TR: James Ivory
CAT: filme

TG: filme sul-americano

TR: Pastor Veja

Richard Gere

CAT: filme

TG: ator

Richard Thorpe

CAT: filme

TG: diretor

TR: O prisioneiro do rock

Ridley Scott

CAT: filme

TG: diretor

TR: 1942: a conquista do paraíso

Thelma e Louise

Ringu

CAT: filme

TG: filme asiático

TR: Hideo Nakata

terror 
Rita Hayworth

CAT: filme

TG: ator

River Phoenix

CAT: filme

TG: ator

Rob Reiner

CAT: filme

TG: diretor

TR: Harry e Sally

Robert Siodmak

CAT: filme

TG: diretor

TR: Os assassinos

Uma vida marcada

Robert Altman

CAT: filme

TG: diretor

TR: Assassinato em Gosford

Park

Mash

O jogador
CAT: filme

TG: ator

diretor

TR: Quiz Show - a verdade dos bastidores

Robert Towne

CAT: filme

TG: diretor

TR: Conspiração Tequila

Robert Wiene

CAT: filme

TG: diretor

TR: O gabinete do Doutor

Caligari

Robert Wise

CAT: filme

TG: diretor

TR: Punhos de campeão

Roberto Farias

CAT: filme

TG: diretor

TR: O assalto ao trem

pagador

Robert Redford 
Roberto Gervitz

CAT: filme

rôle

TG: diretor

CAT: gênero

TR: Feliz ano velho

USE: papel

Roberto Moreira

Roma, cidade aberta

CAT: filme

CAT: filme

TG: diretor

TG: filme europeu

TR: Contra todos

TR: Roberto Rossellini

Roberto Rossellini

Román Chalbaud

CAT: filme

CAT: filme

TG: cinema moderno

TG: diretor

diretor

TR: El caracazo

TR: falso-raccord

neorealista

Roman Polanski

Roma, cidade aberta

CAT: filme

TG: diretor

Rodrigo Triana

TR: Repulsa ao sexo

CAT: filme

TG: diretor

Romy Schneider

TR: Soñar no cuesta nada

CAT: filme

TG: ator

Roger Vadim

CAT: filme

Rouch in reverse

TG: diretor

CAT: filme

TR: E Deus criou a mulher

TG: filme africano 
TR: Manthia Diawara

Rua Seis, Sem Número

CAT: filme

TG: filme sul-americano

TR: João Batista

CAT: filme

TG: filme norte-americano

TR: filme noir

Willian Keighley

Ruth em questão

CAT: filme

TG: filme norte-americano

TR: Alexander Payne

Saam gaang Yi

CAT: filme

USE: Three extremes

Sábado

CAT: filme

TG: filme sul-americano

TR: Juan Villegas saco de areia

CAT: equipamento

TG: maquinaria

saco preto

CAT: equipamento

TG: maquinaria

\section{Safrana}

CAT: filme

TG: filme africano

TR: emigração

Sidney Sokhona

salto

CAT: técnica

UP: jump cut

TG: raccord

Samaria

CAT: filme

USE: Samaritan girl

Samaritan girl

CAT: filme

UP: Samaria

TG: filme asiático

TR: Kim Ki Duk 
CAT: filme

TG: filme africano

TR: colonialismo

movimentos de libertação

Ousmane Sembène

Sandra Bullock

CAT: filme

TG: ator

Sanjay Leela Bhansali

CAT: filme

TG: diretor

TR: Devdas

Sanou Kollo

CAT: filme

TG: diretor

TR: Paweogo

Santa não sou

CAT: filme

TG: filme norte-americano

TR: Wesley Ruggles
CAT: equipamento

TG: maquinaria

Sarraounia

CAT: filme

TG: filme africano

TR: colonialismo

Méd Hond

movimentos de libertação

Sarzan

CAT: filme

TG: filme africano

TR: independência africana

Momar Thian

Satyajit Ray

CAT: filme

TG: diretor

TR: Canção da estrada

Sean Connery

CAT: filme

TG: ator 
Sebastian Kamba

CAT: filme

TG: diretor

TR: Rançon d'une alliance

Secuestro express

CAT: filme

TG: filme sul-americano

TR: Jonathan Jakobowicz

Sega Coulibaly

CAT: filme

TG: diretor

TR: Le destin

segmentação

CAT: técnica

TR: montagem

parâmetro

Segredos e mentiras

CAT: filme

TG: filme europeu

TR: Mike Leigh

Sejnane

CAT: filme
TG: filme africano

TR: Abdelatif Bem Ammar

sequência

CAT: estética

TR: cena

Sérgio Bianchi

CAT: filme

TG: diretor

TR: Quanto vale ou é por quilo?

Sérgio Moriconi

CAT: filme

TG: diretor

TR: O vaqueiro voador

seringa de ar

CAT: equipamento

TG: kit ferrramentas

Seven swords

CAT: filme

UP: Chat Gim

TG: filme asiático

TR: Hark Tsui 
CAT: filme

Sexo, mentiras e videotape

CAT: filme

TG: filme norte-americano

TR: Steven Soderbergh

Sharon Stone

CAT: filme

TG: ator

Shinji Aoyama

CAT: filme

TG: diretor

TR: Eureka

Shinlaui dalbam

CAT: filme

USE: Kick the moon

CAT: filme

UP: Swiri

TG: filme asiático

TR: guerra coreana

Kang Je Gyu

Shiri
TG: filme asiático

TR: ação

Ramesh Sippy

shutter

CAT: equipamento

USE: obturador

Sidney Sokhona

CAT: filme

TG: diretor

TR: Nationalité immigré

Safrana

Silmido

CAT: filme

TG: filme asiático

TR: Woo-Suk Kang

Sílvio Tendler

CAT: filme

TG: diretor

TR: Encontro com Milton Santos ou o mundo global visto do lado

Sholay 
Sin City - a cidade do pecado

CAT: filme

TG: filme norte-americano

TR: Quentin Tarantino

Sindicato de Ladrões

CAT: filme

NE: É a metáfora de um

pedido de desculpas de Elia Kazan

por ter delatado seus colegas

durante as perseguições

anticomunistas do senador

McCarthy nos EUA.

TG: filme norte-americano

TR: Elia Kazan

Sobre meninos e lobos

CAT: filme

TG: filme norte-americano

TR: Clint Eastwood

sobreenquadramento

CAT: estética

UP: surcadrage

surcadre

TR: quadro

sociedade burguesa

CAT: filme
TE: tema

TR: A bela da tarde

soft

CAT: equipamento

TG: Acessório de

iluminação

Soleil

CAT: filme

TG: filme africano

TR: emigração

Med Hondo

som

CAT: técnica

TE: cinema mudo

cinema sonoro

Soñar no cuesta nada

CAT: filme

TG: filme sul-americano

TR: Rodrigo Triana

Song Hae Sun

CAT: filme

TG: diretor 
TR: Failan

USE: banda som

Sönke Wortmann

spot

CAT: filme

CAT: equipamento

TG: diretor

TG: Acessório de

TR: O homem mais desejado do mundo

iluminação

spot meter

Sophia Loren

CAT: equipamento

CAT: filme

TG: acessórios

TG: ator

Spyder and Lilies

CAT: filme

Sopyonje

TG: filme asiático

CAT: filme

TR: Zero Chou

TG: filme asiático

TR: Im Kwon Taek

Stan VanderBeek

CAT: filme

Souleymane Cissé

TE: diretor

CAT: filme

TR: underground

TG: diretor

TR: Baara

Den muso

Finyé

Stanley Kubrick

CAT: filme

TG: diretor

TR: 2001: Odisseia no

sound track

CAT: técnica

Barry Lyndon 
De olhos bem fechados

TG: ator

Glória feita de sangue

Laranja mecânica

Steven Soderbergh

Lolita

CAT: filme

Nascido para matar

TG: diretor

grande golpe

TR: Bubble

O iluminado

Building n.7

Irresistível paixão

steadycam

Kafka

CAT: equipamento

O segredo de Berlim

TG: maquinaria

Sexo, mentiras e

TR: movimento de câmera

Stephen Frears

CAT: filme

TG: diretor

TR: A rainha

Sujoy Ghosh

CAT: filme

TG: diretor

TR: Jhankaar beats

Ligações perigosas

Minha adorável lavanderia

sun gun

CAT: equipamento

TG: Acessório de

Steve Kloves

iluminação

CAT: filme

TG: diretor

super-8

TR: Susie e os Baker Boys

CAT: equipamento

TG: bitola

Steve McQueen

CAT: filme

superposição 
CAT: estética

TR: imagem

suporte para ombro

CAT: equipamento

TG: acessórios

surcadrage

CAT: estética

USE: sobreenquadramento

surcadre

CAT: estética

USE: sobreenquadramento

surrealismo

CAT: Escola

TR: L'etoile de mer

Susan Sarandon

CAT: filme

TG: ator

Susie e os Baker Boys

CAT: filme

TG: filme norte-americano

TR: Steve Kloves suspense

CAT: gênero

TG: ficção

Swiri

CAT: filme

USE: Shiri

tabela

CAT: equipamento

TG: acessório de estúdio

tabela de cores

CAT: equipamento

TG: acessórios

tachometer

CAT: equipamento

USE: tacômetro

tacômetro

CAT: equipamento

UP: tachometer

TR: câmera 
CAT: filme

TG: diretor

TR: Three extremes

teatro filmado

CAT: técnica

TR: cinema sonoro

Tell the truth

CAT: filme

TG: filme europeu

TR: Helmut Weiss

tema

CAT: filme

TG: apartheid

colonialismo

crítica

emigração

êxodo rural

guerra coreana

independência africana

liberdade

movimentos de libertação

mulher africana

sociedade burguesa tempo

CAT: técnica

TR: duração

montagem

Tempos felizes

CAT: filme

TG: filme asiático

TR: Zhang Yimou

Tempos modernos

CAT: filme

TG: filme norte-americano

TR: Charles Chaplin

Teorema

CAT: filme

TG: filme europeu

TR: Pasolini

Terence Stamp

CAT: filme

TG: ator

Terra em transe

CAT: filme

TG: filme sul-americano 
TR: Glauber Rocha

terror

CAT: gênero

TG: ficção

TR: Ringu

tesoura

CAT: equipamento

TG: kit ferrramentas

The Black Forest girl

CAT: filme

TG: filme europeu

TR: Hans Deppe

The bow

CAT: filme

UP: Hwal

TG: filme asiático

TR: Kim Ki Duk

The gods must be crazy

CAT: filme

TG: filme africano

TR: Jamie Uys
The happening

CAT: filme

TG: filme asiático

TR: M. Night Shyamalan

The magnificent Ambersons

CAT: filme

TR: plano-sequência

The money order

CAT: filme

TG: filme africano

TR: Ousmane Sembène

The Road on the air

CAT: filme

TG: filme asiático

TR: Li Zhi-Chiang

Thelma e Louise

CAT: filme

TG: filme norte-americano

TR: Ridley Scott

Three extremes

CAT: filme

UP: Saam gaang Yi 
TG: filme asiático

TR: Fruit Chan

Park Chan Wook

Takeshi Miike

Tomás Gutiérrez Alea

CAT: filme

TG: diretor

TR: Las doce sillas

Tidiane Aw

CAT: filme

Toni Venturi

TG: diretor

CAT: filme

TR: Le bracelet de bronze

TG: diretor

TR: Cabra cega

Tim Robbins

Traídos pelo desejo

CAT: filme

CAT: filme

TG: ator

TG: filme europeu

TR: Neil Jordan

título

CAT: equipamento

Trainspotting

TR: etiqueta

CAT: filme

TG: filme europeu

Tod Browning

TR: Danny Boyle

CAT: filme

TG: diretor

transparência

TR: Monstros

CAT: técnica

TG: trucagem

Tom Cruise

CAT: filme

travelling

TG: ator

CAT: equipamento 
TG: maquinaria

TR: movimento de câmera

tripé pequeno

CAT: equipamento

trena

TG: maquinaria

CAT: equipamento

TG: kit ferrramentas

Tropa de elite

CAT: filme

trilho de travelling

TG: filme sul-americano

CAT: equipamento

TR: José Padilha

TG: maquinaria

trucagem

tripé

CAT: técnica

CAT: equipamento

TG: acessórios

NE: É toda manipulação na produção de um filme que acaba mostrando na tela algo que não existiu na realidade.

tripé de luz

TE: efeito Schufftan

CAT: equipamento efeitos especiais máscara

TG: Acessório de iluminação matte transparência

tripé grande

CAT: equipamento

TG: maquinaria

Tsui Hark

CAT: filme

tripé grande de luz

CAT: equipamento

TG: diretor

TR: O tempo não espera

TG: Acessório de

iluminação 
Tudo começou no sábado

CAT: filme

TG: filme europeu

TR: Karel Reisz

Tudo sobre minha mãe

CAT: filme

TG: filme europeu

TR: Pedro Almodóvar

Twin Peaks: Os últimos dias de Laura Palmer

CAT: filme

TG: filme norte-americano

TR: David Lynch

Ultima vida no Universo

CAT: filme

TG: filme asiático

TR: Pen-ek Ratanaruang

Um beijo roubado

CAT: filme

TG: filme asiático

TR: Wong Kar-wai
Um copo de cólera

CAT: filme

TG: filme sul-americano

TR: Aluízio Abranches

Um corpo que cai

CAT: filme

TG: filme norte-americano

TR: Alfred Hitchcock

Um lugar ao sol

CAT: filme

TG: filme norte-americano

TR: George Stevens

Um misterioso assassinato em Manhattan

CAT: filme

TG: filme norte-americano

TR: Woody Allen

Um relatório ambíguo sobre o fim do mundo

CAT: filme

TG: filme europeu

TR: Jural Jabukisko 
CAT: filme

TG: filme europeu

TR: Fritz Lang

Uma aventura na Martinica

CAT: filme

TG: filme norte-americano

TR: Howard Hawks

Uma janela para o amor

CAT: filme

TG: filme europeu

TR: James Ivory

Uma rua chamada pecado

CAT: filme

TG: filme norte-americano

TR: Elia Kazan

Uma Simples Formalidade

CAT: filme

TG: filme europeu

TR: Giuseppe Tornatore
Uma vida marcada

CAT: filme

TG: filme norte-americano

TR: filme noir

Robert Siodmak

underground

CAT: Escola

TR: Jonas Mekas

Stan VanderBeek

vanguardista

Une si simple histoire

CAT: filme

TG: filme africano

TR: Abdelatif Bem Ammar independência africana

Val Kilmer

CAT: filme

TG: ator

Valerie Faris

Uma Thurman

CAT: filme

TG: ator
CAT: filme

TG: diretor

TR: Pequena Miss Sunshine 
CAT: filme

vanguardista

TR: falso-raccord

CAT: Escola

TG: futurista

Victoria Abril

TR: cinema não-encenado

CAT: filme

experimental

TG: ator

underground

Vida de cão

vareta

CAT: filme

CAT: equipamento

TG: filme norte-americano

TG: maquinaria

TR: Charles Chaplin

velocidade dos movimentos

CAT: técnica

TG: parâmetro

TG: filme norte-americano

TR: Cameron Crowne

Veludo azul

CAT: filme

Vidas secas

TG: filme norte-americano

CAT: filme

TR: David Lynch

TG: filme sul-americano

TR: Nelson Pereira dos

Vera Fogwill

CAT: filme

TG: diretor

video-assist

TR: Las mantenidas sin

CAT: equipamento

sueños

TG: acessórios

Viagem à Itália

Vidhu Vinod Chopra 
CAT: filme

TG: filme asiático

TR: Eklavya

visor de contraste

CAT: equipamento

TG: acessórios

Vítimas de uma paixão

CAT: filme

TG: filme norte-americano

TR: Harold Becker

Vittorio De Sica

CAT: filme

TG: diretor

TR: Ladrões de bicicleta

Ontem, hoje e amanhã

Vladimir Carvalho

CAT: filme

TG: diretor

TR: Barra 68

O engenho de Zé Lins
TG: diretor

TR: O viajante

Volver

CAT: filme

TG: filme europeu

TR: Pedro Almodóvar

voz

CAT: equipamento

TR: kinetógrafo

Walter Ruttmann

CAT: filme

TG: diretor

TR: Melody of the world

Walter Salles

CAT: filme

TG: diretor

TR: Abril despedaçado

Central do Brasil

Week-end

CAT: filme

TR: falso-raccord

Volker Schloendorff

CAT: filme

Wesley Ruggles 
CAT: filme

TG: diretor

TR: Santa não sou

western

CAT: gênero

USE: faroeste

When the last sword is drawn

CAT: filme

UP: Mibu gishi den

TG: filme asiático

TR: Yojiro Takita

Whisky

CAT: filme

TG: filme sul-americano

TR: Juan Pablo Rebella

Pablo Stoll

William Holden

CAT: filme

TG: ator

William Wyler

CAT: filme

TG: diretor
TR: Chaga de fogo

Horas de desespero

Willian Keighley

CAT: filme

TG: diretor

TR: Rua sem nome

Windstruck

CAT: filme

UP: Nae yeojachingureul sogae habnida

TG: filme asiático

TR: Jae-young Kwak

Winona Ryder

CAT: filme

TG: ator

Wolfgang Staudte

CAT: filme

TG: diretor

TR: Murderers among us

Wong Kar-wai

CAT: filme

TG: diretor 
TR: 2046 - Os Segredos do

Amor

Amor à flor da pele

Amores expressos

Anjos caídos

As time goes by

Cinzas do passado

Felizes juntos

Nossos anos selvagens

Um beijo roubado
Xala

CAT: filme

TG: filme africano

TR: crítica independência africana

Ousmane Sembène
Yasujiro Ozu

CAT: técnica

TR: parâmetro

Yeopgijeogin

CAT: filme

USE: My Sassy girl

Yojiro Takita

CAT: filme

TG: diretor

TR: When the last sword is drawn

\section{Zero Chou}

CAT: filme

TG: diretor

TR: Spyder and Lilies

TG: diretor

TR: Silmido 
CAT: filme

TG: diretor

TR: Herói

O clã das adagas

voadoras
Tempos felizes

zoom

CAT: equipamento

TR: objetiva 
ANEXO III

RELAÇÃO DE TERMOS EM ORDEM ALFABÉTICA POR CATEGORIA 
equipamento

$16 \mathrm{~mm}$

$35 \mathrm{~mm}$

aberto

abertura

Acessório de iluminação

acessório de estúdio

acessórios

alicate

aperture

assistente

assistente de câmera

bandeira

bandô

banqueta

barn-door

barracuda

bateria

batoque

bitola

boletim de câmera

brut

cabeça de efeito

cabeça de tripé

cabeça do tripé

cabo

cabo de segurança caixa distribuidora

caixa intermediária

calha-brut

câmera

caneta hidrocor

canivete

carregador de bateria

cartão cinza

changing bag

chassis

chave de fenda

chave halen

chave Philips

cinematógrafo

claquete

coaxial

corpo

cunha

data

dedolight

difusor de metal

difusor tecron

dolly

elástico

emulsão

estrela

etiqueta 
filtro

fita adesiva

foco

focus

fotômetro incidente

fresnéis

garra

garra jacaré

gelatina

gobo

grande angular

grifa

grua

hi-hat

HMI

instruções para laboratório

kelvinômetro

kinetógrafo

kino-floo

kit ferrramentas

kit lens cleaner

laçada

lanterna

lápis

lata vazia de negativo

lente

looping louma

lupa

mandrake

maquinaria

mecanismo de tração

metragem

motor

movimento de câmera

multímero

negativo virgem

nome da produtora

números-T

objetiva

obturador

palitos de madeira

pano anti-estático

pano de câmera

pára-sol

perspectiva

photo-flood

pilhas

pinça

pincel médio

plano

plano de dois eixos

praticável

prolonga 
quadro de luz

rebatedor

refletor

saco de areia

saco preto

sargento

seringa de ar

shutter

soft

spot

spot meter

steadycam

sun gun

super-8

suporte para ombro

tabela

tabela de cores

tachometer

tacômetro

tesoura

título

travelling

trena

trilho de travelling

tripé

tripé de luz

tripé grande tripé grande de luz

tripé pequeno

vareta

video-assist

visor de contraste

VOZ

zoom

\section{Escola}

Alemanha

Caligarismo

cinema estrutural

cinema moderno

cinema mudo

cinema nacional

cinema não-encenado

cinema novo

cinema pós-moderno

expressionista

flashback

França

futurista

impressionista

Itália

neorealista

nouvelle vague

realista 
surrealismo

underground

vanguardista

estética

campo

cena

colorido

contracampo

cor

enquadramento

espaço

fora-de-campo

fora-de-quadro

imagem

junção

off

perspectiva

perspectiva temporal

plano

plano de exposição

plano subjetivo

plano-sequência

preto-e-branco

projeção

quadro

regra dos $180^{\circ}$ sequência

sobreenquadramento

superposição

surcadrage

surcadre

filme

1942: a conquista do paraíso

2001: Odisseia no Espaço

2046 - Os Segredos do Amor

21 gramas

A bela da tarde

A câmera de madeira

A concepção

A doce vida

A flor do meu segredo

A força do amor

A fraternidade é vermelha

A gardênia azul

A grande ilusão

A guerra dos Roses

A história real

A igualdade é branca

A insustentável leveza do ser

A irmandade da guerra

A liberdade é azul

A má educação 
A marca da maldade

A menina santa

A morte passou por perto

A noite americana

A pequena loja da rua principal

A perversa

A rainha

A regra do jogo

A rosa púrpura do Cairo

A última sessão de cinema

A última tentação de Cristo

$A$ viagem de Chihiro

A vida de Oharu

A vida secreta das palavras

Abdelatif Bem Ammar

Abra os olhos

Abril despedaçado

Accident

Aconteceu naquela noite

Adrián Caetano

Adrián Suar

Akira Kurosawa

Al Pacino

Alain Delon

Alain Fresnot

Alan J. Pakula

Alberto Lecchi
Alec Baldwin

Alejandro Amenábar

Alejandro Doria

Alejandro González Iñárritu

Alexander Payne

Alexandre Stockler

Alfonso Arau

Alfred Hitchcock

Allah Tantou

Aluízio Abranches

Amor à flor da pele

Amores brutos

Amores expressos

Anant Balani

Andie McDowell

Andrés Cotler

Andrew Adamson

Andrucha Waddington

Andy Garcia

Ang Lee

Anjos caídos

Anna Muylaer

Ann-Margret

Ânsia de amar

Antonio Banderas

António Hernández

Anurag Basu 
apartheid

Après lui

Arthur Penn

As pontes de Madison

As time goes by

Ashwini Chaudhary

Assassinato em Gosford Park

Ata-me!

ator

Atração mortal

Através de um espelho

Audrey Hepburn

Ava Gardner

Awara

Baara

Babaçu

Babel

Baile perfumado

Baixo gávea

Barbara Hershey

Barbet Schroeder

Barra 68

Barry Lyndon

Batismo de sangue

Bayside Shakedown

Bazin

Beijo da morte
Benoît Ramampy

Bernardo Bertolucci

Bicho de sete cabeças

Bicots-nègres, vos voisins

Billy Wilder

Bin-jip

Black girl

Blake Edwards

Blasetti

Boa noite e boa sorte

Bob Rafelson

Bobby

Bolshe Vita

Bonequinha de luxo

Brad Pitt

Bráulio Mantovani

Bridget Fonda

Brigitte Bardot

Brilho eterno de uma mente sem lembranças

Bubble

Building n.7

Burial of a potato

Buttoners

Bye, bye Africa

Cabra cega

Cabra marcado para morrer 
Caçada humana

Cães de aluguel

Cama adentro

Cama de gato

Cameron Crowne

Cameron Diaz

Camp Thiaroye

Campanella

Canção da estrada

Cantando na chuva

Canudos

Carandiru

Carlos Reichenbach

Carlos Sorin

Carne trêmula

Cary Grant

Casa de areia

Casa vazia

Casablanca

Catherine Deneuve

Ceddo

Celebridades

Cenas de um casamento

Central do Brasil

Cesar e Rosalie

Chaga de fogo

Chandni bar
Charles Chaplin

Charles Vidor

Charlie Kaufman

Charlotte Gray

Chat Gim

Chega de saudade

Cheikh Oumar Sissoko

Chico

Chingoo

Christian Slater

Chronique des années de braise

Cidadão Kane

Cidade de Deus

Cidade dos sonhos

Cidade perdida

Cinema Paradiso

Cinzas do passado

Clair

Clark Gable

Claude Sautet

Claudia Cardinale

Clint Eastwood

colonialismo

Como água para chocolate

Conspiração Tequila

Contos da lua vaga

Contra todos 
Correspondente estrangeiro

Crepúsculo dos deuses

crítica

Crônica de um amor louco

Crônicas de Nárnia

Cuba baila

Dançando no escuro

Daniel Burman

Daniel Day-Lewis

Daniel Kamwa

Danny Boyle

Danny Cannon

Danny De Vito

Darren Aronofsky

David Achkar

David Cronenberg

David Lean

David Lynch

De olhos bem fechados

Demi Moore

Den muso

Dennis Quaid

Denzel Washington

Der Kaiser Von Kalifornien

Desconstruindo Harry

Desejo humano

Desmundo
Deus e o diabo na terra do sol

Devdas

Di Moretti

Dikongue-Pipa

diretor

Disque M para matar

Do outro lado da lei

Dogville

Dom Hélder Câmara: o santo rebelde

Domésticas

Don Siegel

Drew Barrymore

Drugstore cowboy

Durval Discos

Dziga Vertov

E Deus criou a mulher

Ed Mort

Eduardo Coutinho

Eduardo Mendonza

Eduardo Schuldt

Edukators

Edwin S. Porter

Eisenstein

Eklavya

El atraco

El brigadista 


\begin{tabular}{|c|c|}
\hline El caracazo & Fanny e Alexander \\
\hline El cielito & Federico Fellini \\
\hline El hombre de Maisinicu & Feliz ano velho \\
\hline Elephant & Felizes juntos \\
\hline Eles não usam black-tie & Feng Xiaogang \\
\hline Elia Kazan & Férias de amor \\
\hline Elia Schneider & Fernando Meirelles \\
\hline Eliseo Subiella & filme africano \\
\hline Elpidio Valdés & filme asiático \\
\hline Elvis Presley & filme europeu \\
\hline emigração & filme norte-americano \\
\hline Emitai & filme sul-americano \\
\hline Emmanuelle Seigner & Finyé \\
\hline $\begin{array}{l}\text { Encontro com Milton Santos ou o } \\
\text { mundo global visto do lado de cá }\end{array}$ & $\begin{array}{l}\text { Finzan } \\
\text { Flora Gómez }\end{array}$ \\
\hline Envolto nas sombras & Francis Ford Coppola \\
\hline Erika Bauer & François Truffaut \\
\hline Ernst Lubitsch & Friend \\
\hline Essa pequena é uma parada & Fritz Lang \\
\hline Esse obscuro objeto do desejo & Fruit Chan \\
\hline Eureka & Fuga do passado \\
\hline êxodo rural & Fugindo do inferno \\
\hline Fabián Bielinsky & Gaël Morel \\
\hline Failan & Garotas do ABC \\
\hline Fale com ela & Gary Oldman \\
\hline Falsa loura & Gene Kelly \\
\hline Família rodante & George Clooney \\
\hline
\end{tabular}


George Stevens

Ghost dog

Gilda

Gillian Armstrong

Giuseppe Tornatore

Glauber Rocha

Glória feita de sangue

Gongdong gyeongbi guyeok JSA

Good boy, bad boy

Grace Kelly

Grandes esperanças

Gregory Peck

Grémillon

Greta Garbo

Gritos e sussurros

Guardafronteras

Guelwaar

guerra coreana

Guimba: un tyran, une époque

Gus Van Sant

Guy Ritchie

Hanns Schwarz

Hans Deppe

Hans Weingartner

Hark Tsui

Harold Becker

Haroldo Marinho Barbosa
Harrison Ford

Harry e Sally

Hayao Miyazaki

Hector Babenco

Helmut Weiss

Helvécio Ratton

Henry Hathaway

Heritage Africa

Herói

Herói acidental

Hideo Nakata

Horas de desespero

Hotaru

Howard Hawks

Hugh Grant

Humberto Solás

Humphrey Bogart

Hung-I Yao

Hwal

Ibolya Fekete

Iciar Bollain

Identité

Im Kwon Taek

independência africana

Ingmar Bergman

Ingrid Bergman

Inoussa Ousseini 
Interlúdio

Ipojuca Pontes

Irmãs

Irresistível paixão

Isabel Coixet

Isabella Rossellini

Isabelle Adjani

Jack Nicholson

Jacqueline Bisset

Jacques Tourneur

Jae-young Kwak

James Dean

James Ivory

Jamie Uys

Jan Hrebejk

Jan Jakub Kolski

Ján Kadár

Jane Fonda

Janela da alma

Janela indiscreta

Jean Renoir

Jean-Luc Godard

Jeremy Irons

Jessica Lange

Jhankaar beats

Jim Jarmusch

Jim McBride
Joana D'arc

João Batista

João Jardim

Joe Wright

Joggers park

Jogos, trapaças e dois canos fumegantes

John Ford

John Huston

John Malkovich

John Sturges

Johnie Waterman

Johnny Depp

Joint security área

Jonas Mekas

Jonathan Dayton

Jonathan Jakobowicz

Jorge Gaggaro

José Eduardo Belmonte

José Joffily

José Padilha

Josef von Sternberg

Joshua Logan

Juan Bautista Stagnaro

Juan Pablo Rebella

Juan Padrón

Juan Taratuto 
Juan Villegas

Juiz

Jules Dassin

Julia Roberts

Julia Solomonoff

Julie Delpy

Juliette Binoche

Júlio Bressane

Julio García Espinosa

Jural Jabukisko

Justiça cega

Juventude transviada

Kabhi Alvidaa Na Kehna

Kabir Khan

Kabul Express

Kafka

Kang Je Gyu

Karan Johar

Karel Reisz

Karim Aïnouz

Kathleen Turner

Katsuyuki Motohiro

Keanu Reeves

Kelly Lynch

Kevin Costner

Kevin McDonald

Kick the moon
Kill Bill

Kim Basinger

Kim Ki Duk

Kim Novak

Kim Sang Jin

Klute, o passado condena

Krzsztof Zanussi

Krzysztof Kieslowski

Kwah Ansah

Kyung-Taek Kwal

Ladrão de casaca

Ladrões de bicicleta

Laís Bodanzky

Lana Turner

Laranja mecânica

Lars Von Trier

Las aventuras de Juan Quinquín

Las doce sillas

Las mantenidas sin sueños

Laura

Lauren Bacall

Lavoura arcaica

Le bracelet de bronze

Le destin

Le prix de la liberté

Leila Diniz

Lemonade Joe radio international 
Lena Olin

Leon Hirszman

Leslie Arliss

L'etoile de mer

Leve meus olhos

Li Zhi-Chiang

liberdade

Life as fatal sexually transmitted disease

Life in a metro

Ligações perigosas

Liz Taylor

Lolita

Los Borgia

Loucos de paixão

Louis Malle

Luc Besson

Luchino Visconti

Lucía

Lucía Cedrón

Luciano Ligabue

Lucrecia Martel

Luis Buñuel

Luis Mandoki

Luis Trenker

Luiz Fernando Carvalho

Luzes da cidade
Lyonel Lucini

M - O vampiro de Dusseldorf

M. Night Shyamalan

Madame Bovary

Madame satã

Madeleine Stowe

Madhur Bhandarkar

Mae West

Mahamat-Saleh Haroun

Malena

Man Ray

Mañana te cuento

Mandala

Manfredo Caldas

Manthia Diawara

Manuel Pérez

Mar adentro

Marcello Mastroianni

Marcelo Schapces

Marco Ferreri

María Victoria Menis

Marilyn Monroe

Marlene Dietrich

Marlon Brando

Marnie - confissões de uma ladra

Martín de Salvo

Martin Ritt 
Martin Scorcese

Mash

Matou a família e foi ao cinema

Matt Dillon

Mauricio Wainrot

Mauro Lima

Méd Hond

Med Hondo

Meg Ryan

Mehboob Khan

Meia-noite no jardim do bem e do mal

Mel Gibson

Melody of the heart

Melody of the world

Memórias de quem fica

Menina de ouro

Mercado de ladrões

Metropolis

Meu nome não é Johnny

Mibu gishi den

Michael Curtiz

Michael Lehman

Michelle Pfeiffer

Mike Figgis

Mike Leigh

Mike Nichols
Minha adorável lavanderia

Minha vida sem mim

Mira Nair

Mohamed Lakhdar-Hamina

Momar Thian

Mononokehime

Monstros

Montgomery Clift

Morangos silvestres

Mortu Nega

Mother India

movimentos de libertação

mulher africana

Mulheres à beira de um ataque de nervos

Muna Moto

Murderers among us

Murnau

My Sassy girl

Nae yeojachingureul sogae habnida

Não é você, sou eu

Naomi Kawase

Nascido para matar

Nastassja Kinski

Nationalité immigré

Neil Jordan

Nelson Pereira dos Santos 
Nicholas Ray

No tempo das diligências

Noivo neurótico, noiva nervosa

Nome de família

Nosferatu

Nossos anos selvagens

Notre fille

Nove rainhas

Ntshaveni Wa Luruli

O abraço partido

$\mathrm{O}$ almoço nu

O anjo azul

$\mathrm{O}$ assalto ao trem pagador

O charme discreto da burguesia

O clã das adagas voadoras

O destino bate à sua porta

O encouraçado Potemkin

O engenho de Zé Lins

O fantasma da liberdade

O filho da noiva

O funeral do chefão

O gabinete do Doutor Caligari

o gordo e o magro

O grande ditador

O grande golpe

O grande roubo do trem

O homem com a câmera de filmar
O homem elefante

O homem mais desejado do mundo

O homem que quis matar Hitler

O iluminado

O jogador

O lado escuro do coração

O leopardo

O mercador de almas

O pântano

O pecado mora ao lado

O prisioneiro do rock

O reverso da fortuna

O segredo de Berlim

O selvagem da motocicleta

O silêncio

O sol por testemunha

O sonho de Cassandra

O tempo não espera

O testamento do Dr. Mabuse

O tigre e o dragão

O último rei da Escócia

$O$ vaqueiro voador

O verão de Victor Vargas

O viajante

Obsessão

Octavio Cortázar 
Odoru Daisosasen

Old boy

Oldrich Lipsky

Ônibus 174

Ontem, hoje e amanhã

Orgulho e preconceito

Ornella Muti

Orson Welles

Os assassinos

Os Incompreendidos

Os pássaros

Os sonhadores

Otto Preminger

Ousmane Sembène

Pablo Stoll

Pablo Trapero

Paolo Agazzi

Paranoid Park

Paris, c'est joli

Park Chan Wook

Pasajeros

Pasolini

Pastor Veja

Paul Newman

Paulo Caldas

Paweogo

Pedro Almodóvar
Pen-ek Ratanaruang

Pequena Miss Sunshine

Perdas e danos

Perseguidor implacável

Peter Bogdanovich

Peter Sollet

Petr Zelenka

Philip Kaufman

Pierre-Marie Dong

Piratas en el Callao

Pousse- pousse

Princess Mononoke

Psicose

Pulp fiction

Punhos de campeão

Punto y raya

Quanto mais quente melhor

Quanto vale ou é por quilo?

Quatro passi tra le nuvole

Quem matou Pixote?

Quentin Tarantino

Quero ser John Malkovich

Quiz Show - a verdade dos bastidores

Radiofreccia

Raj Kapoor

Ralph Fiennes 


\begin{tabular}{|c|c|}
\hline Ramesh Sippy & Roberto Rossellini \\
\hline Rançon d'une alliance & Rodrigo Triana \\
\hline Raquel Welch & Roger Vadim \\
\hline Rashomon & Roma, cidade aberta \\
\hline Reflections & Román Chalbaud \\
\hline Relíquia macabra & Roman Polanski \\
\hline René Clément & Romy Schneider \\
\hline Repulsa ao sexo & Rouch in reverse \\
\hline Réquiem para um sonho & Rua Seis, Sem Número \\
\hline Retorno a Howards End & Rua sem nome \\
\hline Retrato de Teresa & Ruth em questão \\
\hline Richard Gere & Saam gaang Yi \\
\hline Richard Thorpe & Sábado \\
\hline Ridley Scott & Safrana \\
\hline Ringu & Samaria \\
\hline Rita Hayworth & Samaritan girl \\
\hline River Phoenix & Samory \\
\hline Rob Reiner & Sandra Bullock \\
\hline Robert Siodmak & Sanjay Leela Bhansali \\
\hline Robert Altman & Sanou Kollo \\
\hline Robert Redford & Santa não sou \\
\hline Robert Towne & Sarraounia \\
\hline Robert Wiene & Sarzan \\
\hline Robert Wise & Satyajit Ray \\
\hline Roberto Farias & Sean Connery \\
\hline Roberto Gervitz & Sebastian Kamba \\
\hline Roberto Moreira & Secuestro express \\
\hline
\end{tabular}


Sega Coulibaly

Segredos e mentiras

Sejnane

Sérgio Bianchi

Sérgio Moriconi

Seven swords

Sexo, mentiras e videotape

Sharon Stone

Shinji Aoyama

Shinlaui dalbam

Shiri

Sholay

Sidney Sokhona

Silmido

Sílvio Tendler

Sin City - a cidade do pecado

Sindicato de Ladrões

Sobre meninos e lobos

sociedade burguesa

Soleil

Soñar no cuesta nada

Song Hae Sun

Sönke Wortmann

Sophia Loren

Sopyonje

Souleymane Cissé

Spyder and Lilies
Stan VanderBeek

Stanley Kubrick

Stephen Frears

Steve Kloves

Steve McQueen

Steven Soderbergh

Sujoy Ghosh

Susan Sarandon

Susie e os Baker Boys

Swiri

Takeshi Miike

Tell the truth

tema

Tempos felizes

Tempos modernos

Teorema

Terence Stamp

Terra em transe

The Black Forest girl

The bow

The gods must be crazy

The happening

The magnificent Ambersons

The money order

The Road on the air

Thelma e Louise

Three extremes 
Tidiane Aw

Tim Robbins

Tod Browning

Tom Cruise

Tomás Gutiérrez Alea

Toni Venturi

Traídos pelo desejo

Trainspotting

Tropa de elite

Tsui Hark

Tudo começou no sábado

Tudo sobre minha mãe

Twin Peaks: Os últimos dias de Laura Palmer

Ultima vida no Universo

Um beijo roubado

Um copo de cólera

Um corpo que cai

Um lugar ao sol

Um misterioso assassinato em Manhattan

Um relatório ambíguo sobre o fim do mundo

Um retrato de mulher

Uma aventura na Martinica

Uma janela para o amor

Uma rua chamada pecado

Uma Simples Formalidade
Uma Thurman

Uma vida marcada

Une si simple histoire

Val Kilmer

Valerie Faris

Veludo azul

Vera Fogwill

Viagem à Itália

Victoria Abril

Vida de cão

Vida de solteiro

Vidas secas

Vidhu Vinod Chopra

Vítimas de uma paixão

Vittorio De Sica

Vladimir Carvalho

Volker Schloendorff

Volver

Walter Ruttmann

Walter Salles

Week-end

Wesley Ruggles

When the last sword is drawn

Whisky

William Holden

William Wyler

Willian Keighley 
Windstruck

Winona Ryder

Wolfgang Staudte

Wong Kar-wai

Woody Allen

Woo-Suk Kang

Xala

Yeopgijeogin

Yojiro Takita

Zero Chou

Zhang Yimou

gênero

abstrato

ação

adaptação

afílmico

animação

aventura

burlesco

cinema de poesia

clássico

comédia

criminal

documentário

drama

épico estrutural

experimental

faroeste

ficção

filme noir

gângster

indireto livre

melodrama

não-ficção

papel

paródia

personagem

remake

rôle

suspense

terror

western

técnica

acompanhamento ao vivo

Alexandre Nevski

ângulo da câmera

banda som

Carl Dreyer

cinema mudo

cinema sonoro

cinematurgia 


\begin{tabular}{|c|c|}
\hline composição & montagem \\
\hline contraponto orquestral & montagem cubista \\
\hline corte seco & montagem harmônica \\
\hline decupagem & montagem métrica \\
\hline dimensão dos planos & montagem vertical \\
\hline direção dos movimentos & música \\
\hline direto & música gravada em película \\
\hline divismo & pantomima \\
\hline duração & paramétrico \\
\hline duração dos planos & parâmetro \\
\hline efeito Kulechov & plano \\
\hline efeito Schufftan & plano americano \\
\hline efeitos especiais & plano aproximado \\
\hline Eisenstein & plano de conjunto \\
\hline establishing shot & plano geral \\
\hline fala & plano médio \\
\hline falso-raccord & plano-sequência \\
\hline flashback & primeiríssimo plano \\
\hline fragmento & primeiro plano \\
\hline implant & raccord \\
\hline intervalo & raccord espaço-temporal \\
\hline Jacques Tati & relação campo /contra-campo \\
\hline jump cut & salto \\
\hline junção & segmentação \\
\hline Kenji Mizoguchi & som \\
\hline máscara & sound track \\
\hline matte & teatro filmado \\
\hline
\end{tabular}


tempo

transparência

trucagem velocidade dos movimentos

Yasujiro Ozu 